\title{
Die Jagdfronen in Württemberg
}

\author{
Von Wilfried OtT
}

\section{Ursprung}

Zweifellos ist die Fronarbeit ein Produkt der im Mittelalter entstandenen und im 19. Jahrhundert mit dem liberalen Verfassungsstaat wieder verschwundenen feudalen Gesellschaftsordnung. Die Frage, ob für ihre vielfältigen Erscheinungsformen im Einzelfall die Gerichts-, Grund- oder Landesherrschaft ursächlich war, ist bei der häufigen Vermischung der Rechtstitel freilich meist nur spekulativ zu beantworten und oft kaum eindeutig zu klären, da sie nicht auf förmlichen Rechtssetzungsakten beruht. Lange Zeit wurde die Fronpflicht ausschließlich gewohnheitsrechtlich praktiziert und von Generation zu Generation mündlich tradiert. Schon die frühesten Belege, die aus dem späten 15. und frühen 16. Jahrhundert stammen, verweisen auf das alte Herkommen, das nie in Frage gestellt wurde, wenn zwischen den Beteiligten Übereinstimmung bestand, dass schon immer entsprechend verfahren worden $\mathrm{sei}^{1}$.

Selbstverständlich waren für die betroffenen Untertanen alle Fronverpflichtungen mit Belastungen verbunden, die zwar häufig nur widerwillig, in der Regel aber unwidersprochen hingenommen wurden, obwohl die Gegenleistung - etwa herrschaftlicher Schutz oder die Verleihung von Grund und Boden - längst nicht mehr erkennbar war. Zahllose Beschwerden lösten in Württemberg jedoch die aus verschiedenen Gründen als besonders drückend empfundenen jagdlichen Hilfsdienste aus. Von dieser Bürde, an der die ländliche Bevölkerung über Jahrhunderte hinweg schwer zu tragen hatte, legt eine kaum überschaubare Fülle archivalischer Dokumente beredtes Zeugnis $\mathrm{ab}^{2}$. Gleichwohl ist das sozialgeschichtlich bedeutsame Phänomen der Jagdfronen noch nie systematisch untersucht worden ${ }^{3}$. Ihre

\footnotetext{
1 Zur Kennzeichnung der „Observanz“ fanden häufig auch andere Formulierungen Verwendung, z. B. von alters und biß hero, je und alwegen, je und je, bey Manns gedencken, usser altem Gebrauch, von obnerdencklichen Jahren, lenger dan Menschen gedechtnus.

2 Die Jagdfronen wurden auch auf zahlreichen Landtagen - so 1514, 1565, 1583, 1595, 1629, 1652, 1680, 1739, 1753 und 1797 - behandelt.

${ }^{3}$ Rudolf von Wagner streift in seinem Standardwerk: Das Jagdwesen in Württemberg unter den Herzogen. 1876. S. 23-33, nur wenige Aspekte. Dasselbe gilt für die auf das 18./19.
} 
Entwicklung von den ersten Aufzeichnungen bis zur endgültigen Beseitigung im Jahr 1836 soll daher im Folgenden dargestellt werden.

\section{Landesherrschaft und Jagdherrschaft}

Wie in anderen Territorien spielten auch in Württemberg die forstlichen und jagdlichen Hoheitsrechte eine wesentliche Rolle beim Aufbau der Landesherrschaft. Das bis zum späten Mittelalter weitgehend durchgesetzte Forst- und Jagdregal verschaffte den aufstrebenden Regenten die Möglichkeit, die für die Rohstoffversorgung unentbehrliche Waldnutzung zu reglementieren und das Jagdrecht weit über ihren Eigenbesitz hinaus exklusiv auszuüben. Landes- und Jagdherrschaft waren somit untrennbar miteinander verbunden.

Zur Bewältigung der mit dem Forst- und Jagdwesen zusammenhängenden Fragen wurde eine Fachverwaltung geschaffen, die bereits für das 15. Jahrhundert nachweisbar ist. Zu diesem Zweck hatte man das Land in großräumige Forste gegliedert und dem Forstpersonal nicht nur die Forst- und Jagdhoheit, sondern auch die Waldnutzung und den Jagdbetrieb übertragen. Forstmeister und Forstknechte - seit 1760 als Oberforstmeister bzw. seit 1771 als Förster bezeichnet und jeweils für einen Forst- bzw. Hutsbezirk zuständig - waren daher unverzichtbare Organe der Feudaljagd, denn der Landes- und Jagdherr konnte natürlich sein ganzes Fürstentum nicht selbst bejagen ${ }^{4}$. Aber auch die Forst- und Jagdbeamten benötigten Unterstützung, wenn das feudale Jagdsystem funktionsfähig sein sollte. Diese Hilfskräfte durften keine Kosten verursachen und hatten daher ihre Arbeit in der Fron zu verrichten ${ }^{5}$. Die Fronpflicht war auf diese Weise zu einem unentbehrlichen Instrument der Herrschaftsjagd geworden.

Nach einem ungeschriebenen Gesetz konnten ausschließlich Männer zu Jagddiensten herangezogen werden ${ }^{6}$. Außerdem mussten sie württembergische Unter-

Jahrhundert beschränkte Arbeit von Wilhelm Hans Eckardt: Herrschaftliche Jagd, bäuerliche Not und bürgerliche Kritik (Veröffentlichungen des Max-Planck-Instituts für Geschichte 48). 1976. S. 112-126, die sich im Wesentlichen auf Gesetzes- und Verwaltungsvorschriften stützt.

${ }^{4}$ Als jagdrechtliche Hoheitsgebiete erstreckten sich die Forsten nicht nur auf die Wälder, sondern auch auf alle übrigen Flächen. Das Forstpersonal besaß daher weitreichende jagdliche Kompetenzen. Zu seiner Unterstützung sowie für spezielle Aufgaben stand die Jägerei - eine kleine Truppe von Berufsjägern - zur Verfügung. Sie war - von einem Jägermeister geleitet - unmittelbar dem Landesherrn zugeordnet, wurde aber im 18. Jahrhundert weitgehend in die Forstverwaltung integriert.

${ }^{5}$ Bereits 1514 erklärte Herzog Ulrich, an den Frondiensten sei ihm zuo ersparung des cammerguots nicht wenig gelegen (HStA Stuttgart A 59 Bü 4).

${ }^{6}$ Aus den Akten sind nur wenige Fälle einer Beteiligung von Frauen an Jagdfronen ersichtlich. Als 1768 das Oberforstamt Ludwigsburg eine 30-köpfige gemischte Arbeitsgruppe zur Aufbereitung von Wildheu anforderte, dekretierte die Obrigkeit auf eine Beschwerde der Stadt Bietigheim kategorisch: Weiber können zu Forstlichen Dienstbarkeiten nicht ange- 
tanen sein, deren Wohnsitz einem Forst, d. h. einem Amtsbezirk der Forstverwaltung und damit einem Bereich zugeordnet war, in dem die Herrschaftsrechte an Wald und Wild dem Haus Württemberg zustanden. Der strikt eingehaltene Grundsatz der Landeszugehörigkeit lässt den Schluss zu, dass die Jagdfronen aus der Landesherrschaft abgeleitet worden $\operatorname{sind}^{7}$.

Allerdings waren Landes- und Forstgrenzen nicht immer deckungsgleich. Das württembergische Schwarzwaldkloster Herrenalb unterstand beispielsweise der markgräflich-badischen Jagdhoheit, während der Zwiefalter Forst sich überwiegend auf landesfremde Gebiete erstreckte. Auch in dieser Gemengelage war die Jagdfronpflicht konsequent an die „Staatsbürgerschaft" gebunden ${ }^{8}$. Württembergische Landeskinder mussten selbst dann dienen, wenn sie jenseits der Landesoder Forstgrenze wohnten ${ }^{9}$. Nur bei allzu großer Entfernung zum nächsten württembergischen Jagdrevier galten sie nicht als Forsteingesessene und wurden deshalb dispensiert. Die Untertanen anderer Herrschaften blieben dagegen stets jagensfrei, was sich in gemischten Ortschaften mitunter als problematisch erwies ${ }^{10}$.

balten werden (HStA Stuttgart A 558 Bü 40). Bei Fronarbeiten in der Landwirtschaft und im Gartenbau wurden dagegen auch Frauen und Kinder beschäftigt.

7 Die Jagdfronen könnten allerdings zum Teil schon vor der Ausbildung der Landeshoheit aus der grundherrlichen Vogtei hervorgegangen sein (August Ludwig Reyscher. Das gemeine und württembergische Privatrecht. 1843. Bd.1. S. 508).

${ }^{8}$ Schon 1524 berichtet der Zwiefalter Forstmeister von Flecken seines Forsts, die Edelleuten und nicht dem württembergischen Regenten zugethan und daher keine Dienstleistungen schuldig seien. Frondienste leisteten nur jene Ortschaften, die zu dem Lannd gehern (HStA Stuttgart A 59 Bü 3a). Diese Verpflichtung galt selbst für einzelne Lehenhöfe. In der Zwiefalter Forstbeschreibung von 1555 heißt es von den Untertanen der Herren von Speth und von Stein in Unterwilzingen: dienen nichts, vom einzigen württembergischen Hof dieser Gemeinde dagegen: derselbig muß dienen (HStA Stuttgart A 565 Bü 32). Für manche Forste wird pauschal konstatiert: Die Flecken anderen Oberkaiten zugeherig dienen nichts (Wildbad 1561: HStA Stuttgart A 59 Bü 5).

${ }^{9}$ Das war z.B. bei den Kommunen Löwenstein und Heinriet der Fall, die in der Freien Pirsch bzw. der Grafschaft Löwenstein lagen und im benachbarten Reichenberger Forst Jagdfronen leisten mussten (HStA Stuttgart H 107/14 Bd.2). Als die Gemeinden Öschelbronn und Wurmberg 1698 den Jagddienst im Leonberger Forst mit der Begründung verweigern wollten, sie befänden sich im Gebiet der Markgrafschaft Baden, verwies man sie auf das Leonberger Forstlagerbuch von 1556, das ausdrücklich feststellte: Etlich Flecken usserhalb Forsts gelegen, so doch Württembergisch (sind) und mit dem (Leonberger) Forst gränzen, müssen helffen Förstliche Dienstbarkait tragen und leisten (HStA Stuttgart A 227 Bü 1194).

${ }^{10}$ Die Gemeinde Schlechtbach (Reichenberger Forst) bestand sowohl aus württembergischen als auch aus Gräflich Limpurgischen Einwohnern. Obwohl letztere nicht jagdfronpflichtig waren, wurden sie ebenfalls zu den Jagden zitiert. Im Forstlagerbuch der Schenken von Limpurg von 1555 heißt es dazu, ihre Herrschaft habe ihnen verboten, dieser Aufforderung Folge zu leisten, wenn man sie aber bitte, sollen sie es thun. Die Schenkischen beteiligten sich deshalb nur gelegentlich und nach eigenem Gutdünken am Aufgebot (HStA Stuttgart A 561 Bü 80). In der Gemeinde Schwieberdingen (Leonberger Forst), die teilweise dem Haus Württemberg und teilweise den Herren von Stockheim gehörte, konnten sich die Einwohner bei der Annahme des Bürgerrechts frei für eine der beiden Herrschaften entscheiden. Da die Württemberger im Gegensatz zu den Stockheimischen jagdfronpflichtig waren, 


\section{Wesensmerkmale}

Das Fronwesen, wie es in den archivalischen Quellen sichtbar wird, war vielschichtig. Neben Dienstleistungen, die für Gemeinden und Grundherrschaften zu verrichten waren, gab es außerhalb des Jagdbetriebs noch weitere Landesfronen, die von den Regenten beansprucht wurden. Dazu zählten vor allem die Unterhaltung von Wegen, Straßen und Brücken, Bauleistungen an Burgen und Schlössern, Brennholz-, Frucht- und Weinfuhren zur Hofhaltung, Arbeiten in herrschaftlichen Keltern sowie die Bestellung von landwirtschaftlichen Gütern des Hauses Württemberg. Sie waren nicht selten von Lehenhöfen, meist aber von einer Ortschaft oder einem Amt zu erbringen und in Kellereilagerbüchern verzeichnet, deren Spezialvorschriften häufig mit der Präambel eingeleitet wurden, die Einwohner seien vogtbar, rayßbar (zum Kriegsdienst verpflichtet), steuerbar und dienstbar.

Im Vergleich zu diesen Fronen nehmen die Jagddienste eine Sonderstellung ein. Sie waren ausnahmslos ungemessen, $\mathrm{d}$. h. von unbestimmtem Umfang und konnten daher beliebig - so offt das die Notturft erfordert - angesetzt werden. Daran änderte auch die Tatsache nichts, dass sie in Jagenszeiten saisonal gehäuft in Anspruch genommen wurden. Jedenfalls war ihr Zeitpunkt nicht kalkulierbar. Im Übrigen fanden sie überwiegend im Herbst oder Winter statt, wenn schlechtes Wetter den Fronpflichtigen oft genug zu schaffen machte. Die übrigen Frondienste dagegen waren häufig gemessen, d. h. auf eine bestimmte Zahl von Tagen im Jahr beschränkt oder wenigstens ihrer Natur nach an gewisse Fristen (z. B. Erntezeiten) gebunden, soweit sie nicht ohnehin nur in größeren Zeitabständen anfielen.

Obwohl die Jagdfröner im Allgemeinen nur innerhalb der Grenzen des heimatlichen Forstbezirks verwendet wurden, war die Distanz zum Einsatzort oft beträchtlich ${ }^{11}$. Nichts fiel ihnen schwerer, als in die Ferne gezogen zu werden. Die langen An- und Abmarschwege und der Aufenthalt in unbekannten Gegenden erschienen ihnen schon deshalb als Zumutung, weil die anderen Fronarbeiten am Wohnsitz oder zumindest in gewohnter Umgebung verrichtet werden konnten. Hinzu kam, dass es bei den Jagddiensten weder Frongeld noch Fronbrot gab, das sonst als Trostpflaster für die unbezahlte Leistungserbringung üblich war. Diese patriarchalischen Begleiterscheinungen des Fronsystems hatten sich im Jagdwesen fast nirgends durchgesetzt oder waren - sofern sie überhaupt existierten - nach Ablauf des 16. Jahrhunderts wieder verschwunden ${ }^{12}$.

ging ihr Anteil zurück. Um dieser Entwicklung Einhalt zu gebieten, wurde seit der 2. Hälfte des 17. Jahrhunderts die Fronpraxis spürbar gelockert (HStA Stuttgart H 107/10 Bd. 1 und A 557 Bü 288).

11 Der Stromberger Forst reichte beispielsweise von der Enz zwischen Mühlacker und Besigheim im Süden und von dort den Neckar entlang über Heilbronn hinaus im Osten bis zur Landesgrenze gegen die Kurpfalz und den Kraichgau im Norden und Westen.

12 In der Commun-Ordnung von 1758, die Taxen für Frondienste festlegte, heißt es kurz und bündig: Für Jagd-Dienste paßieret nichts (August Ludwig Reyscher: Vollständige, histo- 
Ein wesentlicher Unterschied bestand schließlich in der gegenläufigen Entwicklungsdynamik der Fronformen. Die notorisch schlechte Produktivität und Qualität der Zwangsarbeit hatte nämlich zur Folge, dass die Fronherren im alten Württemberg vielfach ihre Landwirtschaftsgüter veräußerten, die Eigenbewirtschaftung aufgaben oder die Naturalfronen durch Geldzahlungen ihrer Hintersassen ablösten $^{13}$. In der Feudaljagd dagegen erhielten die Dienstbarkeiten im 17. und 18. Jahrhundert einen enormen Auftrieb ${ }^{14}$. Die spezifischen Belastungsfaktoren der Jagdfronen erzeugten allmählich einen solchen Problemdruck, dass sich die ständigen Bitten und Beschwerden immer mehr in regelrechte Anklagen verwandelten.

\section{Hagen und Jagen}

Als die Jagdfronen ins Licht der Geschichte traten, spiegelten sie den Jagdbetrieb wider, der sich an der Wende vom Spätmittelalter zur frühen Neuzeit herausgebildet hatte. Er wurde immer noch von der alten Hetz- und Verfolgungsjagd bestimmt, die dazu diente, Rot- und Schwarzwild zu Pferd und mit Hilfe von Hunden zur Strecke zu bringen. Die Einzeljagd hatte allerdings bereits an Bedeutung verloren, da man zunehmend dazu überging, das Wildpret den Jägern an günstigen Stellen in größerer Zahl zuzutreiben und zu diesem Zweck das Jagdgebiet zu umstellen (Fürstehen), um ein seit- oder rückwärtiges Ausbrechen zu verhindern.

Die älteste, zweifellos bereits im Mittelalter entstandene Einrichtung, mit der diese Jagdmethode praktiziert wurde, war der Hag, eine natürliche oder mit Baumwipfeln und -ästen hergestellte künstliche Hecke, die an Plätzen angelegt wurde, die sich erfahrungsgemäß zur Erlegung des zugetriebenen Schalenwildes eigneten. Soweit die Einfriedigung Lücken aufwies, wurden sie mit Seilen, später auch mit Garnen (Netzen) geschlossen, in denen sich die flüchtigen Tiere verfingen und dann erbeutet werden konnten. Das Hagen, d. h. die Pflanzung, Erneuerung, Ausbesserung und Pflege eines Hags hatten die Fronpflichtigen zu besorgen. Schon im Laufe des 16. Jahrhunderts ging jedoch sein Gebrauch zurück, da er durch Garne

risch und kritisch bearbeitete Sammlung der württembergischen Gesetze. Bd.1-19. 18281851. Hier Bd. 14. S. 702).

13 Eine vom Kirchenrat 1738 durchgeführte Erhebung ergab, dass die Fronen bei den meisten Klosterverwaltungen keine Rolle mehr spielten. Bebenhausen klagte über unsauberes Mähen, weshalb diese Dienstleistung durch ein Mähgeld abgelöst worden sei, weil die Schnitter nicht einmal das Essen verdient hätten (HStA Stuttgart A 282 Bü 526). Ein Bericht aus dem Jahr 1753 über die Gemeindefronen enthält die Feststellung, die Fröner zeigten kein Ernst und Geschicklichkeit zum Geschäft und sollten daher durch Taglöhner ersetzt werden (HStA Stuttgart A 227 Bü 309).

${ }^{14}$ Diese Tendenz war eine Folge der durch den 30 -jährigen Krieg verursachten Wolfsplage, einer verstärkten Bejagung des Nieder- und Federwilds und des Übergangs zu Treibjagden großen Stils. 
und Tücher ersetzt wurde ${ }^{15}$. Die Verwendung von transportablem Jagdzeng ermöglichte nicht nur eine Flexibilisierung, sondern auch die Ausweitung und Intensivierung des Jagdbetriebs, der auf diese Weise mehr denn je auf Frondienste angewiesen war. Beim Jagen lief ohne die wachsende Schar der Helfer nichts mehr.

Ursprünglich nur als Ergänzung des Hags zum Umstellen der Jagdfläche verwendet, wurde mit der Zeit aus der stehenden eine mobile Treiberwehr, die das Wild großflächig zusammen- und dann den Schützen zutrieb. Aus dieser Entwicklung resultierte ein steigender Bedarf an zusätzlichen Dienstleistungen. So bedurfte es einer immer größeren Zahl von Seil- und Zengwägen, um die vielen Seile, Netze und Tücher heran- und fortzuschaffen, die erforderlich waren, um den gewünschten Jagderfolg zu gewährleisten ${ }^{16}$. Die Gespanne waren von Hofbauern zu stellen, die geeignetes Zugvieh (Pferde oder Ochsen) besaßen und deshalb „Fuhrfronen" übernehmen konnten. Der mühsame Auf- und Abbau (Richten) des Jagdzeugs im Bestand oder auf Waldwegen und Waldschneisen (Richtstätten) blieb dagegen ebenso wie das Hagen, Vorstehen und Zutreiben denen überlassen, die nicht über entsprechenden landwirtschaftlichen Grundbesitz verfügten und daher „Handfronen“ verrichten mussten: Tagelöhner, Seldner, Kleinbauern, Handwerker, Weingärtner.

Damit war aber das Aufgabenspektrum der Forstlichen Dienstbarkeiten keineswegs erschöpft. Als Hundzieher hatten die Jagdfröner die Hundemeuten zum Treffpunkt und wieder zurück oder zur nächsten Jagdstelle zu bringen ${ }^{17}$. Außerdem mussten sie das erlegte Wild zu Sammelplätzen schleifen und mit Fuhrwerken an den manchmal weit entfernten Bestimmungsort abtransportieren ${ }^{18}$. Helfen ha-

15 Herzog Friedrich erteilte 1594 den Befehl, keinen Hag mehr zu machen oder zu pflegen (HStA Stuttgart A 227 Bü 52).

${ }^{16}$ Die Jagdzeugfuhren waren in frequentierten Jagdgebieten im regionalen Staffettenverfahren organisiert, um einen reibungslosen Transport über größere Entfernungen sicherzustellen. Für den Schönbuch wurde noch 1803 eine seit unvordenklichen Zeiten bestehende Übereinkunft bestätigt, wonach die Zeugwagen an festgelegten Übergabestationen von Nachbargemeinden übernommen und bis zum nächsten Wechsel gefahren wurden (HStA Stuttgart A 227 Bü 3057).

17 Die nach Hunderten und Tausenden zählenden Jagdhunde waren zum Teil in herrschaftlichen Hundeställen stationiert, mussten jedoch meist von Bauern und Müllern aufgezogen und gehalten werden. Diese Verpflichtung zur Aufstockung kann durchaus als Frondienst im weiteren Sinn verstanden werden, bleibt aber hier außer Betracht. Das Verbringen der Jagdhunde zum nächsten Einsatzort erfolgte häufig von Ortschaft zu Ortschaft, oft aber auch über große Entfernungen.

18 Abzuliefern war die Jagdbeute in Sammelstellen der näheren Umgebung, Amtsstädten, Forstamtssitzen oder in den Land- und Jagdschlössern, wenn sich dort der Hof aufhielt (Hoflager). Die Müller im Weinsberger Amt waren sogar verpflichtet, das gesamte Wildbret des Neuenstadter Forsts nach Stuttgart in die Hofküche zu fahren. Eine Entschädigung stand ihnen nicht $\mathrm{zu}$, doch wurden sie großzügig verpflegt und von anderen Fronen freigestellt (1564: HStA Stuttgart A 386 Bü 42 und 1586: A 249 Bü 3488). Für den Wildtransport erhielten sie 1759 nur noch einen symbolischen Geldbetrag, obwohl er wegen der üblen Saison und der schlimmen Wege gewöhnlich drei Tage dauerte (HStA Stuttgart A 227 Bü 1685). 
gen und jagen - hinter dieser gefälligen Formel verbarg sich die raue Wirklichkeit einer harten und zeitraubenden Arbeit.

\section{Erste Nachrichten}

Die ältesten Informationen über jagdliche Hilfsdienste stammen aus den Jahren 1486-1489. Dabei handelte es sich um Fronverzeichnisse des Amts Urach, die belegen, dass die Untertanen zum Hagen und Jagen, Seilwagen-, Wildbret- und Hundeführen gebraucht wurden ${ }^{19}$. Schon vor Beginn der Neuzeit hatten sich also die Grundstrukturen herausgebildet, die jahrhundertelang die Fronpraxis der Feudaljagd kennzeichneten. Quantitativ bewegte sie sich freilich auf bescheidenem Niveau, wobei zu berücksichtigen ist, dass die Bevölkerungsdichte damals noch ziemlich gering war ${ }^{20}$.

Auch die wenigen Aufzeichnungen, die aus dem frühen 16. Jahrhundert erhalten geblieben sind, enthalten keine Hinweise auf ernsthafte Probleme ${ }^{21}$. Vor diesem Hintergrund ist es verständlich, dass die Jagdfronen in den sozialen Konflikten des frühen 16. Jahrhunderts keine wesentliche Rolle spielten. Im „Armen Konrad“von 1514 trugen sie immerhin zu den vielen dörflichen Beschwerden bei, die sich gegen die Ausweitung der landesherrlichen Frondienste und die Abkehr von althergebrachten Gewohnheiten wandten ${ }^{22}$. Unter anderem wurde beanstandet, dass die Jagdherrschaft mancherorts die Verköstigung der Fronpflichtigen einstellte und die Entschädigung der Fuhrfronen reduzierte. Herzog Ulrich vertröstete die Beschwerdeführer im Tübinger Nebenabschied vom 8. Juli 1514 mit der Ankündigung einer allgemeinen Fronordnung, die überall erträgliche und gleichartige Verhältnisse schaffen sollte ${ }^{23}$. Obwohl diese Zusage nicht eingelöst wurde, waren die Jagddienste im Bauernkrieg 1525 kein Thema mehr.

Dazu mag auch beigetragen haben, dass nach der Vertreibung Herzog Ulrichs $1519 \mathrm{im}$ Jagdwesen anarchische Zustände herrschten. Nach einem Bericht des von

${ }^{19}$ HStA Stuttgart A 54a Bd. 209. Erwähnt werden die Jagdfronen auch in der Amts- und Landschadens-Ordnung des Grafen Eberhard im Bart vom 28. Oktober 1489 (Reyscher [wie Anm.12] Bd.12. S.1-3).

${ }^{20}$ Die Fronmannschaften waren überschaubar und wurden meist nur an ein bis zwei Tagen eingesetzt („Hagen und Jagen“: sechs bis neun Mann, „Arbeit am Hirschhag“: 20 bis 25 Mann, „Hundziehen“: 17 Mann).

${ }^{21}$ Detaillierte Angaben zur Jagdfronpflichtigkeit ihrer Bürger liefern die Rechtssammlungen einiger Städte, z. B. das Ehehaften-Buch Stuttgart von 1508 (HStA Stuttgart A 557 Bü 290) und das Annal- und Freyheitsbuch Bietigheim von 1526 (HStA Stuttgart A 227 Bü 1234). Die Zusammenstellung der württembergischen Jagdgerechtigkeiten von 1523 beschränkt sich dagegen auf pauschale Feststellungen: In disem Vorst seind die unnderthannen schuldig zu Jagen unnd zu Hagen, Hund unnd den Saulwagen zu furen, auch alle fron zu thun was zum Jagen gehörig (HStA Stuttgart A 59 Bü 35).

22 Andreas Schmauder: Württemberg im Aufstand. Der Arme Konrad. 1998. S. 161.

${ }^{23}$ Reyscher (wie Anm.12) Bd.2. S. 50. 
der österreichischen Regierung eingesetzten Jägermeisters Reinhart Spät jagten die Forstmeister auf eigene Faust. Vernachlässigung des Jagdzeugs und große onordnung in den Frondiensten waren die Folge. Erzherzog Ferdinand, der nach seinen eigenen Worten begierig darauf war, Ergötzung im Waidwerk zu suchen, wollte diese Schmälerung seiner Vörstlichen Oberkeit und Herligkeit nicht hinnehmen. Er wies deshalb 1523 alle Amtleute und Schultheißen an, die bylff der fron beim Jagen wieder herzustellen, wie sie bisher nach altem Herkommen üblich gewesen $\operatorname{sei}^{24}$. Diese Aufforderung scheint auf fruchtbaren Boden gefallen zu sein. Im Übrigen überließ jedoch die habsburgische Regentschaft ebenso wie Herzog Ulrich nach seiner Rückkehr aus dem Exil die Handhabung der jagdlichen Dienstbarkeiten weiterhin den örtlichen Instanzen. Die Zeit für eine Neuordnung war erst gekommen, als 1550 sein Sohn Christoph die Nachfolge antrat.

\section{Bestandsaufnahme}

Schon nach wenigen Jahren begann Herzog Christoph damit, sich intensiv mit dieser Problematik zu beschäftigen. Es war ihm zugetragen worden, dass es eine alte Vergleichung mit der Landschaft gebe, wonach jeder Württemberger zu Jagdfrondiensten verpflichtet sei mit Ausnahme derjenigen, die einen speziellen Schein vorweisen könnten. Daraufhin erteilte er 1554 der Rentkammerregistratur den Auftrag, nach diesem Schriftstück zu forschen. Die eifrige Suche blieb jedoch ergebnislos, denn eine entsprechende Vereinbarung war nie abgeschlossen worden.

Ob dieser Befund Anlass zu den Forstbeschreibungen gab, die er in den Jahren 1555-1557 anfertigen ließ, ist ungewiss. Sicher ist aber, dass im Rahmen dieser systematischen Erhebung der Hoheits- und Besitzrechte, die dem Haus Württemberg in den Forsten zustanden, die Dienstbarkeiten eine besondere Rolle spielten ${ }^{25}$. Jedenfalls kam es auf diese Weise zu einer zentral gesteuerten Erhebung der auf lokaler Ebene entstandenen Fronpraxis, die erstmals einen landesweiten Überblick ermöglichte. Die Durchführung dieser Aktion, die ihren Niederschlag in den Forstlagerbüchern fand, erfolgte jeweils durch einen hohen Verwaltungs- und Jagdbeamten unter Beteiligung des zuständigen Forstmeisters. Die gewohnheits-

${ }^{24}$ HStA Stuttgart A 59 Bü 1.

25 Eine allgemeine Anordnung der Forstbeschreibungen ist anscheinend nicht ergangen. Offenbar sind sie auf spezielle Verfügung des Herzogs Christoph entstanden. Erhalten geblieben ist sein Schreiben vom 26. August 1555, mit dem er den Empfang der Stuttgarter Forstbeschreibung bestätigt und dem Rentkammerrat Johann Zaiser und dem Jägermeister Urban Huber den Auftrag erteilt, noch vor Wintereinbruch den Zwiefalter Forst zu bereiten und aufzuzeichnen. Was ihn dazu veranlasste, geht aus seiner Aufforderung an die Rentkammer hervor, die festgestellten Mängel abzustellen. Im Übrigen sprach er die Erwartung aus, dass die Forstmeister diese Unterlagen dazu nutzten, sich um die Jagdfronen zu kümmern, damit kain eingriff oder an allter gerechtigkeit ainicher Abbruch geschehe (HStA Stuttgart A 59 Bü 33). 
rechtlichen Frondienste wurden für alle Städte, Dörfer, Weiler und Höfe durch Befragung der Bürger ermittelt und waren von den Gemeindevertretern unterschriftlich anzuerkennen ${ }^{26}$.

Schon bei einer flüchtigen Durchsicht dieser Aufzeichnungen ist erkennbar, dass es der Landesherrschaft bis zur Mitte des 16. Jahrhunderts gelungen war, die Jagddienste im ländlichen Raum auf breiter Front durchzusetzen (Abb. 1). Für die große Mehrzahl der Ortschaften galt eine Generalklausel, deren substanzieller Gehalt in folgender Verpflichtung bestand: helfen hagen und jagen, fürstehen, Hundt ziehen, junge Hundt uffstocken und halten, Wildpret, Seil-und Zengwägen fübren. Wie ausdrücklich festgestellt wird, hatte das alles in fron, d.h. auf Kosten der Dienstpflichtigen zu geschehen. Eine Sonderregelung gab es allerdings für die Gestellung von Gespannen zum Geräte- und Wildtransport. Bei Überschreitung einer bestimmten Wegstrecke - meist eine Meile (ca. 7,5 km) - erhielten die Fuhrleute nach gemeinem brauch des Fürstenthums eine belonung ${ }^{27}$. Sofern die Übernachtung unvermeidlich war, bekamen sie außerdem Verpflegung und Futter für ihre Pferde. Ein Suppen und ein Trunckb - zumindest aber ein Hofbrot - wurde usser Gnaden stets auch dann gewährt, wenn Wildbret der Hofhaltung zugeführt werden muss$\mathrm{te}^{28}$. Diese und andere kleine Ergötzlichkeiten hatten allerdings keinen Bestand. Obwohl sie die Forstlagerbücher schmückten, überlebten sie fast nirgends das 16 . Jahrhundert ${ }^{29}$.

Trotz der weit verbreiteten Dienstpflicht ergab sich aber kein einheitliches Bild. Bei der Feststellung der Observanz stellte sich nämlich heraus, dass von manchen Gemeinden - aus welchen Gründen auch immer - noch nie Hilfsleistungen angefordert worden waren, wobei sich ihre Vertreter stets auf die Aussagen der Eltern und Voreltern oder der ältesten Einwohner beriefen. Verschont blieben vorzugs-

${ }^{26}$ Häufig handelte es sich um Analphabeten, die sich durch schriftkundige Personen vertreten lassen mussten.

${ }^{27}$ Für alle Transportdienste behielt sich die Jagdherrschaft das Direktionsrecht vor. Die Fuhrleute waren gehalten, die Fahrzeuge an den Ort zu bringen, wohin sie beschaiden werden. Die Seil- und Zeugwagen wurden meist vierspännig, manchmal aber auch sechsspännig gefahren und mit einem für Sattel- und Strangrosse unterschiedlichen Tagessatz honoriert.

28 Alles gefallene (verendete) und erlegte Wild wurde fronweise eingesammelt und abgefahren oder weggetragen. Zielorte waren die nächsten Flecken, Amtsstädte oder Forstamtssitze, häufig aber auch der Hof, der sich in den alten Zeiten nicht nur in der Residenz, sondern auch in den Landschlössern aufhielt. Wurde ihm Wildbret gebracht, war es üblich, den Fuhrmann nicht nur zu verköstigen, sondern ihm auch von zerwirktem Rotwild den Kopf zu überlassen.

${ }^{29}$ Es gibt kaum Hinweise, dass diese Bestimmungen im 17. Jahrhundert noch beachtet wurden. Schon 1608 beschwert sich die Landschaft darüber, dass den frönern die von alters gegebene ergötzlichkeit abgestrickt worden sei (Albert Eugen Adam: Württembergische Landtagsakten unter Herzog Johann Friedrich 1608-1620. Stuttgart 1919. Bd. 3. S. 70). Im Leonberger Forstlagerbuch ist in einem Nachtrag aus dem Jahr 1700 vermerkt, für die Seilund Zeugwagenfuhren sei seit Menschengedenken nichts mehr gereicht und von den Fronpflichtigen auch nichts mehr gefordert worden (HStA Stuttgart L 6 Bü 943). 


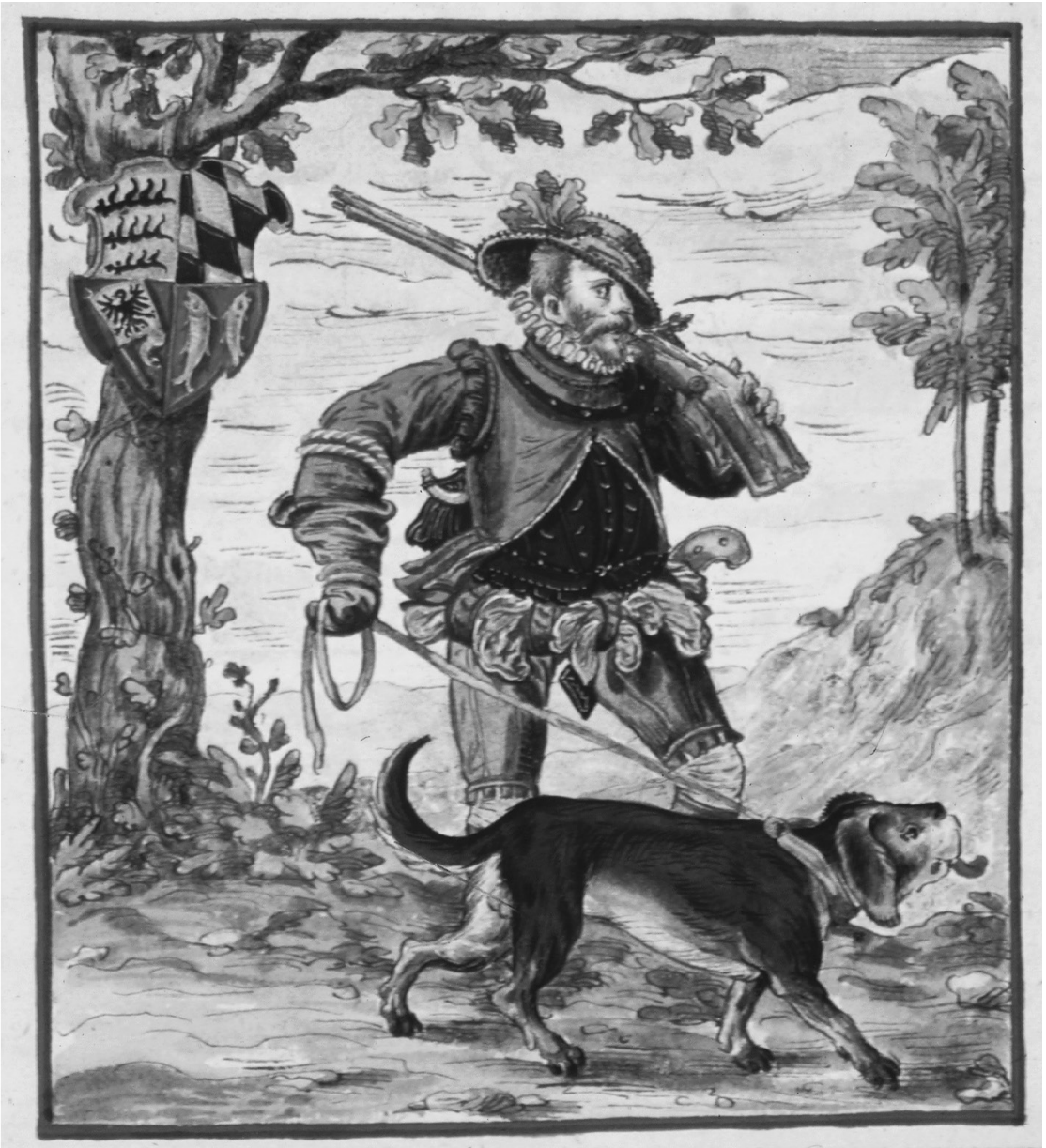

Abb. 1: Württembergischer Jäger des 16. Jahrhunderts (nach Johann von Clamorgan: Von der Wolffsjagt, 1580; WLB Cod. cam. et oec $2^{\circ} 4$ ).

weise Städte, die spezifische Belastungen (insbesondere mit der Unterhaltung von Befestigungs- und Schlossanlagen sowie Wach- und Hofdiensten beim Aufenthalt des Regenten) geltend machen konnten ${ }^{30}$. Bei anderen Orten dürfte die Entlegen-

30 Die Stadt Weinsberg (Neuenstadter Forst) begründete 1558 ihre Jagdfreiheit damit, dass ihre Bürger täglichs an mauern, Pflastern, Thurn und anderem Frondienste verrichten müssten. Die Obrigkeit wurde aufgefordert, den Jägermeister zu befragen, ob sie in den letzten 50 oder 60 Jahren zum Jagen aufgeboten worden seien. Sollte sich das herausstellen, 
heit oder die Waldarmut der Umgebung ursächlich dafür gewesen sein, dass sie wenn überhaupt - nur selten von der Jägerei aufgesucht worden waren ${ }^{31}$. Mancherorts hatte man für bestimmte Dienstleistungen - vor allem zum Hagen und zur Führung der Seilwagen - noch niemand angefordert ${ }^{32}$. Mehrfach wurde behauptet, nur auf der eigenen Markung gefront zu haben. Einige gaben auch an, sie hätten zwar dem Ansuchen der Jäger gelegentlich Folge geleistet, wüssten aber nicht, ob sie schuldig seien, das zu tun. Andere erklärten sogar, dass sie freiwillig geholfen hätten, und stellten deshalb eine Dienstbarkeit rundweg in $\mathrm{Abrede}^{33}$.

Unverkennbar ist im Vorfeld der Forstbeschreibungen eine massive Steigerung der Fronanforderungen feststellbar. Wenn das Ergebnis der Bestandsaufnahme den Erwartungen der Jagdherrschaft nicht entsprach, wurde offensichtlich Druck auf die Untertanen ausgeübt, um sie gefügig zu machen. Ihr Einverständnis zur vollen Fronleistung war oft leicht zu erreichen, denn die Gehorsamspflicht gegenüber dem Landesherrn stand hoch im Kurs. Nichts war ehrenrühriger, als des Ungehorsams bezichtigt zu werden. Unterordnung und Ergebenheit waren im Bewusstsein der armen Leute tief verankert und hatten einen idealen Nährboden für die Akzeptanz der Jagddienste geschaffen ${ }^{34}$. Viele gaben dem Drängen - wenn auch mitunter

wollten sie sich nicht widersetzen (HStA Stuttgart A 59 Bü 34). Auch die Residenzstadt Stuttgart war - bis auf das Führen der Jagdhunde in die Nachbarorte - fronfrei (HStA Stuttgart A 557 Bü 290).

31 Die auf einer Forstgrenze gelegene Gemeinde Cannstatt stützte ihre Jagensfreiheit darauf, dass sie auf beiden Seiten des Neckars von den Wäldern weit entsessen sei (HStA Stuttgart A 59 Bü 34). Auch Bondorf (Nagolder Forst) machte geltend, vom nächsten Wald eine Meile entfernt und deshalb wegen der Leistung von Jagddiensten fast nie angefochten worden zu sein (HStA Stuttgart H 107/11 Bd.2).

${ }^{32} \mathrm{Da}$ in der waldarmen Umgebung von Münchingen (Leonberger Forst) noch nie ein Hag angelegt worden war, verweigerten die Ortsbürger diese Dienstleistung, erhoben aber sonst gegen ihre Fronpflicht keine Einwendungen (HStA Stuttgart A 248 Bü 429). Die Bürger der Gemeinde Berghülen (Blaubeurer Forst) hatten schon alle möglichen Frondienste geleistet, doch war der Seilwagen noch nie zu ihnen gebracht worden. Dennoch erklärten sie: Wollen ihn fübren wie andere Flecken (HStA Stuttgart H 107/2 Bd.1).

33 Aufschlussreich für die rigorose Durchsetzung der Jagddienste ist ein Vorgang in der teils von Württembergern und teils von Hintersassen des Klosters Königsbronn bewohnten Gemeinde Steinheim auf dem Albuch (Heidenheimer Forst). Während die ersteren fronpflichtig waren, beklagten sich letztere 1562 darüber, in jüngster Zeit im Widerspruch zum alten Herkommen mit schweren Hand- und Fuhrfronen beladen und im Forstlagerbuch eingetragen worden zu sein, obwohl sie niemals solliche Dienstbarkeit je einzuschreiben bewilligt hätten. Sie wiesen ausdrücklich darauf hin, dass sie sich lediglich gutwillig und zu keiner Schuldigkeit zu Wolfsjagen gebrauchen ließen und legten Wert auf die Feststellung, nie gebotten, sondern stets erbetten worden zu sein. Herzog Christoph, dem der Fall vorgelegt wurde, bezeichnete den Streit als narrenwerckh und meinte, man solle die Paurn hinziehen lassen, er wolle selber nachdenken, was mit ihnen zu tun sei. An der Fronlast änderte sich dadurch freilich nichts. In einem Nachtrag zum Forstlagerbuch wurde klargestellt: Die gesamte Innwohnerschaft dient in allen Forstlichen Geschäfften (HStA Stuttgart A 227 Bü 770 und $\mathrm{H} \mathrm{107/5} \mathrm{Bd} .2$ ).

${ }^{34}$ In zahlreichen Fällen erklärten sich die Betroffenen als arme gehorsame Unterthanen 
zähneknirschend - nach ${ }^{35}$. Die Methode, aus gelegentlichen Gefälligkeits- und Hilfsdiensten Rechtsfolgen abzuleiten, erwies sich als durchaus erfolgreich. Dennoch blieben genügend Ortschaften übrig, die hartnäckig auf ihrem alten Recht bestanden und es ablehnten, sich den Forderungen der Obrigkeit zu beugen ${ }^{36}$. Auch war die seit der Reformation energisch vorangetriebene Integration der Klöster in das württembergische Fronsystem noch nicht zum Abschluss gekommen ${ }^{37}$. Gleichwohl kann kein Zweifel darüber bestehen, dass die Forsterneuerung sich keineswegs auf die Festschreibung des status quo beschränkte.

Obwohl die Bilanz unter diesem Aspekt für Herzog Christoph erfreulich ausfiel, war er keineswegs zufrieden, denn der Rentkammerprokurator Dr. Michel Schweicker hatte ihm glaublich versichert, dass sämtliche Untertanen Jagdfronen zu leisten hätten. Ausnahmen sollten nach der von diesem Beamten verfassten Regel nur für Bürger in Städten und Flecken gelten, die mit einem schriftlichen Schein ihre Befreiung nachweisen konnten ${ }^{38}$. Mit Billigung des Dienstherrn wurde daher die Anordnung getroffen, zur Erhaltung der fürstlichen Gerechtigkeit die allgemeine Dienstpflicht affirmative in die Forstlagerbücher einzuschreiben. Der da-

bereit, Fronforderungen zu erfüllen, die nicht durch das alte Herkommen gedeckt waren. Sie seien nie zum Hunde- und Seilwagenführen bestellt worden, beteuerten z. B. die Bürger von Ebhausen (Nagolder Forst), gaben sich aber als arme einsessene des Vorsts zu erkennen und sicherten $\mathrm{zu}$ : Wann Inen gebotten werde, theten sie wie die gehorsamen (HStA Stuttgart $\mathrm{H}$ 107/11 Bd.2). Der Flecken Aichelbach (Reichenberger Forst) war überhaupt noch nie zu Jagddiensten eingeteilt worden, weil er dem gejägdt ungelegen gesessen sei. So sie aber erfordert werden, versprachen die Bewohner, thun sie wie gehorsame Leuth (HStA Stuttgart $\mathrm{H}$ 107/14 Bd. 40).

${ }^{35}$ Der zum Stift Öhringen gehörende Müller von Ellhofen (Neuenstadter Forst) übernahm den Wildtransport an den Stuttgarter Hof erst nach Androhung einer Gefängnisstrafe und erklärte, er wolle das jetzt thun, aber aus keiner Gerechtigkeit (HStA Stuttgart A 59 Bü $34)$.

${ }^{36}$ Ein (unvollständiges) Register der Stet und fleckhen so sich vörstlicher Dienstparkhait waigern listet 65 Widerspruchsfälle auf (HStA Stuttgart A 59 Bü 34 und A 227 Bü 15). Besonders ausgeprägt war die Ablehnungsfront in den Städten, deren Selbstbewusstsein sich deutlich von der Gefügigkeit vieler ländlicher Gemeinden abhob.

37 In den Brenztalklöstern Anhausen und Herbertingen (Heidenheimer Forst) wurden die Jagdfronen von den Prälaten unter Hinweis auf die altgenossenen Freibeiten nicht anerkannt (HStA Stuttgart A 227 Bü 764). Sie untersagten deshalb ihren Hintersassen, den Aufforderungen des Forst- und Jagdpersonals nachzukommen. Noch 1611 kam es mit Unterstützung der Klosterverwalter zur Fronverweigerung (HStA Stuttgart A 227 Bü 808). Auch in Königsbronn war dies zeitweise der Fall. Der letzte katholische Abt beklagte sich über die Jagddienste, erklärte sich aber bereit, die Untertanen dazu anzuhalten, sie in gleicher Weise wie die Württemberger zu leisten, obwohl sie unter seinen Vorgängern nit allso hefftig gebraucht worden seien (HStA Stuttgart H 107/5 Bd. 1). Wenn in der Gegend der Abtei Zwiefalten gejagt wurde, musste von Alter her der Prälat oder Klosteramtmann um sein Einverständnis gebeten werden, bevor er den Klosterorten die Fronleistung „verkündigte“ (HStA Stuttgart A 248 Bü 430).

38 Undatierte und unsignierte Nota (HStA Stuttgart A 59 Bü 34). Die einschlägigen Akten sind nur fragmentarisch erhalten. 
raufhin vielfach erhobene Widerspruch wurde als Ungehorsam qualifiziert und eine Ermessensstrafe („poena arbitraria“) angedroht. Unverblümt lief diese Strategie darauf hinaus, althergebrachtes Gewohnheitsrecht zu ignorieren, wenn es mit dem herrschaftlichen Interesse kollidierte.

Der Regent - durch den offenen Widerstand nicht wenig befrembdet - forderte die widerspenstigen Gemeinden zunächst auf, definitiv zu erklären, wie sie sich künftig verhalten wollten. Nicht selten wurden sie daraufhin von Amtsleuten aufgesucht und ernstlich angesprochen, um sie zum Einlenken zu veranlassen. Die abgegebenen Stellungnahmen ließen aber keinen Zweifel aufkommen, dass sie nicht gewillt waren, ihre alten Freiheiten aufzugeben. Die neue Verfügung - vor allem ein mit Weinsberg, Möckmühl und Widdern (Neuenstadter Forst) im November 1558 angestelltes „Verhör“ - löste eine solche Unruhe aus, dass sich die Räte des Herzogs dazu entschlossen, die Notbremse zu ziehen und ihm eindringlich ins Gewissen zu reden. Sie hielten ihm vor, eine generelle Jagdfronpflicht sei weder in facto noch in jure begründet, wiesen ihn auf die nachteiligen Folgen seines Handelns hin und empfahlen ihm dringend, eine Denkpause einzulegen ${ }^{39}$. Diese Standpauke scheint gewirkt zu haben, denn in der Folge kam es zu gütlichen Verhandlungen mit zahlreichen Kommunen ${ }^{40}$. Überwiegend handelte es sich um Amtsstädte, die meistens in der Lage waren, günstige Resultate zu erzielen, während kleine Gemeinden häufig nachgeben mussten. Erst mit den 1563 bis 1565 gefertigten Reinschriften der Forstlagerbücher konnte ein Schlussstrich unter die jahrelangen Auseinandersetzungen gezogen werden.

\section{Streitfälle}

Die Kodifizierung der Jagdfronen in den Forstlagerbüchern war ein wichtiger Beitrag zur Regelung der Beziehungen zwischen Landesherrschaft und Bevölkerung auf einem Gebiet, dem in der Feudalzeit besondere Bedeutung zukam. Im Mittelpunkt dieses Klärungsprozesses stand das altüberlieferte Herkommen, das

${ }^{39}$ Die Gemeinden rechtfertigten ihre Position u.a. damit, dass Herzog Christoph seinen Untertanen bei der Huldigung zum Regierungsantritt zugesagt hatte, das alte Herkommen $\mathrm{zu}$ respektieren und auf Neuerungen zu verzichten. Maßgebend für ihren Widerstand war auch die Befürchtung, den Nachkommen eine unverantwortliche Bürde zu hinterlassen, wenn sie den Fronforderungen zustimmten. Sie schworen hoch und heilig, die Wahrheit ausgesagt zu haben und wehrten sich mit aller Entschiedenheit gegen den Vorwurf des Ungehorsams und der Widersetzlichkeit. Wie groß ihr Widerstand war, erschließt sich aus der Bemerkung, sie wollten sich von ibrem alten herkommen nit weiter treiben lassen, so hart man Inen zuredt.

40 Verhandlungen (sogenannte Tagsatzungen) wurden für 22 Gemeinden anberaumt und vom Rentkammerkollegium (Landhofmeister, Kanzler und Räte) mit bevollmächtigten Vertretern dieser Kommunen geführt. Dr. Michel Schweicker war daran nicht mehr beteiligt, da er wenige Monate nach der Intervention seiner Kollegen zum Oberrat gewechselt war. 
häufig umstritten war, weil man sich in der Regel nicht auf Schriftstücke stützen konnte. Die Entscheidungsfindung entwickelte sich deshalb oft zu einer Kraftprobe. Wie sie unter schwierigen Bedingungen ablief und welche Probleme aus den Lösungsansätzen entstehen konnten, lässt sich an einigen Fallbeispielen aufzeigen.

\section{Wildberg ${ }^{41}$}

Die von der Stadt Wildberg (Nagolder Forst) beanspruchte Jagdfronfreiheit wurde vom zuständigen Forstmeister sofort bestritten, als sie 1556 im Forstlagerbuch festgeschrieben werden sollte. Tatsächlich mussten ihre Vertreter zugeben, dass auf ernstliches Ansuchen der Jäger schon unter Herzog Ulrich Hunde geführt und Wölfe gehetzt worden waren. Dass sie vorgaben, nur aus underthenigem $G e-$ fallen und guter Nachparschafft gehandelt zu haben, half ihnen ebenso wenig wie die Versicherung, sich von Hilfsleistungen nicht völlig ausschließen zu wollen. Da bereits die Pfalzgrafen als Vorbesitzer des 1440 samt Wildbann erworbenen Städtchens dort Hof gehalten und gejagt hatten, unterstellte man, dass schon damals Frondienste geleistet worden waren. Vor diesem Hintergrund wurden 1557 die städtischen Bevollmächtigten in die Stuttgarter Kanzlei bestellt, wo man sie einige Tage hinhielt und dann mit dem Bescheid entließ, der Dissens werde vom Herzog entschieden. Eine erneute Vorladung im Jahre 1561 endete mit einer vollständigen Niederlage. One allen Widerspruch und einred musste Wildberg das Votum der Rentkammer entgegennehmen und sich zu allen Forstlichen Dienstbarkeiten verpflichten. Nicht einmal die erbetene Beschränkung auf den heimatlichen Forstbezirk wurde konzediert.

\section{Vaihingen/Enz ${ }^{42}$}

Die Stadt Vaihingen (Stromberger Forst) berief sich 1556 darauf, seit dem Pfälzischen Krieg (1504) - also nach lengstem gedenckhen - niemals mit Jagdfronen behelligt worden zu sein. Sie begründete dieses Privileg mit den großen Lasten, die sie für den Straßenunterhalt und die Versorgung des herrschaftlichen Bergschlosses zu tragen hatte, dem sie Lebensmittel, Holz, Heu und sogar Wasser auf Eseln zuführen musste. Das Forstlagerbuch enthält zu diesem Sachverhalt allerdings keinen Hinweis, sondern eine Leerstelle, von der später niemand mehr sagen konnte, ob der Sachverhalt ungeklärt blieb, weil er disputierlich oder weil er strittig war. Jedenfalls fand 1557 eine Verhandlung mit der Rentkammer statt, die ohne konkretes Ergebnis blieb. Den Stadtvätern wurde lediglich mitgeteilt, der Herzog werde Vaihingen

${ }^{41}$ HStA Stuttgart A 59 Bü 34. - A 227 Bü 31. - A 573 Bü 6658. - H 107/11 Bd. 2.

${ }^{42}$ HStA Stuttgart A 227 Bü 2564 und 2673. - A 563 Bü 97. - H 107/16 Bd. 1. 
nicht über das alt Herbringen beschweren, weshalb sie wieder nach Hause ziehen und zufrieden sein sollten. Diese mündliche Zusage wurde bis zum Dreißigjährigen Krieg auch eingehalten. Die enormen Bevölkerungsverluste hatten jedoch zur Folge, dass seit 1639 auch die Vaihinger an Jagden beteiligt werden mussten, um Hilfskräfte im notwendigen Umfang zur Verfügung zu haben. Aufgrund fortwährender Streitigkeiten kam es dann 1663 unter Herzog Eberhard III. zu einem Vergleich, wonach Jagddienste nur bei persönlicher Anwesenheit des Regenten zu leisten waren. Dennoch kehrte keine Ruhe ein. Meinungsverschiedenheiten ergaben sich vor allem aus der Frage, ob zur Begründung der Fronpflicht die Ankündigung seines Erscheinens ausreiche oder seine leibhaftige Teilnahme erforderlich sei, was nicht immer der Fall war. Bis weit in die 2. Hälfte des 18. Jahrhunderts hinein wurde deshalb lebhaft über die Missachtung der städtischen Freiheitsrechte geklagt.

\section{Tübingen $^{43}$}

Die Stadt Tübingen (Tübinger Forst) musste ihre ganze Autorität aufbieten, um bei der Forsterneuerung die Fronfreiheit durchsetzen zu können ${ }^{44}$. Nachweislich hatten ihre Bürger bei einer Wildschweinjagd im Schönbuch, die der jugendliche Herzog Ulrich 1499 für Kaiser Maximilian veranstaltete, Hunde geführt und schon in den Jahren 1482-1484 ausgeholfen, als die Amtsorte wegen einer Pestepidemie ihren Verpflichtungen nicht hatten nachkommen können. Es gab auch Zeugenaussagen, wonach die Tübinger der Aufforderung zu Wolfsjagden - man hatte in der Stadt aus diesem Anlass die Trommel geschlagen - gefolgt waren: alles jedoch, wie sie beteuerten, nur aus undertheniger wilfarung und kainer schuldigen pflicht. Unter der österreichischen Regierung unternahm der Jägermeister Reinhart Spät den Versuch, die Dienstbarkeit mit einem Gerichtsverfahren zu erzwingen, blieb dabei aber erfolglos, weil die Beweislast offenbar nicht ausreichte. Auch Herzog Ulrich, der seinen vermeintlichen Rechtsanspruch ebenfalls nicht fallen lassen wollte, bemühte sich 1544 vergeblich darum, den Tübinger Bürgern die Bereitschaft zum Hundziehen abzutrotzen, denn sie verteidigten das große Kleinod ihrer Jagdfreiheit mit Zähnen und Klauen. Trotz ernsthafter Bemühungen gelang es deshalb 1557 nicht, zu einer vertraglichen Regelung zu kommen, die den Vorstellungen der Jagdherrschaft entsprach. Bürgermeister und Magistrat konnten vielmehr ihren Rechtsstandpunkt im Forstlagerbuch verankern und sich auf mini-

${ }^{43}$ HStA Stuttgart A 59 Bü 34. - A 227 Bü 2228, 2821 und 2954. - A 565 Bü 57. - H 107/18 Bd. 11.

44 Sie berief sich dabei nicht nur auf ihre spezifischen Belastungen durch Universität und Schloss, sondern auch auf das Zeugnis früherer Regenten, wonach sie mit Aufopferung Lebens und Bluts sich in besondere Hochfürstliche Gnade gesetzt habe und erwähnte dabei speziell ihr loyales Verhalten in der Landesempörung („Armer Konrad“), das ihr 1514 einen Gnadenbrief des Herzogs Ulrich eingebracht hatte (HStA Stuttgart A 227 Bü 2954). 
male Zugeständnisse beschränken, die mit der Zeit gegenstandslos wurden. Als Herzog Eberhard III. 1666 Jagdfronen einforderte, holte er sich bei dieser Sachlage eine Abfuhr, und Herzog Karl Eugen kam 1754 gleichfalls nicht darum herum, die städtische Immunität ausdrücklich zu bekräftigen.

\section{Brackenheim $^{45}$}

Da die Stadt Brackenheim (Stromberger Forst) 1556 zweifelsfrei nachweisen konnte, seit über 50 Jahren von Jagdfronen frei gewesen zu sein, lehnte sie es mit besonderer Hartnäckigkeit ab, entsprechende Verpflichtungen einzugehen. Spontane Einberufungen, mit denen die Jagdherrschaft ihren Forderungen Nachdruck verleihen wollte, wurden ignoriert. Eine Verhandlung mit der Rentkammer verlief ergebnislos, weil die Brackenheimer unnachgiebig auf ihren alten Freiheiten bestanden. Obwohl Herzog Christoph für den Fall der Fronverweigerung seine bohe Ungnade angedroht hatte, entließ er sie ungeschoren mit dem Bescheid, sie sollten im Nabmen Gottes widerumb heimbzieben. Er gab aber nicht auf, sondern entsandte 1563 unter Leitung des Rentkammerrats Johann Zaiser eine Delegation nach Brackenheim, die den Versuch unternahm, die Stadt mit dem Hinweis unter Druck zu setzen, das fürstliche Forst- und Jagdregal sei vom Kaiser ratificirt und confirmirt worden, weshalb aus der bisherigen Fronfreiheit kein pivilegium geschöpfft werden könne. Die Kommissionäre scheuten sogar nicht davor zurück, weiteren Widerstand als freventlichen Ungehorsam oder Rebellion zu charakterisieren, doch blieben die Brackenheimer standhaft und verwarfen auch einen Kompromissvorschlag. Obwohl in einigen Inquisitionen mit allerley mitel villerlay versucht wurde, die halsstarrigen Leuth umzustimmen, war nichts zu machen. Der Herzog resignierte schließlich und ließ kleinlaut vermelden, er sei nicht geneigt, Zwang auszuüben. Das Städtchen hatte sich gegen seinen Landesherrn behauptet und blieb von Jagddiensten verschont, was Herzog Eberhard Ludwig 1724 noch einmal förmlich bestätigte.

\section{Cannstatt ${ }^{46}$}

Da der Neckar auf weiten Strecken die Scheidelinie benachbarter Forstbezirke bildete, wies die Stadt Cannstatt eine Besonderheit auf: der Hauptort gehörte zum Schorndorfer, die jenseits des Flusses gelegene Vorstadt zum Leonberger Forst. Diese Grenzlage wurde als Grund für die uralte Fronfreiheit genannt, die zwar die Rentkammer, nicht aber Herzog Christoph anerkennen wollte. Erstmals wurden

${ }^{45}$ HStA Stuttgart A 227 Bü 2515 und 2563. - A 563 Bü 83.

${ }^{46}$ HStA Stuttgart A 59 Bü 34. - A 227 Bü 1197 und 2214. - H 107/15 Bd.1. 
die Cannstatter 1554 zu einer Hasenjagd auf dem Waiblinger Feld aufgeboten - sozusagen als Auftakt zu Verhandlungen, mit denen man sie zur Raison bringen wollte, denn schon 1558 eröffneten ihnen hohe Jagdbeamte, dass im Fürstentum Württemberg wie im gantzen Teutschland alle Städte und Flecken eines Forsts der Forstlichen Dienstbarkeit unterworfen seien. Bei den Jagdfronen - so dozierten sie - handle es sich um gemaine lanndesbeschwerden, denen sich niemand ohne spezielle brieffliche schein entziehen könne. Die Stadt, die nichts dergleichen vorweisen konnte, bestand jedoch darauf, wegen der weiten Entlegenheit von allen Waldgebieten schon immer in possessione libertatis gewesen zu sein. Sie erklärte sich lediglich dazu bereit, bei Feldjagden (Hasenhetzen und Fuchsgraben) in der Umgebung mitzuwirken. Wenn in den Nachbarorten die Fronpflichtigen wegen eines Seuchenzugs (sterbende leuff) ausfielen, wollte sie zudem beim Durchzug der Jagdgesellschaft die Hundeführung übernehmen. Das war aber schon das äußerste Entgegenkommen, das ein 1565 zustande gekommener Vergleich enthielt.

\section{Bietigheim $^{47}$}

Die Stadt Bietigheim (Stromberger Forst) besaß eine aus dem Jahr 1526 stammende Rechtssammlung, die man aus den damals vorhandenen Dokumenten zusammengestellt hatte. Sie enthielt auch ein Kapitel Fron zu dem Jagen, aus dem hervorging, dass die Verpflichtung der Bürger zu Jagddiensten von Alters auf die eigene Markung beschränkt war. Angeblich ging dieses Privileg auf die Stadterhebung durch Kaiser Karl IV. im Jahr 1364 zurück. Obwohl es dem Forstlagerbuch nicht einverleibt worden war, wurde es von allen regierenden Herrn respektiert, bis der im Dreißigjährigen Krieg nach Straßburg geflüchtete Herzog Eberhard III. nach der Rückkehr dieses Vorrecht negierte, weil er seine Heimat erödet und von Fronpflichtigen derart entblößt vorfand, dass er fast keine Jagden mehr abhalten konnte. Als sich die Stadt 1648 über die Missachtung ihres Freiheitsrechts beschwerte, reagierte er mit der Erklärung, zur früheren Regelung wieder zurückzukehren, sobald Württemberg durch die Gnade Gottes mehrers populirt sei. Die Wiederherstellung des alten Herkommens zog sich allerdings in die Länge. Erst Herzog Eberhard Ludwig entschloss sich zu diesem Schritt und verankerte die Markungsbegrenzung 1700 im renovierten Forstlagerbuch. Das hinderte ihn freilich nicht daran, sie schon wenige Jahre später wieder zu kassieren, weil er Ersatz für die Ludwigsburger Nachbardörfer brauchte, die er mit Hilfsdiensten in seinem neuen Residenzschloss beschäftigte. Die Rechnung mussten die Bietigheimer bezahlen: mit einer Bürgerschaft von einigen Hundert Köpfen hatten sie zeitweise jährlich fast 6.000 Frontage abzuliefern.

47 HStA Stuttgart A 227 Bü 1208, 1220, 1234 und 2557. - A 557 Bü 262. - A 563 Bü 182. - H 107/10 Bd. 1. 


\section{Markgröningen $^{48}$}

Bei der Bestandsaufnahme der Jagdfronen 1556 hatte die Stadt Markgröningen (Leonberger Forst) zu Protokoll gegeben, niemals zu Forstlichen Dienstbarkeiten angehalten worden zu sein. Vom Rentkammerrat Johann Zaiser, dem diese Aussage gar nicht gefiel, wurde sie daraufhin mit glatten Worten ermahnt, ihre Bereitschaft zum Jagddienst wenigstens für den Fall zu erklären, dass der Herzog in ihrer Nähe jage. Sie stimmte diesem Ansinnen auch zu, lehnte es aber ab, eine Rechtsverpflichtung einzugehen. Im Forstlagerbuch wurden die Markgröninger jedoch hintergangen, indem man ihnen die Schuldigkeit zuwies, ihrem Landesherrn wie andere gesessene landsässen des Vorsts gehorsam zu laisten. Als sie aufgrund dieser Formulierung 1582 und 1586 mit den landes üblichen Fronforderungen konfrontiert wurden, verweigerten sie prompt die Gefolgschaft. Der mit dieser Angelegenheit befasste Oberrat Dr. Georg Gadner empfahl Herzog Ludwig, den Markgröninger Bürgern entgegenzukommen und die mündliche Absprache zu respektieren, denn man habe genug andere fronpflichtige Leute. Der Regent folgte seinem Vorschlag und stellte noch im selben Jahr klar, sie nur in Anspruch nehmen zu wollen, wenn er höchstpersönlich zur Jagd erscheine. Herzogadministrator Friedrich Karl bestätigte 1679 diese woblhergebrachte Gerechtigkeit, doch hob Herzog Eberhard Ludwig 1709 die Ausnahmeregelung ebenso wie in Bietigheim zu Gunsten seiner Ludwigsburger Residenz wieder auf. Die Markgröninger fanden sich aber mit diesem Rechtsbruch nicht ab. Nachdem sie zahlreiche Anläufe unternommen hatten und auch mit gütlichem Zuspruch nicht ruhig zu stellen waren, gab der junge Herzog Karl Eugen ihrem Drängen schließlich nach und stellte 1749 die alte Rechtslage wieder her.

\section{Freiheitsbriefe}

Für die württembergische Obrigkeit gab es nichts, was die Befreiung von Jagdfronen besser rechtfertigen konnte als die Existenz alter Urkunden, die von früheren Regenten zu diesem Zweck ausgestellt worden waren. Allerdings sahen sich die Gemeinden fast nie in der Lage, solche Unterlagen zu präsentieren ${ }^{49}$. In der Regel mussten sie bei den Befragungen gestehen, über keine schriftlichen Nachweise zu

${ }^{48}$ HStA Stuttgart A 227 Bü 1140 und 1269. - A 557 Bü 278. - H 107/10 Bd. 1.

49 Die Stadt Wildberg (Nagolder Forst) legte bei der Forsterneuerung die Kopie eines Freiheitsbriefs des Grafen Ulrich V. von 1449 vor, der aber nicht anerkannt wurde, weil er nur die Freistellung von Baufronen betraf (HStA Stuttgart A 59 Bü 34). Im Dorf Steinheim an der Murr besaß die Ortsherrschaft - das Dominikanerinnenkloster Mariental - pergamentine brieff und Sigel, die nach dem Wortlaut des Forstlagerbuchs die Bürgerschaft von allen Frondiensten befreiten (HStA Stuttgart A 227 Bü 1822). Die Stadt Neuenbürg (Wildbader Forst) machte vergeblich geltend, einen einschlägigen Freiheitsbrief gehabt zu haben, der aber vor ca. 70 Jahren bei einer Feuersbrunst vernichtet worden sei. Ein erneuter Vorstoß 
verfügen. In wenigen Fällen waren jedoch Dokumente vorhanden, deren Gültigkeit außer Frage stand. Der hohe Stellenwert, der ihnen im 16. Jahrhundert zugebilligt wurde, verlor indessen im Laufe der Zeit an Strahlkraft. Die Freiheitsbriefe boten daher nicht immer die Rechtssicherheit, die sich die Begünstigten von ihnen versprachen.

\section{$\mathrm{Urach}^{50}$}

Die Grafen Eberhard der Ältere und der Jüngere stellten der Stadt Urach (Uracher Forst) 1484 einen Brief aus, der die Einwohnerschaft zum Ausgleich für den Abzug der Hofhaltung und ihre Verlegung nach Stuttgart nicht nur von Steuern und Umlagen, sondern auch von allen Diensten freisprach ${ }^{51}$. Das Forstlagerbuch von 1557 sah dementsprechend keine Jagdfronen vor, doch hatten sich die Uracher darauf eingelassen, die Hunde für einen Tagessatz von einem Schilling und die Seilwagen nach der landesüblichen Entschädigung zu führen. Das Freiheitsprivileg wurde zweimal - 1514 von Herzog Ulrich und 1583 von Herzog Ludwig - gegen Geldzahlungen bestätigt, von den folgenden Landesherren aber nicht mehr confirmirt. Gleichwohl gab es keine Probleme. Als 1657 Klagen über allzu häufige Fuhrdienste laut wurden, half ihnen Herzog Eberhard III. ab. Schon kurze Zeit später war die Befreiung Urachs von Frondiensten jedoch heftig umstritten, da Zweifel entstanden, ob das Dokument der Grafen Eberhard nach so langer Zeit noch Gültigkeit beanspruchen könne. Man glaubte daher, ein juristisches Consilium mit jahrelangen Erwägungen des Pro und Contra veranstalten zu müssen. Die Entscheidung fiel erst 1666, nachdem die Universität Leipzig ein Gutachten vorgelegt hatte, das bei den herzoglichen Räten auf Zustimmung stieß. Es mündete in die Empfehlung, die ehemalige Residenzstadt bei der einmal erlangten Freybeit von Fronen und Diensten außerhalb des Hundefübrens zu belassen. Das jagdliche Freiheitsrecht der Uracher war gerettet.

\section{Kusterdingen ${ }^{52}$}

Das je zur Hälfte Württemberg und der Stadt Reutlingen gehörende Dorf Kusterdingen (Tübinger Forst) zeichnete sich durch eine seltene Konstellation aus: es war eine Mundat, d. h. ein gerichtsfreier Ort. Im Jahr 1463 hoben Graf Eberhard im Bart und die Reichsstadt die Mundat auf und regelten in einer Übereinkunft, dass

blieb 1670 ebenfalls erfolglos, weil wiederum nichts grundliches präsentiert werden konnte (HStA Stuttgart A 559 Bü 13 und 153).

${ }^{50}$ HStA Stuttgart A 59 Bü 35. - A 206 Bü 4985. - A 227 Bü 2826. - H 107/19 Bd. 2.

${ }^{51}$ HStA Stuttgart A 107/19 Bd. 7 Bl. 84 (Abschrift von 1787).

${ }^{52}$ HStA Stuttgart H 107/18 Bd. 11 und 12. - L 6 Bü 943. 
Kusterdingen künftig weder mit Schatzung, Steuer, Diensten oder anderen Sachen beschwert sein solle ${ }^{53}$. Kurze Zeit später (1484) wurde die Ortschaft durch einen Schlaich vollständig württembergisch. Bei der Forsterneuerung 1556 verwiesen die Kusterdinger auf den Freiheitsbrief und beteuerten, dass sie noch nie Jagdfronen geleistet hatten. Sie räumten aber ein, dienstbar gewesen zu sein, wenn die württembergischen Landesherrn auf ihrer Markung oder in den nächsten Hölzern jagten und sie von den Jägern darum angesprochen wurden. Eine Rechtsverpflichtung wiesen sie weit von sich, sagten aber zu, auch in Zukunft Hilfsgesuche nicht abzuschlagen. Offenbar hielt sich die Jagdherrschaft an diese Absprache.

\section{Stift Backnang ${ }^{54}$}

Als Graf Ulrich der Vielgeliebte 1477 das Augustiner-Chorherrenstift Backnang (Reichenberger Forst) in ein Kollegiatstift umwandelte, befreite er das reformierte Gotteshaus und alle seine zugebörigen von sämtlichen jagdlichen Dienstleistungen $^{55}$. Die Lehenbauern des Stifts, das über umfangreichen Grundbesitz verfügte, gingen deshalb davon aus, im Besitz der Jagdfreiheit zu sein und widersetzten sich dem Aufgebot. Ihr Anspruch blieb aber umstritten, weil die Fronfreiheit im Forstlagerbuch von 1555 nicht sanktioniert war, während das Stiftslagerbuch die verliehenen Grundstücke als freie eigene Güter bezeichnete. Herzog Friedrich, der sich die Kompetenz eines Stiftspropstes zumaß, verordnete den Stiftsbauern 1594 die Fronpflicht, ohne damit jedoch eine tragfähige Entscheidung getroffen zu haben, denn spätestens im 18. Jahrhundert entwickelten sich aus der widersprüchlichen Sachlage langwierige Streitereien. Zweifelsfrei war nur, dass die Angehörigen des Backnanger Amts - die Amtischen - Jagddienste leisten mussten. Die Hintersassen des Stifts - die Stiftischen - wurden dagegen (zum Ärger der Amtischen) oft gar nicht zum Jagen zitiert. War das der Fall, blieben sie - unterstützt vom Stiftsverwalter - häufig aus oder folgten der Aufforderung lediglich aus Furcht vor Bestrafung ${ }^{56}$. Strikte Fronverweigerung und höchste Protestation vieler Betroffener - einige wurden sogar inhaftiert - veranlassten 1741 Herzogadministrator Karl Friedrich, sie bis zu weiterem Licht in der Sache bei ibrer angeblichen Jagensimmunität zu belassen. Da die Nachforschungen in den Registraturen nichts zutage förderten, gab die Regierung schließlich auf und billigte den Stiftischen 1760 definitiv die Fronfreiheit zu.

\footnotetext{
${ }^{53}$ HStA Stuttgart H 107/18 Bd.11 Bl. 143 (Abschrift von 1745).

${ }^{54}$ HStA Stuttgart A 227 Bü 1541 und 1986.

${ }^{55}$ Christoph Besold: Documenta Ecclesiae Collegiatae in oppido Backhenang. 1631. S.21.

56 Bezeichnenderweise sagte einer aus, er gehe lieber zum Jagen, als dass er zum Forstamt auf den Reichenberg laufe, um seine Strafe zu bezahlen (HStA Stuttgart A 227 Bü 1986).
} 


\section{$\operatorname{Asperg}^{57}$}

Die am Fuß der gleichnamigen Bergfestung gelegene Stadt Asperg (Leonberger Forst) wurde 1489 durch einen Brief des Grafen Eberhard im Bart von Steuern, Abgaben und Dienstleistungen freigestellt ${ }^{58}$. Obwohl dieses Privileg zweifellos auch die Jagdfronen betraf, wurde es 1556 nicht in das Forstlagerbuch aufgenommen. Der unversehrte, versiegelte Freibeitsbrief ist dort zwar erwähnt, doch ebenso die Tatsache, dass die Asperger - wenn auch bisher nicht vibl - zu Forstlichen Dienstbarkeiten gebraucht werden. Da sie sich auf diese Weise in gewissen terminis fronpflichtig machen ließen, war ihr altes Freiheitsrecht nichts mehr wert. Der Hohenasperg hatte seinen Festungscharakter eingebüßt und der alte Freibrief des Grafen Eberhard damit seine Bedeutung verloren. Trotz ungezählter Monitorien wurde daher nach dem Dreißigjährigen Krieg nicht nur die Steuerbefreiung abgeschafft, sondern der Frondienst bis zum Steinerweichen gesteigert. Die ständigen Beschwerden hatten schließlich zur Folge, dass die Obrigkeit es sich verbat, die Stuttgarter Kanzlei auß lauter vorwitz anzulauffen. Im 18. Jahrhundert setzte sich diese Entwicklung - vollends nach der Anlage einer Fasanerie auf der eigenen Markung - ungebremst fort. Dass die Asperger gegen das renovierte Lagerbuch von 1700 Protest einlegten und die Unterschrift verweigerten, blieb folgenlos. Ihr 1711 eingereichtes Gesuch, die Fronverpflichtung mit Geld abzulösen, wurde als Beweis für die Nichtexistenz ihres angeblichen Privilegs gewertet und brüsk zurückgewiesen. Im Jahr 1782 mussten sie sich sogar sagen lassen, niemals im Besitz einer anmaßlichen Freibeit gewesen zu sein, die sie sich illegal erschlichen hätten. Die normative Kraft des Faktischen hatte den Sieg über eine mittelalterliche Urkunde davongetragen.

\section{Erwerbungen}

Für Gebietserwerbungen galt der Grundsatz, dass alle Rechte und Pflichten des Vorbesitzers auf die neue Herrschaft übergingen. Der Eigentumswechsel hatte somit zunächst keine Veränderung der Fronpraxis zur Folge. Ihre rechtliche Absicherung ließ jedoch nicht selten zu wünschen übrig. Der steigende Bedarf an Jagddiensten versetzte die „neuwürttembergischen“ Untertanen deshalb oft in die Notwendigkeit, sich gegen Eingriffe in das altüberlieferte Herkommen wehren zu müssen.

\footnotetext{
57 HStA Stuttgart A 206 Bü 145. - A 227 Bü 1274. - A 557 Bü 260. - A 558 Bü 38.

58 August Ludwig Reyscher: Sammlung der altwürttembergischen Statuarrechte. 1834. S. 106.
} 


\section{Neuenstadt am Kocher, Weinsberg, Möckmühl ${ }^{59}$}

Nach dem Kurpfälzischen Krieg fielen 1504 die Städte Neuenstadt, Weinsberg und Möckmühl mit ihren Ämtern an das Herzogtum Württemberg und wurden auf diese Weise Bestandteil des neu gebildeten Neuenstadter Forsts. Unter den Pfalzgrafen waren sie fronfrei gewesen und blieben das auch nach dem Herrschaftswechsel, ohne dass ihnen dies ausdrücklich zugesichert wurde. Vereinzelte Versuche, sie zu Jagddiensten heranzuziehen, stießen auf energischen Widerstand. Als die drei Städte bei der Forsterneuerung auf ihrer Jagdfreiheit beharrten, kam es $1558 \mathrm{zu}$ einer Konfrontation mit dem Kammerprokurator Dr. Michel Schweicker, der ihnen die bedingungslose Bereitschaft zur Fronleistung abforderte, worauf sich ein Proteststurm erhob. Nachdem Herzog Christoph seine harte Linie aufgegeben hatte, folgten zähe Verhandlungen, die erst 1564 mit einem Vergleich abgeschlossen werden konnten. Danach waren Neuenstadt, Weinsberg und Möckmühl im Wesentlichen nur verpflichtet, zum underthenigen gefallen des Regenten mitzuhelfen, wenn er - was selten geschah - in aigner person bei ihnen jagte. Damit war der Friede wieder hergestellt, bis der 1744 ins Amt gekommene Neuenstadter Forstmeister Johann Baptist von Palm glaubte, neue Saiten aufziehen zu müssen ${ }^{60}$. Sein Vorhaben, den ehemals pfälzischen Städten württembergische Jagdfronen aufzunötigen, schlug jedoch fehl, denn er erhielt die Weisung, sie ungeschmälert bei ihren Privilegien zu lassen.

\section{Sachsenheim $^{61}$}

Nachdem der Ortsadel im Mannesstamm erloschen war, kam die Stadt Sachsenheim (Stromberger Forst) 1578 an das Herzogtum Württemberg und wurde 1581 in die Landschaft inkorporiert. Da die Vorbesitzer kein Jagdrecht auf Rot- und Schwarzwild besessen hatten, konnten sie die Stadtbürger ausschließlich mit Frondiensten in der Niederwildjagd beschäftigen. Herzog Ludwig sagte ihnen bei der Herrschaftsübernahme zu, es dabei bewenden zu lassen und sie nur in Anspruch zu nehmen, wenn er im Amtsbezirk Sachsenheim persönlich oder für fremde Herrschaften mit Fuchs- und Hasenjagen einen Lust zu halten begebre. Herzog Friedrich bestätigte 1594 aus gegebenem Anlass diese Regelung ${ }^{62}$. Sie wurde bis zur

59 HStA Stuttgart A 59 Bü 34. - A 227 Bü 1613 und 1674. - H 107/13 Bd. 4 und 6.

60 Als Herzog Karl Eugen 1747 erstmals in Neuenstadt ein Treibjagen abhielt, brachte es Forstmeister von Palm beispielsweise durch ein Täuschungsmanöver fertig, dass statt des zweitägigen regulären Jagddienstes 40 Mann drei Wochen lang den Ministern und Kavalieren die Gewehre tragen und ihre Pferde halten mussten, was in der Bürgerschaft großes Murren gegen den Magistrat hervorrief, der dem Verfahren unter falschen Voraussetzungen zugestimmt hatte (HStA Stuttgart A 227 Bü 1683).

${ }_{61}^{61}$ HStA Stuttgart A 227 Bü 2644. - A 563 Bü 88.

${ }^{62}$ Der Jägermeister Johann von Breitenbach riet ihm, die Sachsenheimer bei ihren Frei- 
Landesoccupation im Dreißigjährigen Krieg auch eingehalten, in der Folge aber wegen des allgemeinen Leutemangels ignoriert. Sachsenheim musste daher auch dann noch um sein Sonderrecht kämpfen, als es 1672 von Herzog Eberhard III. erneut bekräftigt und in das Forstlagerbuch eingetragen worden war. Nur diesem Rechtstitel ist es zu verdanken, dass im 18. Jahrhundert mehrfache Versuche des Forstpersonals scheiterten, die Stadt um ibre Gerechtigkeit zu bringen.

\section{Besigheim $^{63}$}

Die Stadt Besigheim (Leonberger Forst) war bis 1595, als sie zusammen mit ihren Amtsorten von Württemberg erworben wurde, im Besitz der Markgrafen von Baden-Durlach gewesen, die dort lediglich die Niederwildjagd ausüben durften. Da sie es zudem ihren Vögten überlassen hatten, Füchse und Hasen zu erlegen, spielten die Jagdfronen bis zum Eigentumswechsel kaum eine Rolle. Bei der Huldigung versprach Herzog Ludwig seinen neuen Untertanen, ihre hergebrachten Rechte zu wahren und sie nur auf der eigenen Markung, darüber hinaus aber lediglich dann zu beanspruchen, wenn er selbst in der Umgebung jage. Diese Einschränkung fand 1673 Eingang in das erneuerte Forstlagerbuch. Schon am Ende des 17. Jahrhunderts gingen die Leonberger Forstmeister jedoch dazu über, die Besigheimer an regulären Jagden weit außerhalb ihrer Markungsgrenzen zu beteiligen. Einberufungen bis in den Stuttgarter Raum wurden von der Bürgerschaft mit nicht geringer Bestürzung aufgenommen. Auch die Jagdherrschaft war unsicher, wie sie sich verhalten solle. Herzog Eberhard Ludwig hielt 1706 die Sache für zimblicher maßen dubios und veranlasste Erkundigungen bei alten Leuten, die das Beschränkungsprivileg bestätigten. Es spricht für sich, dass es zwischen 1708 und 1765 nicht weniger als 5-mal verkündet werden musste, ohne damit eine endgültige Befriedung erreichen zu können. Noch 1806 kam es in Besigheim zur Fronverweigerung, die nur deshalb folgenlos blieb, weil sich die Stadt auf ihren eindeutigen Besitzstand berufen konnte.

\footnotetext{
Altensteig $^{64}$

Nachdem 1603 die Ämter Altensteig und Liebenzell von der Markgrafschaft Baden-Durlach in württembergischen Besitz übergegangen waren, entstand aus dieser Neuerwerbung der Altensteiger Forst. Die Stadt, der er seinen Namen verdankt, war unter badischer Herrschaft weitgehend fronfrei gewesen und blieb

heiten zu lassen, biss etwann ain ander gelegenheit sich mit ibnen ergeben werde (HStA Stuttgart A 227 Bü 2644).

${ }^{63}$ HStA Stuttgart A 227 Bü 41 und 1417. - A 557 Bü 261. - A 567 Bü 299.

${ }^{64}$ HStA Stuttgart A 227 Bü 258, 336 und 1552. - H107/1 Bd. 4.
} 
zunächst auch weiterhin von Jagddiensten verschont, bis der Forstmeister Johann Wilhelm von Remchingen 1661 nach seinem Amtsantritt damit begann, die seit obnfürdenkblichen Jabren übliche Jagensfreiheit zu beseitigen ${ }^{65}$. Daraufhin wandten sich die Stadtväter mit der fußfälligen Bitte an Herzog Eberhard III., sie mit dieser Neuerung zu verschonen. Bei der Feststellung der Rechtsgrundlage ergab sich aber der überraschende Befund, dass das 1608 angelegte Forstlagerbuch verschwunden und nicht mehr aufzutreiben war. Gleichwohl erklärte sich der Landesherr dazu bereit, auf die Jagddienstbarkeit zu verzichten, bis sich die kümmerliche Einwohnerzahl des armen Städtchens hoffentlich etwas vergrößert haben werde ${ }^{66}$. Obwohl aus dieser salvatorischen Lösung Contradictiones und Mißverständnisse resultierten, lehnte Herzogadministrator Friedrich Karl 1685 weitere Erörterungen ab und beließ es bis zur Wiederauffindung der Documente beim ungeklärten status quo. Da nichts mehr auftauchte, kam es, wie es kommen musste: nach einem forstamtlichen Zeugnis von 1778 wurden von der Stadt Altensteig die angeforderten Jagdfronen widerspruchslos geleistet.

\section{Rechtssicherheit}

Mit den Forstlagerbüchern des Herzogs Christoph war für die Jagddienstbarkeit eine Rechtsgrundlage geschaffen worden, die bis zum Ende des feudalen Fronsystems im frühen 19. Jahrhundert Bestand hatte. Obwohl die schriftliche Fixierung gegenüber der mündlichen Überlieferung einen großen Fortschritt bedeutete, war sie aus verschiedenen Gründen nicht in der Lage, ausreichende Rechtssicherheit zu bieten.

Dafür war zunächst einmal die weit verbreitete Unkenntnis der Betroffenen verantwortlich, die - insbesondere bei längerer Unterbrechung - über ihre Rechte und Pflichten häufig nicht Bescheid wussten, zumal viele Aufzeichnungen in Kriegszeiten oder durch Brände verloren gingen. Sie hatten auch kaum die Möglichkeit, sich Klarheit zu verschaffen, denn die Forstlagerbücher standen ausschließlich den Forstämtern zur Verfügung, die überdies die Deutungshoheit für sich beanspruchten $^{67}$. Herzog Eberhard Ludwig verbot 1721 sogar ausdrücklich, Extrakte für Dritte anzufertigen und ordnete an, dass nichts mebr propagirt und communicirt wer-

${ }^{65}$ Die Hilfsleistungen waren bisher darauf beschränkt, an Wolfsjagden teilzunehmen und Brot, Wein, Haber und Hundsmehl zur Versorgung der Jäger, Pferde und Hunde an die Jagdorte zu bringen (HStA Stuttgart A 227 Bü 1552).

66 Altensteig zählte 1661 lediglich 46 fronpflichtige Bürger (HStA Stuttgart A 227 Bü 1552).

${ }^{67}$ Nicht einmal die Oberbehörden waren im Besitz von Abschriften und mussten deshalb Auszüge anfordern, um Streitfragen entscheiden zu können. Die eigenmächtige (aber durchaus zutreffende) Interpretation des Forstlagerbuchs durch die Gemeinde Kleinaspach (Reichenberger Forst) wurde vom Oberforstamt 1771 als unanständiges Verhalten gerügt (HStA Stuttgart A 227 Bü 2043). 
$\mathrm{de}^{68}$. Erst als die Geheimniskrämerei im späten 18. Jahrhundert auf wachsenden Unmut stieß, verfügte Herzog Karl Eugen im Erbvergeich 1770 die Herausgabe der Unterlagen, die aber selten oder nur widerwillig herausgerückt wurden ${ }^{69}$. Bei dieser Sachlage kann es nicht verwundern, dass zahllose Gesuche um vollständige oder teilweise Fronenbefreiung aussichtlsos waren, weil sie häufig auf irrtümlichen Annahmen beruhten und die Antragsteller somit ohne große Umstände ein und vor allemal ab-und zur Rube gewiesen werden konnten.

Die unbefriedigende Rechtslage ergab sich ferner aus der Tatsache, dass die Observanz weiterhin als Grundlage für Jagddienstanforderungen anerkannt war. Sobald sich durch zeitweiligen Gebrauch neue Gewohnheiten etabliert hatten, galten sie als herkömmliche Verpflichtung, obwohl sie in den Forstlagerbüchern nicht verzeichnet waren ${ }^{70}$. Es ist deshalb verständlich, wenn sich die Fröner dagegen sträubten, dem Forstmeister zu willfabren und gutwillig Leistungen zu erbringen, die später für eine Gerechtigkeit gehalten wurden. Die Sorge vor der schädlichen consequenz ihrer Nachgiebigkeit war allgegenwärtig, wenn sie sich auf unkonventionelle Hilfsdienste einließen. Irritationen entstanden schließlich durch Organisationsänderungen, mit denen ganze Landstriche benachbarten Forstbezirken zugeschlagen wurden. Vor allem aber traten an die Stelle althergebrachter Frondienste neue Bedürfnisse, weil der Jagdbetrieb sich weiterentwickelte. Die alte Schreibart der Forstlagerbücher war daher im 18. Jahrhundert teilweise unverständlich geworden. Das galt insbesondere für das Hagen, nachdem die mit diesem Begriff bezeichnete Jagdmethode im 17. Jahrhundert aufgegeben worden war.

Überhaupt erwiesen sich die Bestimmungen der Forstlagerbücher über die Art und Weise der fronpflichtigen Dienste als interpretationsfähig. Zeitpunkt und Ausmaß blieben ohnehin der Disposition des Forstpersonals überlassen. Die Jagdherrschaft griff selten ein, denn sie war an einer angemessenen Begrenzung nicht sonderlich interessiert, weil sie hohe Wildstände anstrebte, um nach Herzenslust jagen und den enormen Bedarf an Küchen- und Deputatwild decken zu können. Wenn die Regierung das lamentiren der Untertanen, sie würden mit dem Jagen

${ }^{68}$ HStA Stuttgart A 531 Bü 16. - L 6 Bü 937. Extrakte wurden auch gegen Bezahlung nicht abgegeben.

${ }^{69}$ Als 1773 der Schultheiß von Neckarweihingen (Reichenberger Forst) einen Lagerbuchauszug verlangte, wurde der Antrag erst genehmigt, nachdem sich die Bauern an den Herzog gewandt und damit gedroht hatten, den Ortsvorsteher nach Stuttgart zu schicken, um die Aushändigung durch einen Advokaten durchzusetzen (HStA Stuttgart A 227 Bü 1455). Wie die Landstände in ihren Forst- und Jagdbeschwerden 1797 feststellten, waren viele Gemeinden dem harten Druck der hohen und niederen Forstbedienten zu sehr ausgesetzt, um sie mit einer Beschwerde über die Verweigerung der Einsichtnahme zu reizen (Neues Forstarchiv. 1799. S. 87).

70 Den Güglinger Stadtvätern war der Lagerbuchauszug 1770 mit dem Bescheid zugesandt worden, wenn sie gegen die zu leistenden Fronen opponiren, sollen sie wissen, daß die wohlhergebrachte Observanz keineswegs ausgeschlossen sei, da die Lagerbücher und Landtagsabschiede sich selbst darauf beziehen (HStA Stuttgart A 563 Bü 87). 
allzu hart mitgenommen, allzu oft angestrengt oder allzu weit mitgeschleppt, nicht mehr hören konnte, redete sie sich gerne mit der Behauptung heraus, die intensive Bejagung diene der Reduzierung der Wildschäden in der Feldflur, die von den Bauern entschädigungslos hingenommen werden mussten. Noch häufiger wurden die Eingaben mit einem Bürotrost abgespeist. Die Forstämter erhielten dann die Weisung, sie sollten die Bürger so viel möglich verschonen, leidenlich tractiren, nicht wider die Billigkeit praegraviren oder ihnen Sublevation angedeihen lassen, was nur allzu häufig ein frommer Wunsch blieb. Es kam aber auch vor, dass man sich aus der Affäre zog, indem man ihr Anliegen wegen besonderer Umstände einfach auf sich beruhen ließ oder es auf fernere Verordnung oder eine kommende Final-Resolution vertagte ${ }^{71}$.

Zahlreiche Verstöße gegen Wortlaut und Tenor der Forstlagerbücher gingen schließlich auf das Konto der Eigenmächtigkeit des Forstpersonals. Der geringe Bildungsstand des Landvolks trug ein Übriges dazu bei, die Untertanen der Willkür der Beamtenschaft auszuliefern, sodass sie sich erst in äußerster Not dazu durchrangen, die Landesherrschaft anzurufen. Selbst jene, die einen unzweideutigen Rechtstitel geltend machen konnten, mussten sich gegen Übergriffe kräftig zur Wehr setzen, wenn sie ihn behaupten wollten. Ein Appell an die weltberühmte Generosität des Herzogs bot dafür noch keine Gewähr. Im Übrigen verschafften die Steuerungs- und Aufsichtsdefizite der Feudalbürokratie und die zeitbedingten Kommunikationsprobleme den örtlichen Forstbehörden einen Freiraum, der ungesetzlichem Verwaltungshandeln Vorschub leistete. Die Leitungsinstanzen waren unfähig, diesem Treiben Einhalt zu gebieten. Die Mißachtung aller Landesverträge und Lagerbücher drückt die Untertanen zu Boden, klagten 1761 die Landstände ${ }^{72}$, nachdem Herzog Karl Eugen erst wenige Jahre zuvor sein ungnädigstes Befremden über diesen Sachverhalt geäußert hatte ${ }^{73}$. Allerdings mussten die Forstmeister wiederholt Erwartungen erfüllen und Vorgaben der Obrigkeit umsetzen, die illegale Praktiken geradezu provozierten ${ }^{74}$. Das von den Regenten in Landtagsabschieden

${ }^{71}$ Die Rentkammer vermerkte 1770 auf einer Eingabe, einstweilen diese piece ad acta zu legen, bis wieder der casus vorkommen wird (HStA Stuttgart A 249 Bü 3195).

${ }^{72}$ HStA Stuttgart L 6 Bü 939.

73 Allgemeiner Befehl der Abstellung verschiedener Forst- und Jagdbeschwerden vom 16. Februar 1754 (Reyscher [wie Anm. 12] Bd.16,1. S. 665). Ein zeitgenössischer Kenner der württembergischen Forstszene beschrieb die Verfahrensweise bei Jagdfronbeschwerden wie folgt: Es gehet mit diesen wie mit anderen Diensten auch, es geschiehet bald auf der einen bald auf der andern Seite zu viel, und das gibt Gelegenheit zu allerhand Klagen, neuen Befeblen und abermaligen Verordnungen, wobey es jedoch gemeiniglich immer beym alten bleibet (Wilhelm Gottfried Moser: Grundsäze der Forst-Oeconomie. 1757. Bd. 2. S. 674).

${ }^{74}$ Der Neuenstadter Forstmeister Johann Baptist von Palm rechtfertigte 1747 rechtswidrige Fronanforderungen mit der Feststellung, der Oberjägermeister habe sie befohlen und Serenissimus wüßte auch davon. Wann er keine Bauren habe, könne er kein Jagen anstellen (HStA Stuttgart A 227 Bü 1683). Der Stromberger Oberforstmeister August Ernst von Rieben bestellte 1778 lagerbuchwidrig die Stadt Sachsenheim zum Jagen, weil er 700 Hasen er- 
und Dekreten gegebene Versprechen, geltendes Recht zu wahren, stand jedenfalls vielfach bloß auf dem Papier.

\section{Organisation}

Die Organisation der Frondienste war Aufgabe der Forstverwaltung, die deshalb auch den Personenkreis bestimmen musste, der unter die Forstliche Dienstbarkeit fiel. In Württemberg bestand er ausschließlich aus Männern zwischen 17 und 60 Jahren, die das Bürgerrecht erworben hatten. In der Regel handelte es sich dabei um den Haushaltsvorstand, der sich im Falle seiner Abwesenheit oder Unpässlichkeit durch einen erwachsenen Sohn oder einen Knecht vertreten lassen musste. Witwen sollten unter diesen Voraussetzungen ebenso verfahren und auf diese Weise ihren Familienbeitrag zum Aufgebot leisten. Zahlungskräftige konnten es sich erlauben, den Jagddienst an Ersatzleute zu verlobnen. Davon wurde nicht selten Gebrauch gemacht, um sich drücken und den eigenen Geschäften nachgehen zu können.

Ungeachtet aller Verbote kam es häufig vor, dass von den Fronpflichtigen Buben oder Alte, die den Strapazen nicht gewachsen waren, zum Jagen geschickt wur$\operatorname{den}^{75}$. Es gab aber auch viele Kränkliche und Presthaffte in den besten Mannesjahren, die wegen ihrer Leibsschäden vom Jagen freigesprochen werden mussten. Als die Einwohner dem Forstpersonal noch persönlich bekannt waren, konnte die Beurteilung des Gesundheitszustands nach dem Augenschein erfolgen. Seit der 2. Hälfte des 18. Jahrhunderts wurden von den Untüchtigen jedoch medizinische Atteste verlangt. Im frühen 19. Jahrhundert begann man dann damit, die Jagddiensttauglichkeit auf der Grundlage konkreter Befunde und objektiver Kriterien systematisch zu überprüfen. Diese Erhebungen vermitteln einen aufschlussreichen Einblick in die miserable körperliche Verfassung der gemeinen Leute. Armut, harte Arbeit, schlechte Ernährung und unzureichende ärztliche Versorgung hinterließen unübersehbare Spuren ${ }^{76}$. Viele galten deshalb als unbrauchbar, sodass sich die ganze Last auf die Geraden und Gesunden konzentrierte.

legen und verkaufen sowie weitere 100 an die Stuttgarter Militärakademie liefern musste (HStA Stuttgart A 563 Bü 88).

75 Der Jägermeister Hans Heinrich von Gölniz hatte 1662 die Unsitte beanstandet, auch Kinder, so allein zur schuel angehalten werden solten und alte Leute, so nit gefolgen khinden, als Treiber zu verwenden (HStA Stuttgart A 59 Bü 50). Nachdem der Größere Ausschuss des Landtags ebenfalls forderte, künftig nicht mehr zu alte und abgekommene und allzu junge, ungeschickbte und untüchtige Leute zuzulassen, führte Herzog Eberhard III. 1664 eine entsprechende Altersbegrenzung ein (Reyscher [wie Anm. 12] Bd. 16,1. S. 466). Dennoch wurden bis ins 19. Jahrhundert Buben, die kaum in den Wald laufen können, zu Jagddiensten missbraucht.

76 Verbreitete Gebrechen waren Brüche, Geschwüre, Geschwulste, Kröpfe, Höcker und andere Missbildungen, böse (kurze, offene, geschwollene) Füße, Verwachsungen, Läh- 
Als nach dem Dreißigjährigen Krieg weitläufige Jagden mit starker Treiberwehr üblich wurden, fasste man die Fronpflichtigen einer Gemeinde zur Jagensmannschaft zusammen, die gewöhnlich nur zur Hälfte zum Einsatz kam, um die Ortschaften nicht leer stellen und Frauen, Kindern, Gebrechlichen und Greisen überlassen zu müssen. Schon wegen der permanenten Feuersgefahr hielt man es für unvertretbar, Dörfer und Städte gänzlich zu evacuiren. Da es keine Polizei gab, war diese Vorkehrung aber auch geboten, weil fahrendes Volk - Zigeuner, Landstreicher und in Kriegszeiten durchziehende Soldaten - die Gegend unsicher machte. Die Fronmannschaft wurde deshalb in Rotten eingeteilt, um bei mehrtägiger Abwesenheit eine Ablösung zu ermöglichen. Schon seit dem frühen 17. Jahrhundert waren den Treibern Obleute zugeordnet, die sie zum Geschäfft antreiben und beginnende Widersetzlichkeiten verhindern sollten. Diese Aufgabe wies man Respektspersonen $\mathrm{zu}$, in erster Linie Schultheißen, Bürgermeistern sowie Gerichts- und Ratsmitgliedern, die ihre Pflichten allerdings - wenn überhaupt - mehr schlecht als recht erfüllten.

Wenn eine Jagd bevorstand, wurde das Aufgebot meist mündlich, seit dem 18. Jahrhundert häufig auch schriftlich den Germeindeverwaltungen übermittelt, die daraufhin die Betroffenen auflisteten und verständigten. Mit dem „Gestellungsbefehl“ teilte die Forstbehörde mit, wann und wo sie sich einfinden und auf welche Zeit sie sich mit Brod versehen mussten, wobei selten eine Strafandrohung für diejenigen fehlte, die ausblieben, wenn sie sich nicht mit triftigen Gründen entschuldigen konnten ${ }^{77}$. Die Anwesenheit wurde von den Forstbeamten anhand eines

mungen, Gelenkversteifungen, Buckligkeit, Engbrüstigkeit, Kurzatmigkeit, Schwindsucht, Blutspeien, Auszehrung, Körperschwäche, Schwerhörigkeit und Blödsichtigkeit. Auffällig sind die zahlreichen nicht oder schlecht ausgeheilten Unfallfolgen. Die Ausschlusskriterien der Jagddienstfähigkeit wurden 1812 von der Sektion des Medizinalwesens festgelegt (HStA Stuttgart A 22 Bü 56 und 57. - A 573 Bü 6689. - StA Ludwigsburg D 73 Bü 242. - F 109 Bü 25).

77 Beispiele für „Gestellungsbefehle?: Reisiger Förster Johann Wilhelm Bender von Kleinaspach am 1. November 1777 an die Gemeinden Pfaffenhofen, Güglingen und Frauenzimmern (Stromberger Forst): Nachdeme Sr. Hzgl. Durchlaucht Gnädigst zu befeblen geruhet, daß zu dem auf nächsten Montag den 3. hujus an St. Hubertus-Fest abhaltenden Kessel-Jagen aus diesseitigem Oberforst die halbe Jagens-Mannschaft jedes Orths erfordert und sich biß Abends um 4 Ubr nebst einem Obmann bey Herrschafts-Straaf in Asperg ohnfehlbar einfinden solle, damit die Leute noch selbigen Abends können abgeleßen werden, widrigenfalls aber die Ausbleibende um $2 \mathrm{fl}$. und die ohne Hasen-Klepper erscheinen um $1 \mathrm{fl}$. sollen gestrafft werden und sollen sich die Leute biß Montag Abends mit Brod und Hasen-Klepper versehen, wo sie alsdann wiederum nach Hauß gelassen werden (HStA Stuttgart L 6 Bü 939). - Oberforstmeister Joachim Christoph von Moltke am 30. Dezember 1780 an den Reisigen Förster Johann Jacob Teichmann in Rietenau (Reichenberger Forst): Lieber Förster! Er hat die Bestellung zu machen, daß morgende Dienstag früh um 5 Uhrvon der Rietenauer Jagensmannschaft zehen Männer, ohne alles Feblen und bey Herrschafts-Strafe allhier erscheinen, und sodann deß weiteren gewärttig sein sollen. Ibre Dienste dauren nur 1/2 Tag, in welchem sie wieder nach Hauß kommen werden (HStA Stuttgart A 227 Bü 2062). - Bürgermeister Georg Plag von Knittlingen (Stromberger Forst) am 7. Januar 1799 an seine namentlich auf- 
Rottzettels, der die Namen der Fronpflichtigen enthielt, nicht nur vor Beginn, sondern auch nach Beendigung der Jagd kontrolliert, da sich sonst viele vorzeitig abgesetzt hätten. Insbesondere die Großjagden erforderten einen hohen logistischen Aufwand, der entsprechend dem damaligen „Stand der Technik“ mit einfachsten Mitteln bestritten werden musste. Dass auf diese Weise Pannen und Fehlschläge unvermeidlich waren, versteht sich von selbst. Noch problematischer wirkte sich in dieser Beziehung die Disziplinlosigkeit frustrierter oder erschöpfter Zwangsverpflichteter aus, die den Anweisungen des Forstpersonals nicht nachkamen. Die sich daraus ergebenden Konflikte hatten für die Jagensmannschaften fatale Folgen.

\section{Forstleute}

Für die Forstverwaltung stand bis zu den Fundamentalreformen des frühen 19. Jahrhunderts nicht die produktive Waldwirtschaft, sondern die Verwertung herrschaftlicher Forst- und Jagdrechte im Vordergrund. Auf der Grundlage dieser Orientierung vertraten die Forstleute konsequent die Interessen ihres Dienstherrn. Verständnis für die Bevölkerung - zumindest wenn es um die Jagd ging - gab es kaum $^{78}$. Seit der 2. Hälfte des 17. Jahrhunderts wurden durchweg „ausländische“ Adlige zu Forstmeistern bestellt, deren Amtsführung nach Gutsherrenart unter anderem darin bestand, mit Überredung, Einschüchterung und Bestrafung zu einem immer weiter ausgedebnten Besitzstand der Forstfrobnen zu gelangen. Die Selbstherrlichkeit dieser übermächtigen Classe von Staatsdienern war so groß, dass ihren Vertretern mitunter jedes Rechtsbewusstsein abging ${ }^{79}$. Im 18. Jahrhundert,

geführten Mitbürger: Biß Dienstag den 8. Januar haben bey dem Enßberger Jagen zu erscheinen bey $1 \mathrm{fl}$. Ungehorsams Straff Morgens $7 \mathrm{Ubr}$ zu Millacker (Mühlacker) mit HasenKlepper und Stöcken zu versehen und wird auch kein geringer Bub angenommen (HStA Stuttgart A 227 Bü 2742).

${ }^{78}$ Die Tatsache, dass sich die Jagdfröner bei ihrer unentgeltlichen Tätigkeit auf eigene Kosten verpflegen mussten, wurde 1769 vom Heidenheimer Oberforstmeister Karl August von Schilling mit der Bemerkung kommentiert: Als ob die Leute zu Hauß nicht auch Eßen und Trincken müßten (HStA Stuttgart A 202 Bü 618).

79 Auf dem Landtag 1797 stellten die Landstände dazu fest: Der hohe Forstbediente ist gewohnt, schon den geringsten Widerspruch, selbst die Untersuchung der Frage: ob man auch zu Leistung seiner Forderung rechtlicher Weise verbunden sey, als eine Art Ungehorsam, und selbsten bisweilen als Rebellion anzusehen ... Es läßt sich selbst annehmen, daß er bey allem nicht einmal dolose zu Werke gehet, weil ihn seine juristische Unkenntniß von der Abndung seines Gewissens dispensirt (Neues Forstarchiv. 1799. S. 86). Selbst die Herzogliche Regierung stellte ihnen 1785 kein gutes Zeugnis aus: Übrigens da es hauptsächlich darauf ankommt, wie ein Oberforstmeister die Unterthanen behandelt und mit Liebe und Vorstellungen zu gewinnen sucht, so kann bey guter Art ein solcher Oberforstmeister vieles aus freyem Willen zu wegen bringen, das bey andern zu vielen Klagen Anlaß geben würde. Ein solcher Mann aber muß von allen Nebenabsichten frey sein. Ein ziemlich seltener Fund (HStA Stuttgart A 202 Bü 572). Die Handlungsmaxime eines Oberforstmeisters wurde 1752 
als viele Forstamtschefs gleichzeitig Hofchargen ausübten, waren sie in ihrer Servilität zu einem skrupellosen Vollzugsorgan der Jagdherrschaft geworden.

Im Grunde verhielt es sich mit dem unteren Forst- und Jagdpersonal nicht anders, obwohl es dem bäuerlichen und kleinbürgerlichen Milieu entstammte ${ }^{80}$. Allerdings waren die Forstknechte, Förster und Jäger für den reibungslosen Ablauf der Jagden verantwortlich und mussten sich mit Hilfskräften abgeben, die ihnen immer wieder das Leben schwer machten. Schon 1608 hatte Herzog Friedrich aus eigener Erfahrung bemängelt, wie fahrlässig und saumbaft sie ihre Aufgabe erfüllten. Auch Herzog Johann Friedrich monierte 1626 den Ungehorsam und Herzog Eberhard III. 1656 den Mutwillen und Unfleiß der Fronleute, wie er mit ungnädigem Mißfallen selbst wahrnehmen konnte. Vor allem ließ ihre Präsenz trotz angekündigter Geldbußen, die oft nur mit großen Schwierigkeiten und manchmal überhaupt nicht eingetrieben werden konnten, sehr zu wünschen übrig ${ }^{81}$. Außerdem kamen viele zu spät und verzögerten mit ihrem verzettelten Eintreffen den Beginn der Jagd. Konsequenz: Was man an einem Jagen verrichten könnte, muß man hernach in 2, 3 oder mehr Jagen unnüzlich vornebmen. Schädliche Folgen hatte ferner der unachtsame Umgang mit den Jagdgerätschaften. Was das unter Erfolgsdruck stehende Aufsichtspersonal aber fast zur Verzweiflung brachte, war das ungeordnete Vorrücken der Treiberkette, weil in diesem Fall das Wild zurückwechselte und entkommen konnte ${ }^{82}$. Verhängnisvoll wirkte sich in dieser Hinsicht auch das Zusammenstehen, Schwätzen und Schreien sowie die mangelhafte Betreuung der Hunde aus, die sich einander anschnaubten und in ein Gebiß verwickelten, wenn man sie sich selbst überließ.

Die Reaktion der gestressten Forstbeamten auf dieses Fehlverhalten bestand im groben tractament aller Jagdfröner, die sich in ihren Augen der Nachlässigkeit oder Aufsässigkeit schuldig machten. Bereits 1555 sah sich Herzog Christoph gezwungen, in einem Hochfürstlichen Befehl gegen das Schelten und Schlagen einzuschreiten $^{83}$. Besonders schlimm scheint es nach dem Dreißigjährigen Krieg zugegangen

mit den Worten charakterisiert: sic volo, sic iubeo. So will ich es und so befehle ich es (HStA Stuttgart A 227 Bü 1683).

80 Die herrschende Geisteshaltung kommt in dem Sprichwort zum Ausdruck, mit dem 1790 der Reisige Förster Georg Adam Schoch aus Cleebronn (Stromberger Forst) eine rechtswidrige Strafandrohung rechtfertigte: Wenn der Baner nicht muß, regt er weder Hand noch Fuß (HStA Stuttgart A 227 Bü 2712).

${ }^{81}$ Zuweilen erschien nur die Hälfte der einbestellten Mannschaft. Nach einer Äußerung des Oberrats von 1684 waren die Strafgelder von den mebrertheils verarmten Leuthen schwerlich heraußzubringen (HStA Stuttgart A 227 Bü 2575).

82 Die Obleute hatten beim Vorrücken voranzugehen und dafür zu sorgen, dass ihnen die Treiber in gerader Linie folgten und keiner zurückblieb. Wie rigoros darauf geachtet wurde, belegt die Aussage eines 30-jährigen Herrenberger Bürgers, der sich 1769 vom Jagddienst befreien lassen wollte, weil er wegen seines dicken Halßes und daber rübrenden kurzen Athems nicht fortkommen konnte und deshalb schon öfters onschuldig gestossen und geschlagen worden war (HStA Stuttgart A 565 Bü 57).

${ }^{83}$ HStA Stuttgart A 227 Bü 671. 
zu sein, der eine unglaubliche Verrohung zur Folge gehabt haben muss. Nicht nur Fluch- und Schimpfworte, sondern auch üble Stöße und Straiche waren offenbar an der Tagesordnung. Alles müsse nach Kopff und Willen der Weidleute geschehen, hieß es 1679 in den ständischen Forst- und Jagdbeschwerden, wobei die armen, ermühten Untertanen geprügelt würden, als ob sie nicht auch Menschen wären ${ }^{84}$. Sie machten sich auch kein Gewissen daraus, ihre Helfer stundenlang warten zu lassen, während sie selbst im Wirtshaus saßen ${ }^{85}$. Dass es nicht immer beim Schänden und Schmähen der Treiber blieb, sondern gelegentlich sogar auf sie geschossen wurde, ist verbürgt ${ }^{86}$. Im 18. Jahrhundert dürfte es zwar etwas besser geworden sein, doch gab die schikanöse Behandlung und eine von aller Barmberzigkeit entfernte Strenge weiterhin Anlass zur Beanstandung. Machtmissbrauch und Gewaltanwendung als Disziplinierungsmittel waren selbst im frühen 19. Jahrhundert noch durchaus üblich ${ }^{87}$. Es dauerte lange, bis sich im hierarchischen Gefüge des Staatsapparats humane Umgangsformen auf allen Ebenen durchgesetzt hatten.

${ }^{84}$ HStA Stuttgart L 6 Bü 936. In seiner Stellungnahme konnte der Jägermeister Georg Christoph von Schönfeldt diese Vorwürfe nicht ernsthaft bestreiten. Welches Ausmaß die Misshandlungen annahmen, macht eine Notiz von 1698 deutlich, wonach die Besigheimer Jagdfröner von ihrem Forstknecht mit Schläg dermaßen tractiret wurden, dass sich niemand mehr brauchen lassen wolle (HStA Stuttgart A 557 Bü 261).

${ }^{85}$ Die Zustände illustriert ein Vorfall, der sich im September 1668 abspielte. In Urach wurden abends 30 Mann auf den nächsten Morgen um 5 Uhr bestellt, um die herrschaftlichen Jagdhunde in die Nachbarstadt Neuffen zu führen. Sie waren pünktlich zur Stelle, mussten aber bis $8 \mathrm{Uhr}$ auf die Jäger warten, die sich in einer Gastwirtschaft berauschten und unterwegs wild um sich schossen. In Neuffen unterblieb die versprochene Ablösung, weshalb man die Uracher zum Weitertransport der rabiat gewordenen Meute in die nächste Amtsstadt mit der Bemerkung aufforderte, der Tag sei noch lang und der Rücken werde ihnen nicht abbrechen. Weil die Hundeführer sich weigerten, wurden die Jäger handgreiflich, wobei ein Junge durch Stöße und einen Schuss lebensgefährliche Verletzungen davontrug (HStA Stuttgart A 21 Bü 589).

${ }^{86}$ HStA Stuttgart L6 Bü 936. Prälaten und Landschaft beschwerten sich 1651 darüber, dass die Forstleute mit Schlägen und Gewalttaten gegen die Untertanen vorgingen und der Jägermeister nach ihnen schieße, sie dabei tödlich verletze und für die Beschädigten nicht einmal ein gutes Wort übrig habe. Speziell erwähnt wird ein Fall aus Neckarhausen im Nürtinger Amt. Herzog Eberhard III. bestätigte dieses Verhalten mit dem Hinweis, die Treiber würden etwann mit schießen sehr schnöd und übel tractirt (Reyscher [wie Anm. 12] Bd. 16,1. S.390).

${ }^{87}$ Bei einer großen Zeugjagd im Schönbuch war 1812 ein elternloser junger Taglöhner eine Klinge heruntergerutscht und erschöpft sitzen geblieben, während sich die Treiber weiter vorwärts bewegten. Der Obmann verließ daraufhin seinen Posten, um ihm zu helfen. Der aufsichtsführende Unterförster stellte ihn deshalb fluchend zur Rede und schlug ihm mit einem Stecken ins Gesicht, bis er zerbrach. Die Frage, ob dies der Allerhöchste Wille seines allergnädigsten Königs seye, trene und willige Unterthanen so zu behandeln, wurde mit weiteren Flüchen und Schlägen beantwortet. Die eingereichte Klagschrift wies König Friedrich mit der Begründung zurück, dass der Forstbeamte mehr durch Diensteifer als durch Brutalität und Hitze verleitet worden sei (HStA Stuttgart E 6 Bü 143). 


\section{Personalfreiheit}

Es waren nicht nur Kommunen, die sich immer wieder um exemtion von den lästigen Jagdfronen bemühten. Auch zahlreiche Bürger nutzten jede Chance, sich als Person dieser Verpflichtung zu entledigen. Alle wollen befreit sein, stöhnte 1710 das Oberforstamt Stromberg über diese Antragsflut, die verständlich ist, wenn man die Probleme kennt, die sich für die arbeitende Bevölkerung aus dem Jagddienst ergaben ${ }^{88}$.

Sie existierten allerdings nicht für das Besitz- und Bildungsbürgertum, denn niemand wäre auf den Gedanken gekommen, der Oberschicht Fronarbeiten zuzumuten. Auch die Beamtenschaft in Staat und Kirche blieb a priori außen vor. Da es keine positive Definition der Dienstpflicht gab und stets nur Ausnahmetatbestände geregelt wurden, bedurfte es nicht einmal einer ausdrücklichen Klarstellung, um diese Selbstverständlichkeit zu sanktionieren. Lange Zeit glaubte man, auf Formalitäten überhaupt verzichten zu können, denn die Personalfreiheit war bis ins 18 . Jahrhundert gewohnheitsrechtlich begründet. Erst 1753 entschloss man sich, die Vergünstigungen zu reglementieren, um die evidente Ungleichbeit zu beseitigen, die auf diese Weise entstanden war. Allerdings konnte die angestrebte Gleichförmigkeit nur unzureichend realisiert werden. Dafür sorgte schon der unausrottbare Verwaltungsschlendrian. Außerdem wurden weiterhin Einzelfallentscheidungen getroffen, deren Ergebnis häufig mit dem Praedicat des Antragstellers oder der Beförderung des herrschaftlichen Nutzens in Zusammenhang stand. Hinzu kam die offenkundige Parteilichkeit der örtlichen Forst- und Verwaltungsbeamten ${ }^{89}$. Selbstverständlich ließen es sich im Zeichen des Absolutismus auch Landesherren und Obrigkeit nicht nehmen, in dieser Hinsicht nach Belieben zu verfahren ${ }^{90}$. Unter Herzog Karl Eugen war es in manchen Forstbezirken sogar möglich, die Frei-

${ }^{88}$ Nachdem der Altensteiger Forstmeister 1662 das Befreiungsgesuch eines jungen Baders abgelehnt hatte, beklagte sich dieser arme Tropf mit weinenden Augen, dass ihm durch den häufigen Jagddienst die Existenzgrundlage entzogen werde, weil er weder die Badstube versehen noch seine Patienten versorgen könne (HStA Stuttgart A 227 Bü 269).

89 Vom Forstpersonal wurden mitunter eigenmächtige Befreiungen gegen Geschenke und private Dienstleistungen erteilt. Auch von Begünstigung aufgrund persönlicher Beziehungen und Benachteiligung auf Veranlassung übel gesinnter Bürger ist die Rede (HStA Stuttgart A 227 Bü 100).

90 Ein Barbier konnte sich 1695 seine Befreiung bei einer Begegnung mit Herzog Eberhard Ludwig im Heidenheimer Schloss auswirken, obwohl seine Kollegen dienstpflichtig waren (HStA Stuttgart A 227 Bü 839). Die Lieferanten der Ameiseneier für die herzoglichen Fasanerien erhielten 1747 die begehrte Jagensimmunität (HStA Stuttgart A 557 Bü 295). Herzog Karl Eugen dispensierte 1780 durch Spezial-Resolution einen Orgelzieher mit der Begründung, ein Vertreter würde die Blasbälge ruinieren (HStA Stuttgart A 227 Bü 2653). Die Fellbacher Kirchenmusiker wurden 1776 freigesprochen, weil beim Gemeindegesang die Andacht störende Abfälle und Unordnungen entstünden, wenn sie fehlten (HStA Stuttgart A 227 Bü 2425). Aus ähnlichen Erwägungen (Aufmunterung der Geistlichen Gemüter) hatte Herzog Eberhard Ludwig 1717 die Wildberger Kirchenmusici und 1724 die Herrenberger Stadtmusici privilegiert (HStA Stuttgart A 248 Bü 1771 bzw. A 565 Bü 59). 
stellung von der Jagdfronpflicht mit der Lieferung des Jagdhabers oder der Bezahlung eines Jagdtalers zu erkaufen, obwohl die Ablösung der Naturalfronen durch Geld- oder Sachleistungen grundsätzlich abgelehnt wurde ${ }^{91}$.

Mit jeder Befreiung war unausweichlich eine Zusatzbelastung der übrigen Jagdfröner verbunden. Dennoch gelang es zahlreichen Berufsgruppen, generell dispensiert zu werden. Privilegiert war jeder, der irgendein $\ddot{A} m$ tlein - und sei es auch noch so gering - bekleidete: Schulmeister, Heiligen- und Armenkastenpfleger, Organisten, Zinkenisten, Mesner, Apotheker, Chirurgen, Zoller, Acciser und andere Geldeintreiber, Stadt- und Amtsknechte, Wachtmeister, Torwarte, Küfer, Kastenknechte, Stadtboten, Eicher, Krankenwärter, Leichsäger (Personen, die Begräbnisse ansagten), Bettelvögte, Totengräber, Schultheissen, Gerichtsschreiber, Unterpfleger, Wald- und Feldschützen, Schäfer, Hirten, Nachtwächter, Büttel, Feuerschauer und auch Hebammenmänner, weil ihre Frauen zur Geburtshilfe häufig abwesend waren ${ }^{92}$. Wer eine Wöchnerin (Webmutter, Kindbetterin) zu Hause hatte, wurde für diese Zeit ebenfalls freigesprochen. Hinzu kamen Bürger, denen aufgrund von Spezialvorschriften die Fronfreiheit zugebilligt werden konnte, z. B. Kaminfeger, Badmeister, Salpetersieder, Brunnenmeister sowie alle Metzger, die Pferde hielten und das herrschaftliche Postwesen besorgten ${ }^{93}$. Eine Sonderstellung nahmen Bauern ein, die den Vorspann für die Wagenfuhren stellten und dafür in der Regel keine Handfronen zu leisten brauchten.

Der Anteil der aus beruflichen oder gesundheitlichen Gründen befreiten Bürger betrug im Landesdurchschnitt etwa ein Drittel, konnte sich aber in manchen Gemeinden auch bis zur Hälfte der Fronpflichtigen oder noch mehr aufsummieren. Berücksichtigt man das gehobene Bürgertum, die fronfreien Städte und Ortschaften sowie die gekauften Stellvertreter, ist unschwer erkennbar, dass nur ein Bruch-

${ }^{91}$ Vom Sonderfall der Wolfsjagden abgesehen, konnten Fronleistungen nicht durch Geld ersetzt werden. Ein Ablösungsversuch war 1663 an der fehlenden Bereitschaft der meisten Städte und Ämter gescheitert, die zur Finanzierung bezahlter Hilfskräfte erforderliche Summe aufzubringen (HStA Stuttgart A 59 Bü 50). Außer den kleinen Ortschaften Garrweiler und Gaugenwald (Altensteiger Forst), die sich 1669 beim Erwerb durch Württemberg freikaufen konnten (HStA Stuttgart H 107/1 Bd. 4), gelang es lediglich einigen armen Waldensersiedlungen, Fronfreiheit gegen Bezahlung zu erreichen. So mussten in Nordhausen und Schönenberg (Stromberger Forst) die dienstfähigen Männer jährlich einen Symbolbetrag entrichten, da sie sich in der herbstlichen Hauptjagdzeit zum Hanf- und Flachshecheln im Rheintal und in der Pfalz aufhielten (HStA Stuttgart A 248 Bü 429. - A 563 Bü 98).

${ }_{92}$ Generalreskript vom 12. November 1753 (Reyscher [wie Anm. 12] Bd. 16,1. S. 661). Die Personalfreiheit wurde in der Regel mit der Notwendigkeit der ständigen Anwesenheit dieses Personenkreises begründet. Für zahlreiche kommunale Dienstposten war sie jedoch auch ein Äquivalent für die schlechte Besoldung.

${ }_{93}$ Die Metzger waren hinsichtlich der Jagdfronen von ubralten Zeiten her in quieta possessione, weil sie bei Hofjagden die Postritte zu übernehmen hatten (HStA Stuttgart A 227 Bü 2590). Eine formelle Regelung der Fronfreiheit mit landesweiter Geltung erfolgte allerdings erst 1753. Die jagdliche Metzgerpost musste unentgeltlich besorgt werden, während sie in sonstigen Herrschaftsangelegenheiten vergütet wurde (HStA Stuttgart A 563 Bü 92). 
teil der Bevölkerung die Jagddienste tatsächlich verrichtete und die völlige Last dem gemeinen Mann über den Halß gezogen wurde ${ }^{94}$. Ergebnis der Selektion: es war die ärmste Volksklasse, an der sie hängen blieb.

\section{Lasten und Leiden}

Als Angehörige der Unterschicht waren die Jagdfröner nicht in der Lage, ihre Sorgen und Nöte zu dokumentieren. Individuelle Selbstzeugnisse, die Aufschluss über ihre Lasten und Leiden geben, existieren daher nicht. Sehr wohl konnten sie aber ihre Kümmernisse kommunalen und ständischen Vertretern vortragen, denen sie oft genug in den Ohren lagen. Was wir über dieses düstere Kapitel wissen, entstammt deshalb den ungezählten Bittschriften, die unter der Bezeichnung Supplication, Memoriale, Exbibitum oder Gravamen auf den Schreibtischen der Regenten oder ihrer Regierungsbeamten landeten. Sie wurden in kräftigen Farben gemalt und vermitteln gerade deshalb ein ungeschminktes Bild der Realität. Allerdings gab es enorme Belastungsunterschiede, weil die Intensität der Jagdausübung sowohl regional als auch zeitlich erheblichen Schwankungen unterworfen war. So blieb eine wildarme oder entlegene Gegend viele Jahre weitgehend ungeschoren, während man eine andere konzentriert bejagte. Vor allem der mittlere Neckarraum mit seinen wildreichen und residenznahen Waldgebieten war stark beansprucht. Es ist kein Wunder, dass hier die meisten Klagen über exzessive Jagdfronen und obnerträgliche Jagddienste laut wurden.

Das Grundproblem bestand zweifellos in der Armut vieler Jagdfröner, für die es eindeutige Belege gibt ${ }^{95}$. Die Not war manchmal so groß, dass es im Haus nichts mehr zu beißen und zu brechen gab $^{96}$. Einigen aus dem Bodensatz der Feudalgesell-

${ }^{94}$ Nach einer von Herzog Karl Eugen 1769 veranlassten Erhebung waren (bei ca. 450.000 Einwohnern im Jahr 1750) in den 14 Forsten des Landes 40.269 Mann, 10.747 Pferde, 12.919 Paar Ochsen und 2.094 Stiere jagdfronpflichtig (HStA Stuttgart A 8 Bü 41).

95 Einen konkreten Einblick in die Lebenswelt der Unterschicht vermittelt ein Bericht der Gemeinde Gönningen (Tübinger Forst) aus dem Jahr 1716, in dem die wirtschaftliche Lage 62 mittelloser Bürger in knapper Form charakterisiert wird, um ihre Befreiung vom Wolfsjagdgeld zu erreichen. Von diesen Zengen der Armseligkeit waren viele hoch verschuldet, sieben mit der amtlichen Bettelerlaubnis (Sammelpatent) ausgestattet und weitere drei beauftragten damit ihre Kinder. Der größte Teil der Einwohner war bettelarm, invalid oder alt (HStA Stuttgart A 249 Bü 3647). Auch sonst enthalten die Jagdfronakten über Jahrhunderte hinweg eine Fülle armutsrelevanter Hinweise. Vom Amtsstädtchen Wildberg (Nagolder Forst) heißt es 1557, der größte Teil der Bürger benötige Unterstützung aus dem Armenkasten, wenn sie mehr als zwei Tage krank seien (HStA Stuttgart A 227 Bü 231). Von den Weingärtnern in Hohenhaslach (Stromberger Forst) wird 1790 gesagt, es fiele ihnen schon in guten Jahrgängen schwer, ihre Brotschulden zu bezahlen und sich bis zum nächsten Herbst durchzuhelfen, hätten aber in schlechten Weinjahren nur Kummer und Hunger zu erwarten (HStA Stuttgart L 6 Bü 936).

${ }^{96}$ Als im Sommer 1680 die Gemeinde Holzgerlingen (Böblinger Forst) von dem er- 
schaft blieb nichts anderes übrig, als zu betteln oder die Kinder nach dem Almosen zu schicken, um überleben zu können. Umso härter war es für sie, bei den Jagden aus dem aignen Seckel zehren zu müssen. Die Ärmsten konnten sich bei längerer Abwesenheit nicht einmal mit dem benöthigten trockenen Brot versehen. Andere nahmen den letzten Laib oder den letzten Kreuzer mit in die Wälder und ließen ihre Familien unversorgt zurück. Manchen gingen Geld und Nahrungsmittel vorzeitig aus, sodass sie gezwungen waren, ehrliche (ehrbare) Leute um ein Stückblen Brot anzusprechen. Wer sich vom Treiben entfernte, um etwas Essbares aufzutreiben, musste mit Bestrafung rechnen. Dabei wusste die Jagdherrschaft genau, wie wichtig die Verpflegung für die Funktionsfähigkeit des Fronwesens war. Es ist daher unverständlich, dass im 17. Jahrhundert die wenigen Ergötzlicbkeiten restlos gestrichen wurden.

Bitter geklagt wurde immer wieder über die weiten Wege zum Einsatzort, die bei Großjagden einen mehrstündigen oder sogar ganztägigen Anmarsch erforderten, sodass die Jagensmannschaft gänzlich abgemattet ankam und entkräftet war, bevor die Arbeit begann ${ }^{97}$. Das konnte vor allem dann der Fall sein, wenn in Nachbarforsten gejagt wurde und dort nicht genügend Fronpflichtige zur Verfügung standen. Die Forstlagerbücher sahen zwar nicht ausdrücklich eine Beschränkung der Jagddienstbarkeit auf den Heimatforst vor, doch galt sie als hergebrachtes Observanzrecht, gegen das die Jagdherrschaft je länger desto mehr verstieß. Benachteiligt waren in dieser Hinsicht vor allem Ortschaften, die an der Landes- oder Forstbezirksgrenze lagen, wobei letztere mit zweyen Ruthen geschlagen wurden, wenn sie sich Anforderungen von beiden Seiten ausgesetzt sahen. Hinzu kam, dass sich mit zunehmender Distanz vom Wohnort auch die Einsatzdauer verlängerte und bei mehrtägigen Jagden elendiglich in der Fremde übernachtet werden musste - entweder in den Wäldern oder auf eigene Kosten in Behelfsquartieren ${ }^{98}$. Häufig wurde

zürnten Gott im Himmel mit mehreren Hagelschlägen heimgesucht wurde und die meisten Bürger sich des Bettels kaum erwehren konnten, mussten sie den Jagddienst mit hungerigem Bauch absolvieren (HStA Stuttgart A 227 Bü 530).

97 Wenn die Jagensmannschaft des isoliert gelegenen Ämtleins Heubach (Heidenheimer Forst) bis an die entfernteste Grenze des Forstbezirks kommandiert wurde, hatte sie acht bis neun Stunden zu gehen und benötigte für den An- und Rückmarsch volle zwei Tage. Obwohl die Entlegenheit für die Fronpflichtigen mit großem Aufwand verbunden war, gab der zuständige Oberforstmeister Johann Wilhelm von Schilling 1761 seiner Verwunderung über eine Beschwerde der Heubacher Ausdruck und behauptete, sie würden Strapazen vorschützen, die andere Ortschaften keineswegs davon abhielten, sich zum Jagen zu bequemen (HStA Stuttgart A 227 Bü 832 und A 555 Bü 145).

98 Aus der 2. Hälfte des 17. Jahrhunderts wird berichtet, dass sich die Untertanen im Winter fünf oder sechs Tage und Nächte ständig in den Wäldern aufhalten und in Ermanglung warmer Kleider aneinand bleiben und elendiglich erfrieren mussten (HStA Stuttgart L 6 Bü 936). Das nächtelange Herumliegen in grossem Schnee und schröckblichem Regen ging selbst Herzog Eberhard III. zu weit, der 1670 eine Regelung erließ, wonach höchstens eine Nacht im Freien verbracht werden durfte, die aber wenig Beachtung fand und bald wieder vergessen war. Den Leuten blieb in diesen Fällen nichts anderes übrig, als sich mit Lagerfeuern durch- 
die Mannschaft schon am Vorabend einbestellt, um den rechtzeitigen Jagdbeginn am nächsten Morgen zu garantieren. Außerdem erwies sich die Ablösung bei großer Entfernung als äußerst störungsanfällig, wodurch oft lange Wartezeiten entstanden, die bei ungünstiger Witterung auch sonst unzumutbar waren ${ }^{99}$. Auch sonst machten Dauerregen, Frost und Schnee den Jagdfrönern schwer zu schaffen, da viele übel gekleidet und mit schlechtem Schuhwerk zum Dienst erschienen, weshalb viele krank oder mit Erfrierungen an den Gliedmaßen heimkehrten ${ }^{100}$. Zu gefährlichen Situationen kam es, wenn Hirsche und Keiler - von Hunden gehetzt - die Treiberwehr annahmen und dabei böse Verletzungen verursachten, für deren Folgen niemand einzustehen hatte.

Bei harmlosen Kleinjagden waren solche Vorfälle nicht zu befürchten. Dennoch konnten auch sie ein Ärgernis sein, denn sie wurden von den Forstbeamten öfters aus bloßem Plaisir angestellt oder verfolgten den Zweck, Hasen in die eigene Küche zu schießen. Eine demotivierende Wirkung ging schließlich von Veranstaltungen aus, die trotz großen Aufwands ergebnislos verliefen oder - aus welchen Gründen auch immer - abgesagt wurden, nachdem die Mannschaft bereits an Ort und Stelle eingetroffen war. Bleibt noch zu erwähnen, dass die Jagddienste einen empfindlichen Verlust an Arbeits- und Freizeit bedeuteten. Trotz wiederholter Verbote musste nicht selten mit Verabsäumung Göttlichen Worts auch an Sonn- und Feiertagen gefront werden. Andererseits fiel die Rot- und Schwarzwildbejagung in die

zubringen, wodurch am Holz merkblicher schaden entstand (Reyscher [wie Anm.12] Bd. 16,1 . S. 475,494$)$.

99 Am 9. Januar 1778 mussten 37 Jagdfröner von Sersheim (Stromberger Forst) von halb 9 Uhr bis 11 Uhr auf den Oberforstmeister August Ernst von Rieben warten, ohne dass er erschien. Als sie es vor Kälte nicht mehr aushielten und glaubten, die Hasenjagd sei abgeblasen, gingen sie nach Hause, wofür sie eine Strafverfügung kassierten (HStA Stuttgart A 563 Bü 88).

100 Wie es im Winter zuging, schildert ein Bericht über eine Luchsjagd, die am 9. Februar 1665 bei grausamer Källte im Deckenpfronner Wald (Böblinger Forst) stattfand. Das Hauptkontingent der Treiber stellten 100 arme, an Stubenarbeit gewöhnte und heillos gekleidete Knappen (Tuchmachergesellen) aus der $10 \mathrm{~km}$ entfernten Amtsstadt Calw, die zwischen 7 und 8 Uhr am Einsatzort eintrafen. Dort mussten sie bis 10 Uhr warten, bis das Treiben begann. Nachdem sie einige Stunden lang erfolglos hin und her, bergab und berguf durch den büschigen, dornigen und ganz mit Schnee überwachßenen Wald geführt worden waren, wurde endlich um 13 Uhr der Luchs festgemacht, der jedoch wieder ausriss. Erst um 15 Uhr konnte er mit Jagdzeug umstellt werden, doch waren die Calwer inzwischen so matt, erkhalltet und erstarret, dass sie sich weigerten, noch einmal von vorne anzufangen. Es kam zu Auseinandersetzungen, in deren Verlauf der Meisterjäger Joachim Hornung mit gezücktem Hirschfänger auf die Handwerker losging, die das Treiben nicht ohne Leibsgefabr fortsetzen zu können glaubten und verlauten ließen, wenn gleich Hundert Forstknecht da weren, wollten sie doch nicht mebr in den Wald hineingehen, man habe sie nunmebr lang genug umbgetrieben. Einer der beiden Obleute kommentierte den Vorgang mit den Worten, er habe geglaubt, man jage Tiere, doch tatsächlich jage man Menschen. Daraufhin traten die Knappen den Heimweg an. Sie kamen mit einem scharfen Verweis und der Kostenerstattung für eine Untersuchungskommission davon (HStA Stuttgart A 227 Bü 524). 
besten Schaffzeiten - Heuet, Ernte, Öhmd und Weinlese - und beeinträchtigte auf diese Weise die Landwirtschaft, deren Ertrag für die meisten von existenzieller Bedeutung war. Das schmerzte den Landmann, doch noch mehr hatten Handwerker und Tagelöhner unter Verdienstausfällen zu leiden, die viele kaum verkraften konnten, weil sie von der Hand in den Mund lebten ${ }^{101}$.

\section{Fuhrfronen}

Das jagdliche Fronsystem bestand aus einer Zwei-Klassen-Gesellschaft. Einerseits gab es Handfröner, die vom Verkauf ihrer Arbeitskraft lebten und sie auch beim Jagen einsetzen mussten, andererseits aber Fuhrfröner, die zur Bewirtschaftung ihres Grundbesitzes Zugvieh hielten, das sie für Jagdzeug- und Wildbretfuhren verwenden konnten. Schon im 16. Jahrhundert stritt man darüber, ob die Rosshalter verpflichtet seien, auch gewöhnliche Jagddienste zu verrichten, solange sie nicht als Fuhrleute gebraucht wurden. Formell blieb diese Frage lange Zeit unentschieden. Erst 1758 trat eine Verordnung in Kraft, nach der den Bauern Personalfreiheit zustand, wenn sie mit ihren Pferden und Ochsen Transportleistungen übernahmen ${ }^{102}$.

Allerdings hatte sich in der Praxis diese Regelung schon seit langem zwar nicht vollständig, aber doch weitgehend durchgesetzt. Dabei spielte der Umstand eine Rolle, dass es unzumutbar erschien, die Zugtiere im Stall stehen zu lassen, wenn der Eigentümer als Treiber am Hagen und Jagen teilnahm und sie deshalb in dieser Zeit nicht nutzen konnte. Die Freistellung löste freilich soziale Spannungen aus, weil die Fuhrfröner in den Augen der Handfröner, die überwiegend dem ländlichen Proletariat entstammten, als Vermögende und Reiche galten, die dem gemeinen Mann die ganze Last der eigentlichen Fronarbeit aufbürdeten. In der Tat wurden die Fahrdienste nicht so oft wie andere Dienstleistungen angefordert und erstreckten sich meistens auch nicht über mehrere Tage. Hinzu kam, dass körperliche Schwerarbeit im Fuhrgeschäft kaum eine Rolle spielte, weil anstrengende Fußmärsche entfielen und das mühsame Auf- und Abladen der Tücher und Netze, die bei nasser Witterung sehr schwer waren und zum Aufstellen im Wald herum-

101 Der Güglinger Vogt berichtet 1663, zahlreiche Bürger hätten kein Brot und könnten wegen 40 Tage währender Jagden nichts verdienen, sodass bereits einige in die Pfalz verzogen seien oder in den Nachbarorten ungescheut bettelten (HStA Stuttgart A 59 Bü 50). Aus dem Leonberger Forst bekam Herzog Karl Eugen 1749 von 10 Gemeinden zu hören, dass viele appetit verspürten, lieber nach Pensylvanien auszuwandern als noch länger unter den Bedrückungen zu schmachten und voll und totaliter ruinirt zu werden (HStA Stuttgart A 557 Bü 259).

102 Commun-Ordnung vom 1. Juni 1758 (Reyscher [wie Anm. 12] Bd. 16,1. S. 697). Nach den Gepflogenheiten der Feudalverwaltung war damit jedoch keineswegs die Einhaltung dieser Vorschrift gewährleistet. Es gab weiterhin Ortschaften, deren Bauern observanzmäßig neben Fuhrfronen auch Handfronen leisten mussten. 
geschleppt werden mussten, der Jagensmannschaft überlassen blieb. Zur Erhaltung des Dorffriedens trug diese Arbeitsteilung jedenfalls nicht bei.

Obwohl die Bauernschaft das bessere Los gezogen hatte, gab es aber auch für sie genügend Anlass zur Beschwerde. Dazu gehörte in erster Linie der Transport über weite Distanzen und die übermäßige Beanspruchung des Zugviehs, das manchmal so geschunden wurde, dass es nach der Heimkehr zum Feldbau fast undichtig (unbrauchbar) war. Ging es zugrunde, hatte der Besitzer den Verlust entschädigungslos zu tragen ${ }^{103}$. Herzog Karl Eugen kamen 1769 fast täglich Klagen zu Obren, dass beim Jagdvorspann die Unterthanen unnötig über die Zeit aufgehalten jezuweilen gar mißhandelt oder ibnen Pferdte zu schanden geritten werden ${ }^{104}$. Vor allem bei großen Jagden mussten nämlich die Bauern der Jagdherrschaft nicht nur ihren Zug für die Führung der Seil- und Zeugwagen, sondern auch gesattelte Reitpferde für unberittene Forst- und Jagdbedienstete zur Verfügung stellen. In Kriegszeiten, wenn die Bürgerschaft ohnehin mit Einquartierungen geplagt war, machte durchziehendes Militär die gleichen Ansprüche geltend. Zur Belastung konnten schließlich insbesondere im Einzugsbereich der Residenz die umfangreichen Wildbretlieferungen an die Hofküche und zahllose Deputatsberechtigte werden ${ }^{105}$.

\section{Wolfsjagden}

Es gibt kein wilderes Thier als ein Wolff. Mit dieser Charakterisierung lieferte 1679 der Jägermeister Georg Christoph von Schönfeldt das Erklärungsmuster für ein Feindbild, das bis in die jüngste Vergangenheit die Verfemung dieser Raubwildart motiviert hat ${ }^{106}$. Auch in Württemberg wurden die Wölfe schon im 16. Jahrhundert gnadenlos verfolgt. Die Gründe für den abgrundtiefen Hass, der die

${ }^{103}$ In schwierigem Gelände und auf grundlosen Wegen mussten bis zu neun Pferde vorgespannt werden (HStA Stuttgart A 227 Bü 112 I). Was dem Fronvieh zugemutet wurde, zeigt der Fall des Bauern Joseph Schwehr aus Eggingen (Ulmer Forst). Er hatte im Oktober 1814 den Auftrag erhalten, lebende Wildschweine von Bermaringen nach Urach zu transportieren und dafür zwei Pferde zur Verfügung zu stellen. Die vierspännigen Wagen wurden abends, nachdem die Pferde den ganzen Tag im Wald gestanden hatten, geladen und nachts acht Stunden lang ohne Rast und Fütterung an den Bestimmungsort gebracht. Die schweren Kästen, das Regenwetter und der bodenlose Weg über nasse Ackerfelder, auf denen die Pferde bis zur Brust einsanken, machten die Fronfuhr zu einer Tortur, an der eine 10-jährige Stute trotz tierärztlicher Behandlung einging. Der an König Friedrich gerichtete Schadensersatzantrag wurde mit der Begründung abgelehnt, das Faktum sei nicht zureichend erwiesen (StA Ludwigsburg E 245 I Bü 1134).

${ }^{104}$ HStA Stuttgart A 565 Bü 57.

105 Der Bedarf für den Hofbrauch war immens. In der Regel erfolgte der Transport von Ort zu Ort. Seit Errichtung der Militärakademie (später Hohe Karlsschule) in Stuttgart 1770/1775 konnten die Anforderungen aus der Residenz nur durch Einbeziehung der seither weitgehend verschonten Grenzforste befriedigt werden (HStA Stuttgart A 227 Bü 1552).

106 HStA Stuttgart L 6 Bü 936. 
gesamte Bevölkerung erfüllte, sind nicht nur in den Schäden zu sehen, die sie unter den Wild- und Nutztieren anrichteten, sondern auch in einer geradezu hysterischen Angst, sie gefährdeten die öffentliche Sicherheit. Wenn diese Bestien nicht vertrieben würden, so ließ sich 1639 Herzog Eberhard III. vernehmen, könne kein Mensch bei dem andern verbleiben, sicher wohnen oder Weg und Steg seiner Nahrung nach gebrauchen; selbst wer auf den Straßen der Gefahr entginge, werde ihnen anderswo in den Rachen lauffen ${ }^{107}$.

Die Bekämpfung der Wölfe galt daher quasi als ein Akt der Landesverteidigung, ein allgemein nuzliches Werk ${ }^{108}$. Wegen ihrer unsteten Lebensweise war dieses Vorhaben jedoch äußerst schwierig. Bleiben andurch kein Nacht wie die ander, stöhnte 1582 ein Meisterjäger, traben Tag und Nacht fort. Wenn man sie gespürt habe und mit dem Jagdzeug umstellen wolle, verlautete im 17. Jahrhundert, seien sie oft schon wieder außgerissen und durchgangen. Vor diesem Hintergrund waren diverse Strategien und Techniken entwickelt worden, um das Unziefer zu vertilgen: die Hetze mit Hunden (Wolfhatz), Abschuss am Luderplatz oder im Wolfsgarten, Ausnehmen junger Nestwölfe, Bügelfallen (Wolfseisen), Legbüchsen (Selbstgeschoß), Giftkugeln, Wolfsgruben und vor allem das Wolffen - großflächige Treibjagden, die allerdings nur mit Jagensmannschaften Erfolg versprachen, die möglichst 200 Fronpflichtige umfassen sollten, manchmal aber auch eine Größenordnung von 500-1000 Hilfskräften erreichten. Diesem enormen Aufwand ist es zuzuschreiben, dass die Ausrottung schon in der ersten Hälfte des 18. Jahrhunderts gelang.

Bevor es so weit war, bedurfte es jedoch eines gewaltigen Kraftakts, denn als Folge des Dreißigjährigen Kriegs hatten sich die Wölfe in ganz Deutschland explosionsartig vermehrt. Die Entvölkerung weiter Landstriche, die Verödung zahlreicher Ortschaften, die Verwilderung brachfallender Felder und die zeitweise Einstellung aller jagdlichen Aktivitäten schufen den Nährboden für eine unerhörte Wolfsplage ${ }^{109}$. Als der Landesherr aus dem Exil in seine Heimat zurückkehrte, gingen bei der Fürstlichen Kanzlei täglich Klagen, Supplicationen, Sollicitationen und Anmahnungen besorgter Landeskinder ein, die ihn um Abhilfe baten ${ }^{110}$. Fast von Tag zu Tag, so konnte man von ihm hören, ließen sich Wölfe sehen, manchmal in Haufen von 15 und mehr Stück, und diese Truppen liefen herum, um überall einzubrechen. Sie aus der Welt zu schaffen, war somit das Gebot der Stunde ${ }^{111}$. Die Leid-

107 Dekret vom 12. Oktober 1639 (HStA Stuttgart A 573 Bü 6681).

108 Nach einem Reskript Herzogs Eberhard III. vom 16. Februar 1664 sollte im Fürstentum kein Ort vom Wolfsjagen befreit sein (HStA Stuttgart A 227 Bü 290). Abweichend von der üblichen Praxis waren auch Untertanen fremder Herrschaften an der Wolfsbekämpfung beteiligt. Wenn Wölfe in größeren Rudeln auftraten, wurde nach altem Brauch mit Trommel und Sturmglocke zum Sturmstreich aufgerufen.

109 Die Einwohnerzahl des Herzogtums war von 450.000 im Jahr 1623 auf 100.000 im Jahr 1639 gesunken. Auch vier Jahre nach Kriegsende (1652) lag noch ein Drittel der landwirtschaftlichen Nutzfläche brach.

${ }^{110}$ HStA Stuttgart A 573 Bü 6681.

111 In Mönsheim (Leonberger Forst) wurde noch zu Beginn des 18. Jahrhunderts jährlich 
tragenden der Anstrengungen, die dieses Vorhaben forderte, waren außer dem Forst- und Jagdpersonal vor allem die Treiber. Die Wolfsjagden fanden nämlich in der unwirtlichsten Jahreszeit statt, weil die Anwesenheit der vagabundierenden Raubtiere nur bei Neuschnee zuverlässig festgestellt werden konnte. Auf einer Vorsuche musste dann den frischen Fährten nachgespürt und durch das Umschlagen (Kreisen) aller Waldteile, die sie durchquert hatten, der Standort ermittelt werden, an dem sie sich aufhielten, worauf man in aller Eile die Treiber mobilisierte, um so bald wie möglich mit dem Jagen beginnen zu können.

Dabei traf die Wolfsbekämpfung das Landvolk im Zustand größter Not, denn die unsäglichen Kriegswirren hatten viele in tiefstes Elend gestürzt. Die meisten waren so verarmt und ausgesogen, dass sie sich nicht einmal winterfeste Kleidung leisten konnten. Das stundenlange Herumstehen in grimmkalter Zeit und das Waten im knietiefen Schnee blieb daher für Leute, die keine harte Natur hatten, nicht folgenlos. Sie würden an ibren Leibern preßthaft und armselig, monierte 1664 die Landschaft und ließ nicht unerwähnt, dass erst im Jahr zuvor ein übel disponierter Mann sein Leben eingebüßt habe und ein Knab erfroren sei. Hinzu kam, dass sowohl der drastische Bevölkerungsrückgang als auch der hohe Personalbedarf den Aktionsradius der Jagensmannschaften und damit häufig auch die Wegstrecke beträchtlich vergrößert hatte. Oft mussten die Fröner in aller Herrgottsfrühe, zuweilen sogar schon um Mitternacht aufbrechen und kamen - ohne sich mit einer warmen Mahlzeit gestärkt zu haben - so spät zurück, dass sich kaum das Ausziehen lohnte, wenn die Ablösung ausblieb und es am nächsten Morgen weiter ging. Das war häufig genug der Fall, weil durchgebrochenen Wölfen stets nachgesetzt wurde.

Ganz schlimm ging es zu, wenn tagelang in einem fort gejagt werden musste, ohne dass an eine Heimkehr zu denken war. Mancher kam so verfroren zurück, dass man ihm prophezeite, das werde ihm Jahr und Tag nachgehen. Einige glaubten sogar, sie würden schier crepiren. Als Skandal empfand man auch die zahllosen legalen, halblegalen und illegalen Personalbefreiungen. Selbst hohe Forst- und Jagdbeamte stießen sich daran, dass viele Bürger hinter dem warmen Ofen sitzen bleiben durften, während die anderen zum Jagen gehen mussten und dazu noch von den Reichen vexirt und außgelacht wurden ${ }^{112}$. Großer Unmut entstand schließlich, sobald sich herausstellte, dass nichts gefangen wurde und alle Mühe umsonst gewesen war. Als wegen der abnehmenden Zahl der Wölfe gegen Ende des 17. Jahrhunderts die Fehljagden sich häuften, wuchs die Verärgerung immer mehr. Immer laut-

8- bis 15-mal gewolft. Ein Vorsucher gab an, in einem Winter 34-mal auf dem Wolfsjagen gewesen zu sein (HStA Stuttgart A 557 Bü 280). Nach unvollständig erhaltenen Unterlagen für die Jahre 1638-1663 wurden in diesem Zeitraum durch das Forst- und Jagdpersonal 1755 Wölfe geschossen, gefangen (abgestochen) oder auf andere Weise umbgebracht (HStA Stuttgart L 6 Bü 676 und A 59 Bü 50).

112 Schreiben des Böblinger Forstmeisters Otto Heinrich von Bültzingslöven vom 16. April 1711 (HStA Stuttgart A 227 Bü 552). Ungeachtet gegenteiliger Anordnungen konnten sich Bürger, die Personalfreiheit genossen, der Verpflichtung zur Wolfsjagd weitgehend entziehen. 
stärker war der Vorwurf zu hören, man werde in die Wälder hinausgesprengt, obwohl sich weit und breit kein Wolf sehen lasse. Vier- und fünfmal müsse man laufen, hieß es, bis einer fürgezaigt werden könne ${ }^{113}$. Keine Frage: die Leidensgeschichte des Jagdfronwesens erreichte in den Wolfsjagden mit ihren barbarischen und unchristlichen Verfabrungen einen traurigen Höhepunkt.

Für die Glaubwürdigkeit der massiven Beschwerden gibt es einen Kronzeugen. Als sich der bereits zitierte Jägermeister Georg Christoph von Schönfeldt mit dieser „widerwärtigen Materie“ befasste, musste er eingestehen, in seiner 27-jährigen Dienstzeit keine größeren Klagen erlebt zu haben als bei der Bejagung der Wölfe ${ }^{114}$. Die armen Leute müssen in winterlicher Zeit vom früben Morgen an bis zu Abend dem Gejäg abwarten, und wann sich die Wölf gelegt, abends mit dem Zeng- und Garn-Richten beschäftigt sein, da dann oftmals geschieht, daß manche Bauren solchermaßen hart erfrieren, daß sie in ferner Lebzeit damit zu tun haben und Krüppel seyn und bleiben müssen. Und er fügte hinzu: es sei leicht zu begreifen, dass ein Mensch, der den ganzen Tag in Schnee und Kälte jage und dann noch bei finsterer Nacht einen sechs- bis siebenstündigen Heimweg zurücklege, gänzlich erstarren müsse, selbst wenn er gut gekleidet sei, was bei den meisten nicht zutreffe. Gleichwohl sah auch er keine Möglichkeit, dieser Misere abzuhelfen, denn Wölfe - so seine Rechtfertigung - ließen sich nicht in die Stube bannen oder mit Stricken anbinden, sondern müssten verfolgt werden, so weit sie traben. An der rauen Praxis des Wolffens änderte sich daher nichts, weil niemand an der Notwendigkeit zweifelte, die Unthiere vollständig aus dem Weg zu raumen.

Diesem Ziel kam man gegen Ende des 17. Jahrhunderts rasch näher, als der konzentrierte Jagddruck die stabilen Populationsstrukturen weitgehend aufgelöst hatte. Letzter Rückzugsraum der württembergischen Wölfe war naturgemäß der Schwarzwald ${ }^{115}$. Um den ständigen Lamentationen den Wind aus den Segeln zu nehmen, erklärte sich die Regierung seit 1675 bereit, ganze Gemeinden gegen Entrichtung einer jährlichen Gebühr freizustellen. Zu diesem Zweck hatte jeder fronpflichtige Bürger ein Kopfgeld abzuliefern. Von der Umlage, mit der Schussgelder

113 Die Gemeinde Meimsheim (Stromberger Forst) wurde im Winter 1697/1698 11-mal aufgeboten. Obwohl die Mannschaft stets erschien, wurde nie gejagt. Manchmal fand sich nicht einmal der Forstknecht ein, der Anordnung zu dem Jagen gemacht hatte (HStA Stuttgart A 227 Bü 112 III).

114 Schreiben vom 26. Januar 1679 (HStA Stuttgart A 227 Bü 178). Um die Zahl der beschwerlichen Wolfsjagden vermindern zu können, plädierte er für die Errichtung von Wolfsgärten. Im konkreten Fall empfahl er eine große Anlage auf der Feuerbacher Heide bei Stuttgart, über die ein Wolfswechsel lief. Das Projekt scheiterte jedoch an Einwendungen der Residenzstadt.

115 Schon 1718 heißt es: Das Wolfjagen ist gar selten nöthig, weil sich dergleichen Raubthiere größtentheils im Land verloren haben (HStA Stuttgart A 249 Bü 3647). Von den meisten Orten des Landes wird 1731 berichtet, dass sich seit vielen Jahren kein Wolf mehr zeige (HStA Stuttgart L 6 Bü 676). Im Jahr 1735 wurden jedoch im Altensteiger Forst noch drei und im Winter 1741/1742 im Neuenbürger Forst sechs Wölfe zur Strecke gebracht (HStA Stuttgart A 248 Bü 1771). 
und Einrichtungen zum Wolfsfang finanziert werden sollten, blieb selbstverständlich verschont, wer Personalfreiheit für sich in Anspruch nehmen konnte. Zur Befriedung trug diese Regelung deshalb wenig bei. Häufig wurde die Abgabe auch dann erhoben, wenn gar nicht hätte gewolft werden können, weil entweder die Wölfe ausblieben oder kein Schnee gefallen war. Manche Kommunen hatten den Eindruck, mit sinnlosen Aufgeboten schikaniert zu werden, weil sie sich für den Jagddienst und gegen das Lösegeld entschieden hatten. Es gab sogar Forstämter, die Treiber zu Wolfsjagden bestellten, obwohl das Surrogat bereits bezahlt war. Unter diesen Umständen nahm das Wolfsgeld den Charakter einer Forstcollecte an. Herzog Karl Alexander machte der Abzockerei schließlich 1736 mit der Begründung ein Ende, dass die Untertanen obnebin die Jagdfronen in natura praestiren müssen, wann sich über kurtz oder lang Wölffe wieder spübren lassen. Dieser Vorbehalt erledigte sich von selbst ${ }^{116}$.

\section{Herrscher und Untertan}

In der Feudaljagd kam es zu einem merkwürdigen Zusammenwirken der beiden Pole des hierarchisch strukturierten Gesellschaftsgefüges: der Landesherr als oberster staatlicher Repräsentant, der entschied und dirigierte, bediente sich einer sozial deklassierten Bevölkerungsschicht, die auf der untersten Stufe des Gemeinwesens stand und den Anordnungen seiner Vollzugsorgane bedingungslos Folge zu leisten hatte. Widerspruch konnte auch bei offenkundiger Willkür nur verbal artikuliert werden, weil - wie es die Landstände 1797 formulierten - der fordernde Theil zugleich Richter und der Rechtsweg damit ausgeschlossen war. Das aus dieser Konstellation resultierende beiderseitige Verhältnis ist, wie sich aus den Quellen erschließt, als zwiespältig zu bezeichnen. Auf der einen Seite wurde es von einer natürlichen Ehrfurcht der Untertanen gegen den Landesfürsten bestimmt, die sich in unzähligen Gehorsamsbekundungen bei der Festschreibung der Forstlichen Dienstbarkeiten im 16. Jahrhundert wie auch bei späteren Anlässen manifestierte ${ }^{117}$. In gleicher Weise kam sie in der Bereitschaft fronfreier Gemeinden zum Ausdruck, Jagddienste zu unterthänigsten Ehren dann zu leisten, wenn der Herzog in höchster Person erschien. Andererseits gibt es eine erdrückende Fülle von Belegen, aus denen hervorgeht, dass viele Jagdfronpflichtige sich nicht nur hart, sondern auch un-

116 HStA Stuttgart L 6 Bü 676. Die im späten 18. und frühen 19. Jahrhundert in Württemberg auftauchenden Einzelwölfe waren Zuwanderer aus fernen Wolfsregionen. Der letzte wurde am 10. März 1847 bei Cleebronn im Stromberg geschossen.

117 Ein typisches Beispiel für diese Verhaltensweise ist das Entgegenkommen des fronfreien Dorfs Lauffen am Neckar (Stromberger Forst), dessen Vertreter sich 1565 auf die Verpflichtung einließen, die Seilwagen bis in die nächsten Flecken zu führen, wenn sie beim Durchzug der herrschaftlichen Jagdgesellschaft nicht weiter kämen, weil sie Ir Fürstl. Gnaden im feldt nit steckhen lassen wollten - wie Underthanen gepuert (HStA Stuttgart H 107/16 Bd. 1). 
gerecht behandelt fühlten. Das von Justinus Kerner gemalte Bild, wonach in Württemberg der Regent in noch so großen Wäldern sein Haupt jedem Untertan kühnlich in den Schoß legen konnte, entspricht in seiner romantischen Verklärung jedenfalls nicht der historischen Realität ${ }^{118}$.

$\mathrm{Zu}$ Beginn der Frühen Neuzeit hielten sich in der Regel die Belastungen noch in erträglichen Grenzen, da die Dimensionen des Jagdbetriebs bescheiden und - wie manche Verpflegungsusancen erkennen lassen - Relikte patriarchalischer Umgangsformen erhalten geblieben waren, die aber bald verschwanden ${ }^{119}$. Als im 17. und 18. Jahrhundert immer weniger Wild an seinem Standort aufgesucht, sondern zunehmend mit wachsender Treiberzahl massenhaft zusammengetrieben und in eingestellten Jagen totgeschossen wurde, schwoll die Beschwerdeflut an. Die Reaktion der Jagdherren bestand in Ankündigungen, die Übelstände und Exzesse abzustellen, ohne dass sich jedoch in der Praxis viel änderte. Um eine nachhaltige Verbesserung zu erreichen, hätte es einer Ausmerzung der systemimmanenten Mängel der Feudalverwaltung durch eine Reform an Haupt und Gliedern bedurft, die aber unterblieb. Auch die Androhung von Sanktionen gegen das Forst- und Jagdpersonal erwies sich deshalb als stumpfes Schwert, denn Förster und Jäger, die sich Übergriffe zuschulden kommen ließen, wurden nie zur Rechenschaft gezogen. Die in aller Öffentlichkeit geäußerte Absicht, die lieben und getreuen Unterthanen zu schonen, entpuppte sich somit als Lippenbekenntnis ${ }^{120}$. Es drängt sich der Eindruck auf, dass es der Landesherrschaft primär um eine Pflichtübung ging, die den Zweck verfolgte, Beschwerdeführer und Bittsteller ruhig zu stellen. Symptomatisch für diese Optik ist das Verhalten des Herzogs Karl Eugen, der nie daran dachte, seinen landesvätterlichen Entschließungen Taten folgen zu lassen ${ }^{121}$.

118 Das auf einer fragwürdigen Überlieferung beruhende Gedicht bezieht sich speziell auf Graf Eberhard im Bart. Ein Vorgang aus seinem Jagdumfeld spricht dafür, dass auch der „reichste Fürst“ der idealtypischen Vorstellung der württembergischen Landeshymne nicht gerecht wurde (Wilfried Ott: Der Jägeratz in Württemberg. In: ZWLG 69 (2009) S. 186/187).

119 Herzog Christoph war persönlich darum besorgt, dass die Fuhrleute bei rechter Zeit das althergebrachte Essen bekamen, wenn sie sich am Hof aufhielten (HStA Stuttgart A 59 Bü 6a). Aus Böblingen wird 1591 berichtet, Herzog Ludwig habe Fronpflichtigen, die in seiner Anwesenheit den Jägern beim Dachsgraben halfen, etwas usser Gnaden geschenkt (HStA Stuttgart A 206 Bü 956).

120 Schon die Verfügung des Herzogs Eberhard III. vom 4. Mai 1670, mit der er den Forstund Jagdbeamten eine wohlempfindliche und exemplarische Strafe für üble Behandlung der Untertanen ankündigte, war wirkungslos geblieben (Reyscher [wie Anm.12] Bd.16,1. S. 495). Nicht anders verhielt es sich mit späteren Regelungen. Im Laufe des 18. Jahrhunderts bemühte sich zwar die Regierung zunehmend darum, eklatante Rechtsverstöße der Forstamtsleiter zu korrigieren, ließ sie selbst aber durchweg ungeschoren.

${ }^{121}$ Er erließ aufgrund von Informationen, die ihm unterthänigst hinterbracht worden waren, am 2. September 1776 ein persönlich verfasstes und immediate verschicktes Dekret zum Verbot von Missbräuchen bei Jagdfron-Forderungen, das Oberforstmeistern und Förstern untersagte, Treibjagden nur zum Vergnügen oder zur Beschaffung von Küchenwild zu veranstalten und ihnen bei Nichtbeachtung scharfe und ungnädige Ahndung androhte. Er gestattete sogar den Untertanen, dergleichen unnötigen Jagensgeboten keine Folge zu leisten 
In den Aktenkonvoluten findet sich nicht der geringste Hinweis darauf, dass die Regenten an Kontakten mit den fronenden Landeskindern interessiert waren ${ }^{122}$. Unvorstellbar, dass sie jemals in die Situation hätten kommen können, ihnen den Kopf in den Schoß zu legen. Von Idylle keine Spur. Ungeachtet aller rhetorischen Beteuerungen ist echte Anteilnahme an ihren Lasten und Leiden nirgends erkennbar. Jagenspflichtige wurden von der höfischen Elite offenbar nur als Herrschaftsobjekte wahrgenommen, ihre Mühsale anscheinend nicht einmal registriert - eine zweckhafte Perspektive ohne sozialethische Implikationen ${ }^{123}$. Es gibt Vorfälle, die eine geradezu erschreckende Gefühlskälte offenbaren ${ }^{124}$. Die Jagdfröner dürften

(HStA Stuttgart A 565 Bü 58). Nach den Feststellungen der Landstände 1797 ist dieses heilsame Rescript niemals eingehalten worden. Es hat vielmebr dazu gedient, daß diejenige Jagensmannschaft, die sich auf dasselbe berief und aus diesem Grund das Aufgebot nicht achtete, noch vor die Oberforstämter gefordert und mit Geld-und Turmstrafe belegt wurde (Neues Forstarchiv. 1799. S. 90).

${ }^{122}$ Das gilt auch für Herzog Karl Eugen, dem man Umgänglichkeit in seiner reifen Lebensphase nachsagte: Vertrauend auf seinen persönlichen Einfluß, suchte der Herzog wo immer möglich durch mündliche Erörterung der Frage auf die Betheiligten einzuwirken und in den meisten Fällen war das von Erfolg; die Frage wurde in gütlichem Wege ins Reine gebracht. Auch in allen Nöthen stand er seinen Unterthanen immer bei. Bei jedem Zusammentreffen, namentlich auch auf den Jagen, wußte er mit den Bauern trefflichst zu verkehren und durch leutseliges, gewinnendes Benehmen sie für sich einzunehmen (von Wagner [wie Anm. 3] S. 521). Diese Darstellung muss nach dem Quellenbefund in das Reich der Legendenbildung verwiesen werden. Nach zeitgenössischem Urteil blieb er auch in dieser späteren Periode, wo er den Landmann, den Hausvater und den Philosophen spielte, im Grunde immer derselbe, nur daß sich sein Charakter nicht mehr mit der Heftigkeit der Jugend äußerte (Anonymus: Geheimnisse eines mehr als fünfzigjährigen wirtembergischen Staatsmannes, nach seinem Tode herausgegeben. 1799. S.53).

123 Der Freiherr von Buwinghausen-Wallmerode, der den Herzog Karl Eugen von 1767 bis 1773 auf zahlreichen Jagden begleitete, erwähnt in seinem Tagebuch mit keinem Wort die Jagdfronen (Das Tagebuch des Herzoglich Württembergischen Generaladjutanten Freiherrn von Buwinghausen-Wallmerode über die „Land-Reisen“ des Herzogs Karl Eugen von Württemberg in der Zeit von 1767 bis 1773. Hg. von Freiherr Ernst von Ziegesaar. 1911). Franziska von Hohenheim notiert eine Damwildjagd am 5. September 1781 mit der Bemerkung: Es wabr recht schen und alles war vergniegdt darbey (Tagbuch der Gräfin Franziska von Hohenheim. Hg. im Auftrag des württembergischen Geschichts- und Altertumsvereins von A. Osterberg. 1981. S.112).

${ }^{124}$ Auf einer Rotwildjagd des Herzogs Friedrich im Pulverdinger Holz (Leonberger Forst) war der Weingärtner Hans Stahl aus Markgröningen im Juni 1604 durch einen angeschossenen und von Hunden gehetzten Hirsch, der ihn beim Vorstehen in vollem Lauf angenommen und zu Boden gestoßen hatte, am Unterleib und am rechten Schenkel schwer verletzt worden. Das Unglück, durch das er auch sein rechtes Auge verlor, wurde dem Jagdherrn sofort gemeldet, der ihm daraufhin zur labung einen Becher Wein reichen ließ und veranlasste, dass er auf den Pulverdinger Hof gebracht wurde, wo die Erstversorgung stattfand. Nach einer schmerzhaften sechswöchigen Kur bat er den Herzog um eine Gnadenergötzung. Vogt und Oberrat unterstützten das Gesuch des 60-jährigen und nur noch bedingt arbeitsfähigen Mannes, der eine alte und kranke Frau zu versorgen hatte und kaum über Vermögen verfügte. Sie schlugen vor, ihm 8 Reichstaler aus dem Geistlichen Gut zukommen zu lassen, damit er wenigstens seine Arztkosten bezahlen könne. Herzog Friedrich wies dieses Ansin- 
ihre vom Herzog eingeforderte Devotion daher mehr seiner Amtsautorität als seiner Person erwiesen haben. Respekt statt Verehrung - so könnte es ausgesehen haben. Kaum einer wagte es, dem angestauten Zorn freien Lauf zu lassen ${ }^{125}$. Erst gegen Ende des 18. Jahrhunderts zeichnete sich ein vorsichtiger Wandel ab. Die Untertanen widersetzten sich nicht gerne ihrem Landesherrn und feierlicher Protest sei daher nicht häufig, heißt es 1772, doch genügten Murren und Bezengen, um ibren Widerwillen an den Tag zu legen ${ }^{126}$.

\section{Neue Fronen}

Bereits in der zweiten Hälfte des 17. Jahrhunderts begann sich die enge Bindung der Jagdfronpraxis an die Vorgaben der Forstlagerbücher zu lockern. Mit der Etablierung des absolutistischen Herrschaftssystems veränderte sich der Regierungsstil. Die Potentaten griffen jetzt mit souveräner Hand in das überkommene Regelwerk ein und setzten dort, wo es ihnen opportun erschien, pragmatische Lösungen an die Stelle der traditionellen Forstlichen Dienstbarkeiten.

So wurden seit 1675 auf der Schwäbischen Alb und im Neckarraum mehrere Gemeinden, die Hanfanbau in größerem Umfang betrieben, gegen Lieferung des für die Zeugjagden unentbehrlichen Jagdgarns vom Hagen und Jagen befreit. Das

nen mit der eigenhändig niedergeschriebenen Resolution zurück: Nichts und die Räthe uns mit dergleichen Neuerungen obnmolestirt zu lassen (HStA Stuttgart A 206 Bü 2056). König Friedrich ließ sich 1815/1816 Jagdunfälle vorlegen, bei denen Fronpflichtige ebenfalls durch Hirsche zu Schaden gekommen waren (Kopfwunden, aufgeschlitztes Ohr, starke Quetschungen an Brust und Armen). Seine Reaktion beschränkte sich auf den Vermerk Eingeseben (HStA Stuttgart E 1 Bü 34).

125 Als Herzog Eberhard III. im August 1664 einen Jagdaufenthalt beendete und abreiste, musste der Bauer Martin Egeler aus Öschelbronn (Tübinger Forst) mitten in der Ernte seine beiden Pferde ausspannen und für den Transport des Küchenwagens nach Pfullingen zur Verfügung stellen, weil seine Dorfgenossen mit ihrem Gemüse bereits in die Schweiz gefahren waren, um es dort zu verkaufen. Seinen Ärger darüber, dass ausgerechnet er mit jägerlichen Frondiensten hart beschwert wurde und seine Früchte bei unbeständigem Wetter auf dem Feld liegen lassen musste, verschaffte er mit bösen und losen Worten Luft, indem er in Anwesenheit von fünf Mitbürgern schimpfte, der Herzogswagen solle in der ganzen Welt herumfahren und in die Hölle versinken. Für die Untertanen sei das Jagen, das Tausende Gulden koste, schädlich. Wann Ihr Durchlaucht nicht so jagen theten, so wären Sie ein reicher Fürst, so aber ein Bettelherr. Auch störte er sich daran, wie übel die herzoglichen Köche mit Butter und Schmalz umgingen. Selbstverständlich wurden seine ebrenrübrigen Reden denunziert, die der ansonsten gut beleumundete Delinquent nicht bestritt und damit entschuldigte, dass sie ihm aus obngedult und obnverstandt entfabren seien. Herzog Eberhard III. meinte, er hätte eine scharfe Strafe und wohl auch den peinlichen Prozess verdient. Wegen schlechten Vermögens, seiner vier unmündigen Kinder und eines mit unerträglichen Schmerzen verbundenen Leibschadens, dessenthalben er sich einer Operation unterziehen (schneiden lassen) musste, begnadigte er ihn jedoch zu einer achttägigen Turmstrafe (HStA Stuttgart A 206 Bü 2489).

${ }^{126}$ HStA Stuttgart A 227 Bü 187. 
Dörflein Belsen (Tübinger Forst) brauchte ebenfalls keine Jagddienste mehr zu leisten, weil die Bürgerschaft das Tübinger Schloss- und Besoldungsholz aus Bergen und Kingen der Umgebung zusammentrug und in die Stadt lieferte ${ }^{127}$. Die Ortschaften Derendingen und Weilheim (Tübinger Forst), die Floßfronen am Neckar und Hofdienste im Schloss Hohentübingen verrichteten, wurden dafür 1672 von den Jagdfronen dispensiert ${ }^{128}$. Als Herzog Eberhard Ludwig 1709 seine neue Residenz Ludwigsburg bezog und das Bedienungspersonal aus den benachbarten Flecken holte, entband er die Betroffenen von ihrer Jagenspflicht und ersetzte sie, indem er die Fronfreiheit der Gemeinden Bietigheim, Markgröningen und Asperg aufhob. Auch wenn diese Maßnahmen lokal begrenzt waren, bedeuteten sie im Endeffekt nichts anderes als eine Ausweitung der Fronleistungen, weil stets andere als Lückenbüßer einspringen und zusätzliche Lasten auf sich nehmen mussten.

Der flexible Umgang mit den Rechtsgrundlagen des Jagdfronwesens war jedoch nur das Vorspiel eines Dramas, das in der langen Regierungszeit des Herzogs Karl Eugen (1744-1793) viele Untertanen mit nie erlebten Forstfronen, welche vormals nicht einmal dem Nabmen nach bekannt waren, zur Verzweiflung brachte. Für diese rechtswidrige Entwicklung waren sowohl subjektive als auch objektive Ursachen maßgebend. $\mathrm{Zu}$ einem nicht geringen Teil resultierte sie aus der Prunkliebe und Vergnügungssucht des Regenten, zum andern aber auch aus Veränderungen des Jagdbetriebs und ersten Ansätzen einer geregelten Waldbewirtschaftung. Dabei machte sich die Jagdherrschaft die Willfährigkeit des unbedarften Landvolks zunutze, das häufig bereit war, nicht schuldige Fronen einigemal oder eine Zeit lang, solange sie nicht allzu lästig waren, aus gutem Willen oder Unwissenheit zu leisten ${ }^{129}$. Wenn den Untertanen die Erkenntnis dämmerte, zu solchen Forst- und

127 Der Befreiungsbrief war beim Franzoseneinfall 1688 verloren gegangen und wurde 1693 neu ausgestellt (HStA Stuttgart A 227 Bü 2864). Die Belsener hatten allerdings bei allerböchster Gegenwart des Landesherrn Jagddienste zu leisten. Sie mussten sich in Reserve halten, wenn das herrschaftliche Jagen auf eine Entfernung von vier bis fünf Wegstunden herankam und mitmachen, sobald es auf zwei bis drei Wegstunden herangerückt war (HStA Stuttgart L 6 Bü 943).

${ }^{128}$ Der Neckar floss bis zu seiner Korrektion 1779 zwischen Rottenburg und Tübingen im ungeregelten Bett, sodass es oft zu Überflutungen und Überschwemmungen in der Talaue kam. Die Gemeinden Derendingen und Weilheim mussten seit alter Zeit die in diesem Bereich gestrandeten Flöße mit Pferden und Ochsen wieder flottmachen oder aus dem Wasser holen und zu Land nach Tübingen transportieren. Dieser anstrengende und gefährliche Einsatz, der gewöhnlich im Frühsommer fällig war, hatte nach dem 30-jährigen Krieg Jahr für Jahr an Umfang zugenommen. Zudem wurden die fronpflichtigen Bürger beider Orte damit beschäftigt, den Tübinger Schlosshof und seine Brunnen zu säubern, die Eisgruben zu besorgen, Holz zu legen und andere Bosselarbeiten zu verrichten sowie beim Aufenthalt des Herzogs rund um die Uhr aufzuwarten. Herzog Eberhard III. befreite sie daher vom Jagddienst. Sie empfanden diesen Tausch als schlechtes Geschäft, da ihnen die Befreiung durch weit schwerere Lasten hart versalzen worden sei (HStA Stuttgart A 227 Bü 2855. - A 249 Bü 3647. - A 565 Bü 56).

129 HStA Stuttgart L 6 Bü 941. Die Landstände bemerkten in ihren Forst- und Jagdbeschwerden 1797 zu diesem Phänomen, die Unwissenheit der Untertanen habe unendlich viel 
Jagddiensten wider alle Verbindlichkeit angestrengt worden zu sein, war es meistens schon zu spät. Die Obrigkeit scheute sich nämlich nicht, aus dem Entgegenkommen ein normatives Gewohnheitsrecht abzuleiten. Außerdem interpretierte sie den altüblichen Grundbegriff der Fronverpflichtung - das Hagen und Jagen völlig um und wollte darunter jetzt jede Dienstleistung verstanden wissen, die zur Conservation der Wildfubr nützlich ist ${ }^{130}$. Der Willkür war damit Tür und Tor geöffnet.

Die Fülle der ganz neu aufgekommenen Praestationen lässt sich nur stichwortartig andeuten. So legte Herzog Karl Eugen zahlreiche Tiergärten an, für die Rotund Schwarzwild eingefangen und aus weit entfernten Forsten herbeigeschafft werden musste ${ }^{131}$. Für Festivitäten aller Art hatten jagenspflichtige Mannschaften im Schwarzwald Stechlaub (Stechpalmen) und Tannenreisig in ungemeiner Quantität zu sammeln und in die Schlösser zu führen. Die 1727 abgeschaffte Parforcejagd ließ er 1754 wieder aufleben und zum Bau der umfangreichen Parkumzäunung Arbeiten durchführen sowie aus weitem Umkreis die dafür erforderlichen Palisaden anliefern. Bisher völlig unbekannte Frondienste hingen mit der Wildfütterung zusammen, die in der 2. Hälfte des 18. Jahrhunderts eingeführt wurde. Auf dem Programm standen deshalb jetzt auch das Mähen, Dörren und Einlagern von Heu, das Säubern von Waldwiesen, die Bewirtschaftung von Wildäckern, das

zur Vermehrung und guthmütigen Leistung unbilliger und widerrechtlicher Forstfronen beigetragen (Neues Forstarchiv. 1799. S. 86).

${ }_{130}$ Das Interpretationsspektrum reichte von der Emporbringung und Aufrechterhaltung der Wildfubr (HStA Stuttgart A 249 Bü 3195) bis zur Verbesserung und Aufnabme der Waldungen (HStA Stuttgart A 227 Bü 2656). Wie kaltschnäuzig rechtswidrige Fronen durchgesetzt wurden, zeigt das Beispiel der Stadt Göppingen (Schorndorfer Forst), die das 1762 erstmals angesonnene Eichellesen als eine Neuerung verweigerte. Daraufhin teilte ihr der Oberforstmeister Johann August von Brandenstein unwidersprechlich mit, sie sei dazu verpflichtet und habe es alß eine Gnade zu erkennen, daß sie bißher frey geblieben. Herzog Karl Eugen billigte diese Abfuhr mit der wahrheitswidrigen Begründung, die Bürger seien zum Eichellesen nach dem klaren Buchstaben des Forstlagerbuchs wie zu andern Forst-Frondiensten verbunden (HStA Stuttgart A 227 Bü 2401).

${ }^{131}$ Bereits Herzog Eberhard Ludwig hatte 1715-1717 lebendige Hirsche und wilde Schweine im Heidenheimer Forst beifangen und als eine Verebrung dem Kurfürsten von Bayern nach Donauwörth überbringen lassen (HStA Stuttgart L 6 Bü 979). Unter Herzog Karl Eugen wurde dieser einmalige Vorgang zum Normalfall. Bei den Fangaktionen handelte es sich unter den damaligen Umständen um gefährliche Unternehmungen, bei denen verschiedene Unterthanen vom Wild theils beschädigt, theils ibr Lebtag unglücklich gemacht wurden, zumal man lediglich die stärksten Stücke behielt und die übrigen wieder freiließ (HStA Stuttgart L 6 Bü 939). In der Zeit von 1770-1774 wurden dafür mitten in den Feldgeschäften - manchmal nur wegen weniger Tiere - bis zu 1.000 Bauern aufgeboten (HStA Stuttgart A 248 Bü 1770). Großes Aufsehen erregte 1768 das Einfangen von 82 Sauen im Heidenheimer Forst für einen beim Schloss Solitude angelegten Schwarzwildpark, das für die Dauer von 19 Tagen jeweils 800 Mann in Anspruch nahm. Für den mehrtägigen Transport, der nach Serenissimi höchstselbst ertheilter Ordre erfolgte, waren insgesamt 803 Mann, 1.607 Pferde und 64 sechsspännige Wagen erforderlich. Der Hofjägerei mussten 44 Reitpferde zur Verfügung gestellt werden (HStA Stuttgart A 202 Bü 630 und A 227 Bü 2415). 
Grasrupfen in Wäldern, das Klauben von Eicheln und Wildobst sowie die Versorgung der Fasanerien. Selbstverständlich war es auch Aufgabe der Fröner, Rauhund Kraftfutter (Haber) aus den Hütten und Magazinen zu holen und an die Futterplätze zu tragen. Zudem mussten Hirschsulzen (Salzlecken) angelegt und beschickt werden. Hinzu kam im Winter das Fällen von Weichlaubhölzern zur Verbesserung des Äsungsangebots und das Babnschleifen, um die Fütterungen auch bei hoher Schneelage zugänglich zu machen. Da die Feudalherren starke Hirsche gerne auf der Einzeljagd erlegten, waren Pürsch- und Schleichwege sowie Jagdschirme einzurichten. Schließlich nahm man Frondienste auch für den Lerchenfang in Anspruch, der die Hofküche mit einer begehrten Delikatesse versah $^{132}$. Das Wacholderschlagen und Schlebenbrechen diente ebenfalls der Befriedigung kulinarischer Bedürfnisse. Darüber hinaus fingen die Forstämter damit an, waldbauliche Maßnahmen in der Fron ausführen zu lassen: Einsammeln von Holzsamen, Einzäunungen, Umbrechen und Aufforsten öder Plätze, Ausgraben von Laubbäumen für Alleen und andere Bepflanzungen, Anlage und Pflege von Waldkulturen, wobei das Geschirr - Sensen, Rechen, Schaufeln, Hacken und dergleichen - von den Fronleuten zu stellen war. Bleibt noch zu erwähnen, dass auch Fuhrfronen für jagdfremde Zwecke in einem Ausmaß angefordert wurden, das alles bisher Dagewesene überstieg ${ }^{133}$.

Ein besonderes Kapitel waren die luxuriösen Festjagden, die Herzog Karl Eugen mit Vorliebe zelebrierte. Insbesondere Besuche ausländischer Herrschaften oder persönliche „Events“ boten den Anlass für diese aufwändig inszenierten Lustbarkeiten, die nur mit Hilfe kostenloser Arbeitskräfte realisiert werden konnten. Als herausragende Ereignisse sind in Erinnerung geblieben: das Hochzeitsjagen bei Leonberg am 8. Oktober 1748, das Geburtstagsjagen bei Degerloch am 19. Februar 1763, das Hirsch-Prunft-Jagen bei Heidenheim am 14. September 1769 und das Festin-Jagen am Stuttgarter Bärensee am 24. September 1782 zu Ehren des russischen Großfürsten Paul ${ }^{134}$. Mit Jagd im eigentlichen Sinn des Wortes hatten diese pompösen Massenschlächtereien nichts zu tun.

132 Frondienste für den Lerchenfang gab es schon im späten 17. Jahrhundert. Seit ca. 1710 wurden sie mit steigender Intensität praktiziert. Dabei ließ man auf den Feldern die Lerchen im Spätsommer und Frühherbst durch 15 bis 20 Fronpflichtige in aufgespannte Netze treiben. Die Lerchenfron wurde in den siebziger Jahren des 18. Jahrhunderts als Zumutung empfunden und deshalb mit regulären Jagddiensten verrechnet (HStA Stuttgart A 227 Bü 1454 und A 558 Bü 42).

${ }^{133}$ Nach den geltenden Vorschriften hätten die Kosten für Fuhrfronen, die in Lagerbüchern nicht vorgesehen waren, aus herrschaftlichen Kassen erstattet werden müssen, was aber fast immer unterblieb. Stadt und Amt Wildberg beschwerten sich 1770 über offene Rechnungen in Höhe von 9.000 Gulden und klagten, die Fuhrleute gingen sie fast täglich um Bezahlung an (HStA Stuttgart A 249 Bü 3195).

${ }_{134}$ Die einschlägigen Akten sind nur noch in wenigen Bruchstücken vorhanden, doch existieren von den Feierlichkeiten 1749 und 1763 allgemeine zeitgenössische Berichte (Wilhelm Friedrich Schönhaar: Ausführliche Beschreibung des zu Bayreuth im September 1748 vorgegangenen Fürstl. Beylagers und derer zu Anfang Octobers darauf erfolgten Fürstl. 
Es kann keinem Zweifel unterliegen, dass Herzog Karl Eugen den systematischen Rechtsbruch, der mit den neuen Fronen verbunden war, nicht nur toleriert und gefördert, sondern vielfach sogar selbst veranlasst hat, denn das gesamte Jagdwesen war auf seine Person zentriert. Das änderte sich auch nicht, als er im Erbvergleich 1770 vor dem Hintergrund unzähliger Eingaben das feierliche Versprechen abgab, alle Frondienste abzustellen, die gegen Lagerbücher und Herkommen verstießen. Er vermied es aber peinlich, seine wahre Denk- und Handlungsweise publik werden zu lassen und vermittelte stattdessen den Eindruck, als ob ihm allein das Wohl seiner Landeskinder am Herzen liege ${ }^{135}$. Daraus erwuchs ein widersprüchliches Verhalten, das beispielhaft in einer Frage zum Ausdruck kam, die wie kaum eine andere sein Eigeninteresse berührte. Aufgrund massiver Remonstrationen hatte er 1773 die Anordnung getroffen, dass sich Jagdfronen nicht über die Grenzen eines Forstbezirks hinaus erstrecken durften. Schnell stellte sich jedoch heraus, welchen Bärendienst er sich damit selbst erwiesen hatte, weil die nach Serenissimi

Heimführungs-Festivitäten. 1749. - Joseph Uriot: Beschreibung der Feierlichkeiten, welche bey Gelegenheit des Geburtsfestes Sr. Herzogl. Durchlaucht des regierenden Herzogs zu Würtemberg den 11. und folgenden Tage des Hornungs 1763 angestellet worden. 1763). Für die Jagdbelustigung 1749 hielt man 700 bis 800 Stück Rot- und Schwarzwild bereit, von denen 400 erlegt wurden. Die Hohe Jagd-Gesellschaft fand hiebey das erwünschteste Vergnügen. Sie ergötzten sich bald über das Herunterburzeln des Gewilds von dem dazu gemachten Absprung, bald über das ängstlich-und doch vergebliche Fliehen desselben (Schönhaar, S. 67/68). Für die Geburtstagsjagd 1763, die eine halbjährige Vorbereitung erforderte, hatten die Forstämter im ganzen Land 121 Rothirsche, 330 Sauen, 30 Damhirsche, 130 Rehböcke, 300 Füchse, 120 Dachse, 3.000 Hasen, 530 Rebhühner, 200 Fasanen und 200 Wildtauben einzufangen und nach Degerloch zu transportieren, wo sie in einem eigens erbauten $\mathrm{Am}$ phitheater vor 15.000 Zuschauern abgeschossen wurden (HStA Stuttgart A 8 Bü 47). Die Jäger trieben also das Wildpret in die Esplanade hinüber, und die Fürsten, Fremde und Vornehmste des Hofes, welchen von den Jägern immer frisch geladene Flinten gereichet wurden, hatten die Wabl, nach ibrem Gutdünken jede Arten von Wild zu erlegen, die sie vor sich sahen (Uriot, S. 127). Beim Heidenheimer Hirsch-Prunft-Jagen 1769 waren an 20 Arbeitstagen täglich über 1.000 Fröner mit dem Zusammentreiben beschäftigt, wobei zur nächtlichen Bewachung des eingestellten Wilds 5.532 Feuer aufgemacht wurden (HStA Stuttgart A 8 Bü 38). Zur Vorbereitung der Prunkjagd am Stuttgarter Bärensee 1782 waren durch Serenissimi böchste Disposition Tausende Treiber abkommandiert, die bis zu 40 Tage Jagddienste leisten mussten (HStA Stuttgart A 227 Bü 2662/2663). Am „Jagdtag“ wurden ca. 8.000 Stück Wild ins Wasser getrieben und anschließend (vermutlich aus Zeitmangel) wieder freigelassen, nachdem ca. 600 ertrunken waren. Kommentar der Franziska von Hohenheim: Es war ser schen an zu sehen und muste allen menschen gefallen (Tagbuch [wie Anm.123] S.182).

135 Während der Bau- und Residenzzeit des Schlosses Solitude (1763-1775) wurden Bürger der Gemeinde Feuerbach jährlich an 120 bis 130 Tagen für Frondienste in Anspruch genommen (HStA Stuttgart A 202 Bü 572). Gleichwohl behauptete er 1776, es sei jedermann bekannt, wie er die Untertanen schonen wolle und forderte die Oberforstmeister auf, das buldreiche Beispiel nachzuahmen, das er selbst gebe, indem er so selten einige Jagens-Dienste anfordere (HStA Stuttgart A 565 Bü 58). Wie es in Wirklichkeit damit bestellt war, illustriert ein großräumiges Kesseltreiben 1756 mit 4.600 Mann und die Hubertusjagd von 1769 im Leonberger Forst, zu der allein aus den Nachbarforsten 24 Förster mit 2.000 Fronpflichtigen antreten mussten (HStA Stuttgart A 8 Bü 36 und 37). 
höchster Disposition anberaumten Haupt- und Lustjagen undurchführbar geworden waren. Er revidierte daher schon 1774 diese Beschränkung und verfügte, dass die Jagenspflichtigen in dergleichen außerordentlichen Fällen sich nicht beschweren, sondern in Bezengung ibrer unterthänigsten Devotion sich hierzu erfinden lassen werden. Mit wachsendem Widerstand gegen die übermäßigen Forstbedruckungen wurde die Verunsicherung der Feudalherrschaft schließlich so groß, dass sie zunehmend auf Repression verzichtete und mit moralischem Druck versuchte, widerspenstige Fronschuldige durch Zuspruch und Appell an die Ehrerbietigkeit zum Einlenken zu bewegen ${ }^{136}$. Die Regierungsjuristen drückten sich im späten 18. Jahrhundert nach Möglichkeit um grundsätzliche Entscheidungen, bemühten sich aber im Einzelfall bei Zweifeln an der Rechtmäßigkeit hin und wieder um korrekte Lösungen. Dagegen vertraten die hohen Forstbeamten mit ihren exaltirten Begriffen von der Fronpflicht der Unterthanen unverändert eine unnachgiebige Positi$\mathrm{on}^{137}$. Und sie waren es, die vor Ort den Ton angaben.

\section{Botenlaufen}

Eine Jagdfronspezies, die ausschließlich auf Observanz beruhte und nie schriftlich fixiert wurde, führte lange ein Schattendasein, bevor sie im 18. Jahrhundert zu voller Blüte gelangte: das Botenlaufen. Diese Dienstleistung war unumgänglich geworden, als mit fortschreitender Intensivierung des Verwaltungshandelns Kommunikationsprobleme entstanden. Da es weder technische Hilfsmittel noch flächendeckende postalische Versorgungsnetze gab, blieb nichts anderes übrig, als sie mit einem Medium zu lösen, das in reichem Maße zur Verfügung stand: dienstbare

136 Als sich die Gemeinden Auingen und Meßstetten 1788 weigerten, Wildheu zu machen und Salzlecken zu beschicken, erhielt das Oberforstamt Urach die Anweisung, auf diesen Dienstleistungen zu bestehen, aber alle nur mögliche Mäßigung zu gebrauchen, damit die Unterthanen über die Frequenz und Dauer derselben nicht weitere Beschwerde zu fübren Anlaß finden (HStA Stuttgart A 249 Bü 3691).

137 Nach dem Zeugnis der Landstände war ein wesentliches Motiv für ihre harte Linie das Bestreben, durch eine starke Wildfubr die besondere Gnade und Attention des Jagdherrn zu erwerben. Der Uracher Oberforstmeister Julius Friedrich von Lüzow rechtfertigte 1788 die fronweise Wildfütterung mit dem Hinweis, ein hoher Wildstand gereiche dem Herzog immediate zum Vergnügen (HStA Stuttgart A 227 Bü 3290). Symptomatisch ist auch die Reaktion des Oberforstmeisters Philipp Wilhelm von Kospoth, der 1790 bei der fronfreien Stadt Neuenstadt mit unzulässigen Forderungen auf Widerstand gestoßen war und ihr deshalb vorhielt, die Exemtion sei ihr einst geschenkt worden, doch mache sie durch ihr Verhalten sich dieses großen Geschenks unwürdig (HStA Stuttgart A 227 Bü 1753). Die der Oberschicht entstammenden und als Adlige in die Hofgesellschaft eingebundenen Forstamtsleiter entsprachen durchaus dem allgemeinen Urteil eines zeitgenössischen Beobachters: Alles zitterte vor dem Despoten, alles gehorchte seinem Winke, alles schmeichelte und kroch, und um seinen Diensteifer deutlich an den Tag zu legen, half man zu jeder Ungerechtigkeit (Anonymus [wie Anm. 122] S. 49). 
Untertanen, die für ihre Jagdherrschaft zu den üblichen Verpflichtungen nun auch noch die Nachrichtenübermittlung zu übernehmen hatten. Für die Funktionsfähigkeit des Forst- und Jagdwesens spielten seither Fronboten eine unverzichtbare Rolle.

Zwar sind bereits im ältesten Fronverzeichnis von 1486/1487 Botengänge aufgeführt, doch blieben sie offenbar bis weit in das 17. Jahrhundert hinein auf Einzelfälle beschränkt. Die Stadt Leonberg beklagt sich 1558 darüber, dass neuerdings die Forstmeister von Amts wegen fronpflichtige Bürger mit Briefen in die Flecken schicken, was bisher stets gegen Bezahlung erfolgt sei. Ein gutes Jahrhundert später (1678) ist dort schon die Rede davon, sie würden Postillonen gleich für diese Tätigkeit verwendet ${ }^{138}$. Mit dem Anbruch des 18. Jahrhunderts nehmen die Unmutsäußerungen bedeutend $\mathrm{zu}$, und um die Jahrhundertmitte scheint der rapide anwachsende Schriftverkehr alle Dämme gebrochen zu haben. Herzog Karl Eugen sah sich deshalb 1744 erstmals veranlasst, gegen Übermaß und Missbrauch einzuschreiten ${ }^{139}$. Seine wiederholten Straf-Edikte wurden jedoch vom Forstpersonal niemals respektiert, das auch noch am Ende des 18. Jahrhunderts seine private Korrespondenz häufig unter dem Deckmantel der Amtspost erledigen ließ $3^{140}$.

Eine verbindliche Verfahrensregelung gab es nicht, doch hatte sich spätestens im 18. Jahrhundert der Brauch eingebürgert, Schriftstücke über größere Entfernungen von Ort zu Ort zu befördern, um den Zeitaufwand für die Betroffenen in Grenzen zu halten. Bei Direktlieferungen im Nahbereich oder isolierter Lage mussten allerdings auch mehrstündige Wegstrecken zurückgelegt werden. Im Stafettensystem waren die Schreiben versiegelt und mit einem offenen Begleitpapier versehen, auf dem die Schultheißen die Stunde der An- und Abkunft zu verzeichnen hatten, um einen raschen und sicheren Lauf zu gewährleisten. Die Spedition der Briefschaften erfolgte bei Wind und Wetter und wenn es sein musste auch bei Nacht und Nebel. Die Belastung mit dem Botendienst war je nach den personellen und örtlichen Ver-

138 HStA Stuttgart A 227 Bü 225.

139 Generalreskript vom 15. Oktober 1744 (Christoph Karl Ludwig von Pfeil: Real-Index und Auszug der Hochfürstlich-Würtembergischen Forst-Ordnung. 1749. S. 49). In einer Verordnung vom 30. Oktober 1779 beteuerte er seine stets wachende väterliche Fürsorge für das Wohl seiner lieben und getreuen Untertanen, weshalb er die drückende Unordnung im Botenlaufen nicht länger dulden und Botengänge nur noch in wirklichen unaufschieblichen und auf keine andere Art zu besorgenden amtlichen Geschäften erlauben wolle (HStA Stuttgart A 8 Bü 39).

140 So die Landstände in den Forst- und Jagdbeschwerden 1797. Alle Ausschreiben, die der Oberforstmeister an seine untergebenen Förster erläßt, oder die Berichte, die diese an die Oberforstämter schicken müssen, sind sie auch noch so unbedeutend, werden jedesmal durch eigene Boten von Ort zu Ort fortgeschickt, und beyde glauben sich zu dieser Forderung berechtiget, wenn sie nur ibren Schreiben die Aufschrift einer höchstpressanten herrschaftlichen Sache geben. Hat er unter seinen Förstern irgend einen vertrauten Mann, durch den er auch seine häuslichen Bedürfnisse besorgen lässet, so werden an diesen Briefe erlassen, die aber immer die Form eines amtlichen Ausschreibens behalten, und eben so unter gleicher Firma erhält er die Antwort von seinem Förster (Neues Forstarchiv. 1799. S. 89). 
hältnissen unterschiedlich hoch. Vor allem Kommunen in Residenznähe oder mit einem Forstamtssitz wurden stark in Anspruch genommen ${ }^{141}$. Dasselbe war bei Ortschaften der Fall, die auf frequentierten Routen lagen. Wenn die Überhäufung mit Botengängen ein unzumutbares Ausmaß annahm, versuchte die Obrigkeit, sie durch Anrechnung auf die regulären Jagdfronen zu kompensieren. Auf diese Weise war zwar ein gewisser Ausgleich möglich, doch ging er - sofern er überhaupt praktiziert wurde - auf Kosten anderer Bürger, die zusätzliche Lasten auf sich nehmen mussten. Viele Botenläufer ergaben sich jedoch in ihr Schicksal und beschwerten sich nicht, weil sie glaubten, es müss so $\operatorname{sein}^{142}$.

Im frühen 19. Jahrhundert bahnte sich mit dem Auf- und Ausbau des staatlichen Postdienstes ein Wandel an. Außerdem gingen zahlreiche Gemeinden und Amtskörperschaften dazu über, eigene Lohnboten anzustellen. Bereits 1809 wurde für den Normalfall der ordinäre Posten-Lauf vorgeschrieben. An der Praxis der Forstverwaltung änderte sich freilich zunächst wenig, weil sie strikt darauf achtete, Porto zu sparen. Auch 1821, als das Finanzministerium Fronboten nur noch in dringenden Ausnahmen zuließ, war noch nicht endgültig Schluss ${ }^{143}$. Erst seit 1837 durften sie zur Besorgung amtlicher Versendungen überhaupt nicht mehr in Anspruch genommen werden. Der zum Staatsbürger avancierte Untertan hatte als kostenloser Briefträger ausgedient.

\section{Widerstand und Widersetzlichkeit}

Wie ein roter Faden durchzieht ein Loyalitätskonflikt die Geschichte des Jagdfronwesens. Hin- und hergerissen zwischen der Treuepflicht gegenüber ihrem Landesherrn und der Wahrung ihrer Persönlichkeitsrechte war es für die betroffenen Untertanen schwierig, die richtige Balance zu finden. Gewöhnlich äußerte sich ihr Widerwille gegen den Frondienst nicht in offener Auflehnung, sondern in passivem Widerstand - Disziplinlosigkeit, mangelhafte Präsenz, Nachlässigkeit. Aktiver Widerstand beschränkte sich dagegen lange Zeit auf extreme Belastungssi-

141 Der Stuttgarter Nachbarort Heslach beklagt sich 1770 darüber, dass die Bürger fast täglich Briefe forttragen mussten (HStA Stuttgart A 227 Bü 2815). Die Gemeinde Reichenberg - Sitz eines Forstamts - hatte 1759 Briefschaften an 13 Forstknechte und 12 Orte auszutragen (HStA Stuttgart A 227 Bü 1996). Die Nachbargemeinde Rietenau beanstandet 1780, dass selten ein Tag ohne Botenlaufen vergehe (HStA Stuttgart A 227 Bü 2062).

142 So die Ortschaft Dörnach 1776 bei einer Umfrage im Tübinger Forst. Die Gemeinde Gönningen bemerkte, sie könne nichts Positives berichten, weil alle Briefe pitschiert und mit der Aufschrift pressante Oberforstamts-Sache versehen seien. Die Gemeinde Schlaitdorf verriet: Die Förster tractiren uns, damit wir uns nicht beim Oberforstamt beschweren (HStA Stuttgart A 565 Bü 58).

${ }^{143}$ StA Ludwigsburg E 245 I Bü 1497. Vor allem Jagdbestellungen erfolgten nach wie vor im Frondienst. 
tuationen $^{144}$. Meist platzte den Frönern erst der Kragen, wenn sie drangsaliert und schikaniert wurden. Dann konnte es schon einmal zu verbalen Ausfällen oder sogar zu Drohungen gegen das Aufsichtspersonal kommen, denen aber keine Taten folgten. Ganz anders verhielt es sich, wenn es um objektiv gegebene oder subjektiv empfundene Rechtsverletzungen ging, denen sich die Jagdfronpflichtigen häufig entschieden widersetzten, indem sie die Fronleistung verweigerten. Das war vor allem bei Einsätzen außerhalb des heimatlichen Forstbezirks der Fall, die in der Regel auf massive Proteste stießen und manchmal zur Folge hatten, dass die Fronmannschaften auf der Grenze stehen blieben und das Treiben vorzeitig beende$\operatorname{ten}^{145}$. Die permanente Furcht vor der präjudiziellen Konsequenz ihrer Mitwirkung spielte bei diesen Verhaltensweisen eine wesentliche Rolle.

Spürbaren Auftrieb erhielten Widerstand und Widersetzlichkeit in der zweiten Hälfte des 18. Jahrhunderts durch die unter Herzog Karl Eugen neu eingeführten Fronen ${ }^{146}$. Zudem verlor der in jahrhundertelanger Subordination gewachsene Untertanengeist unter dem Einfluss aufklärerischer Ideen an Substanz. Dumpfe Unterwürfigkeit wich in manchen Köpfen einem Selbstbewusstsein, das in Widerworten zum Ausdruck kam, die bisher undenkbar waren ${ }^{147}$. Die Behörden

144 Erstmals ist dies aus dem Jahr 1554 überliefert, als die Bürgerschaft der Stadt Heidenheim nicht mehr zu Wolfsjagen erschien, nachdem sie drei Wochen lang täglich im tiefen Schnee vergeblich gefront hatte, weil keine Wölfe vorhanden waren. Sie wehrte sich gegen den Vorwurf des Ungehorsams und erklärte sich bereit, jederzeit zur Verfügung zu stehen, wenn Wölfe bestätigt seien. Herzog Christoph befahl daraufhin, sie erst wieder zu zitieren, nachdem sie von Vorsuchern aufgespürt worden waren (HStA Stuttgart A 227 Bü 761).

145 So geschehen 1684 bei einem von Herzog Eberhard Ludwig angeordneten Hirschjagen im Stromberger Forst. Als einige Hirsche die Enz - Grenzlinie zum Leonberger Forst durchschwommen hatten, weigerten sich die Jagensmannschaften unter Berufung auf das altübliche Herkommen, an der Verfolgung teilzunehmen und drohten, jeden Jäger vom Gaul binunter zu schlagen, der ihnen dies abfordern sollte. Sie stammten aus der fünf bis sieben Wegstunden entfernten Maulbronner Gegend. Nach zwei Jagdtagen war den meisten das mitgenommene Brot und Zehrgeld ausgegangen. Wegen ihrer Armut wurden sie nicht zu einer Geldstrafe, sondern zu Arbeiten in einem herrschaftlichen Tiergarten verurteilt (HStA Stuttgart A 227 Bü 2575).

146 Wie er in dieser Beziehung vorging, macht ein Vorgang aus dem Jahr 1768 deutlich, als er anordnete, zur Anlage eines Wildackers beim Jagdschlösschen Einsiedel Leuthe anzustellen. Das Oberforstamt berief zu diesem Zweck mehrere Jagensmannschaften des Tübinger Forsts zum Stumpengraben und zur Vorbereitung einer Habersaat ein, worauf die Herrenberger diese offenkundig rechtswidrige Fronarbeit verweigerten und tags darauf auch alle anderen fernblieben. Eine Untersuchung des Vorfalls ergab, dass schon im Vorjahr aus demselben Anlass Taglöhner beschäftigt worden waren, die aber trotz mehrfacher Anmahnung keinen Lohn erhalten hatten, weshalb man nun auf Fröner zurückgriff. Erst jetzt verfügte Herzog Karl Eugen die Auszahlung der Rückstände und erteilte der Forstbehörde wegen des Frongeschäfts eine Rüge, weil sie nicht in seinem Sinne gehandelt habe (HStA Stuttgart A 227 Bü 2969).

${ }_{147}$ Als 1757 die Stadt Markgröningen (Leonberger Forst) 40 Fronpflichtige mit Schaufeln und Hacken in den Wald stellen sollte, wies sie dieses Ansinnen mit der Begründung zurück, diese Geräte seien zum Jagen ungewöhnlich (HStA Stuttgart A 557 Bü 278). Der Schultheiß 
reagierten auf diese Entwicklung einerseits mit Unnachgiebigkeit und dem Versuch, unbotmäßige Fronschuldige mit repressiven Methoden in die ächten Schrancken des Gehorsams zu bringen. Andererseits löste die wachsende Zahl derer, die nicht mehr bereit waren, sich gehorsamlich zu fügen, Zugeständnisse aus, die an der Entschlossenheit der Obrigkeit Zweifel aufkommen ließen. So wurden beispielsweise Strafnachlässe konzediert, für Wiederholungsfälle aber gleichzeitig Sanktionen angekündigt. Nervosität und Hilflosigkeit kennzeichneten je länger je mehr ein Regierungshandeln, das sich mitunter geradezu verzweifelt darum bemühte, das Gesicht zu wahren, zumal sich die Situation nach der Französischen Revolution von 1789 weiter zuspitzte ${ }^{148}$.

Vor allem die Uracher und Münsinger Alb entwickelte sich zu einem Unruheherd, der die Stuttgarter Regierung in helle Aufregung versetzte ${ }^{149}$. Im Juli 1790 weigerten sich zahlreiche Gemeinden, Wildheu aufzubereiten oder Jagdschirme und Pürschwege für die herbstliche Hirschbrunft herzustellen ${ }^{150}$. Die Einwohner von Grabenstetten machten geltend, sie seien größtenteils so arm, dass sie fast nichts zu leben hätten, während der Schultheiß von Kohlstetten meinte, er könne seinen Bürgern keine Fronen zumuten, die erst vor 20 Jahren aufkamen und nach dem Erbvergleich von 1770 gar nicht geleistet werden müssten. Das Fernbleiben wurde außerdem mit hohen Wildschäden auf den Feldern und der jüngst eingetretenen Teuerung begründet, wobei das Oberforstamt Urach nicht darum herum kam, der Bevölkerung äußerst drückende Lebensumstände zu bescheinigen. Da die Regierung den Ernst der Lage erkannte, drängte sie den Herzog zu raschem Han-

der Gemeinde Oberlengenhardt (Neuenbürger Forst) lehnte 1773 eine Fuhranforderung des Oberforstamts, für die keine Rechtsgrundlage bestand, mit der Feststellung ab: Mithin kommt vor dießmabl kein Fubr und keine Leuth und damit Gott befoblen (HStA Stuttgart A 559 Bü 153). Die Stadt Altensteig verweigerte 1778 den Abtransport eines für die Militärakademie in Stuttgart bestimmten Rehbocks mit dem Hinweis, er könne so lange liegen bleiben als er wolle (HStA Stuttgart A 227 Bü 336).

148 Die Gemeinde Steinheim (Heidenheimer Forst) zeigte 1792 keine Bereitschaft zum Bahnschleifen, worauf Herzog Karl Eugen verfügte, sie solle nicht gegen ihren Willen zu dieser Dienstleistung gezwungen werden. Stattdessen appellierte er an sie, bei eintretender Notdurfft aus Devotion gegen ibren Landesherrn sich dieser Beibilfe nicht zu entzieben (HStA Stuttgart A 227 Bü 919). Ähnlich verhielt er sich 1791 gegenüber der Gemeinde Horrheim (Stromberger Forst), die nur auf ihrer Markung fronpflichtig war. Er bat sie, von dieser Einschränkung Abstand zu nehmen, wenn er im Stromberg jage, da ihm ihr Jagddienst zum besonderen gnädigsten Woblgefallen gereichen werde (HStA Stuttgart A 563 Bü 85).

149 Die Darstellung beruht auf HStA Stuttgart A 202 Bü 572, A 227 Bü 3295 und L 6 Bü 941.

${ }^{150}$ Herzog Karl Eugen pflegte in der Brunftzeit in wenigen Tagen 70 bis 80 Hirsche zu erlegen. Zu diesem Zweck wurden auf den Hauptbrunftplätzen Schießhütten errichtet und Jagdschirme aufgestellt, die aus ca. $2 \mathrm{~m}$ hohen Buchenästen bestanden. In Büschel zusammengebunden boten sie den Schützen Deckung und damit gute Schussgelegenheit. Ein von ihm bevorzugt aufgesuchter Hirschplan befand sich beim Jagschloss Grafeneck im Uracher Forst. 
deln ${ }^{151}$. Der Landesherr zögerte jedoch und erteilte Weisung, zunächst nur die allernothwendigsten Fronen anzuordnen. Diese Taktik verfing auch bei allen Gemeinden bis auf Upfingen, das sich als regelrechtes Widerstandsnest entpuppte und standhaft blieb. Daraufhin holte Herzog Karl Eugen ein Gutachten des Geheimen Rats ein, das den lokalen Streit zur Prinzipienfrage erhob und energisches Durchgreifen empfahl ${ }^{152}$. Mit Dekret vom 10. September 1790 machte er sich diesen Vorschlag zu eigen und bekräftigte seinen Willen, die Sache des Jagdwesens als eine für sein Haus und die ganze Regentennachkommenschaft so wichtige Angelegenheit in die gehörige Ordnung zu bringen. Damit war klar: es ging ihm um die Zukunft der Feudaljagd.

Eine Eskalation erschien unter diesen Umständen unausweichlich, zumal zwei Wildpretbütten in Brand gesteckt wurden, was nach Auffassung des Uracher Oberforstmeisters Julius Friedrich von Lüzow die beimtückische und bösartige Gesinnung der Dorfbewohner offenbarte. In einem Verhör der Gemeindevertreter nahm man einen letzten Anlauf, um sie zum Einlenken zu bewegen, der aber scheiterte. Sie erklärten vielmehr, weder die Fron leisten noch eine Strafe zahlen zu wollen und kündigten die Entsendung eines Beauftragten an die Stuttgarter Landschaft an. Auf die Frage, ob sie es darauf ankommen ließen, die Erfüllung ihrer Dienstpflicht gewaltsam herbeizuführen, gaben sie zur Antwort: Ja - was das Schirmmachen betreffe, lassen sie es darauf ankommen. Jetzt gab Herzog Karl Eugen grünes Licht für ein Militärkommando ${ }^{153}$. Am 11. Oktober 1790 rückten 16 Husaren in Upfingen ein, worauf die Jagdschirme nolens volens angefertigt wurden. Der Landesherr sah zwar von einer Bestrafung ab, bestand jedoch auf Kostenerstattung.

Strategisch erwies sich diese Aktion als Pyrrhussieg, denn die Widersetzlichkeiten hielten an. Sie trafen den Regenten besonders empfindlich, als er auf den 29. Dezember 1790 eine mehrtägige Treibjagd im Ludwigsburger Forst ansetzte, zu

151 Die von den rebellierenden Gemeinden angeführten Beweggründe wurden als Vorwand und ihr Verhalten als Versuch gewertet, die Rechte des Herzoglichen Hauses in Forstund Jagdsachen zu schmälern. Er entspringt der allgemeinen Stimmung, sich von allen Lasten so viel möglich zu befreien. Die Räte prophezeiten, dass der nie zufriedene Unterthan nach dem ersten glücklichen Erfolg sich von einer Schuldigkeit nach der andern loszuwinden suchen würde. Sie empfahlen daher, unter keinen Umständen nachzugeben und im äußersten Falle militärische Gewalt anzuwenden. Sonst werden die Unterthanen ibr Mißvergnügen und ibre Absichten, auf Kosten der landesherrlichen Rechte ibre Verbältnisse zu erleichtern, nicht mehr zurückbalten.

${ }_{152}$ Mit Nachdruck wurde vor der Gefahr gewarnt, daß die Vorrechte des Regenten immer mebr und mehr geschmälert würden und bei der gegenwärtigen Lage in Europa eine zu weit getriebene Nachgiebigkeit von den bedeutlichsten Folgen seyn werde.

${ }^{153}$ Er begründete diesen Schritt mit der unwahren Behauptung, das Schirmmachen gehöre zu der Art von Forstfronen, die seit Jahrhunderten jederzeit unweigerlich geleistet worden seien. Er wolle bei dem unbezweifelten Besiz dieses Rechts sein Haus umso mehr gegen ungehorsame Untertanen erhalten, als die Geseze selbst jedem Privatmann sich in dem Besize seines Eigenthums und seiner Rechte mit Gervalt zu schüzen gestatten. 
der auch 800 Mann aus dem Stromberger Nachbarforst bestellt wurden, die aber die Überschreitung der Forstbezirksgrenze ablehnten, weil sie dazu nicht verpflichtet seien. Sie ließen sich von ihrer Verweigerungshaltung nicht einmal durch die Drohung abbringen, er werde an den Nachlässigen ein warnendes Exempel statuieren, weshalb es sich jeder selbst zuzuschreiben habe, wenn ihm Unannehmlichkeit und Ungnade widerfahre. Ihre Aufsässigkeit ging so weit, dass sie am Ludwigsburger Jagen nur teilnehmen wollten, wenn sich Serenissimus zuvor bei ihnen zur Wegschießung der Hasen einfinde ${ }^{154}$. Daraufhin wurde das Kontingent auf die Hälfte reduziert, doch selbst die Aufforderung, wenigstens aus Liebe und Devotion gegen ihren Landesherrn zu erscheinen, fruchtete nicht. Dem Herzog blieb nur noch übrig, seine Forst- und Jagdbeamten anzuweisen, dafür Sorge zu tragen, dass in Zukunft die erlassenen gnädigsten Befeble vollkommen befolgt werden. Wie ramponiert seine Autorität als Jagdherr inzwischen war, zeigte sich schon ein Jahr später, als eine weitere Kesseljagd im Ludwigsburger Forst gleichfalls im Fiasko endete $^{155}$. Die Krise des Jagdfroninstituts trat offen zu Tage.

\section{König Friedrich}

Naturalfronen in einem Staate mit solchem Zwang verbunden, wie es die Observanz erheischt, sind ein untrügliches Merkmal von Gebrechen in der Staatshaushaltung. Mit dieser Feststellung brachte es 1798 der Rentkammerrat und spätere Finanzminister Ferdinand Weckherlin auf den Punkt: die althergebrachten Jagddienste passten nicht mehr in die Zeit, weil sich der feudalistische Gesellschaftsentwurf überlebt hatte ${ }^{156}$. Bereits ein Jahr zuvor hatten die Landstände in die gleiche Kerbe gehauen: Die Klagen über das Übermaß der Jagdfronen sind heutzutage nicht mebr so allgemein als sie in der Regierungszeit des Höchstseligen Herzogs Carl waren. Doch werden gleichwohl die gegenwärtig vorhandenen Beschwerden

154 Im 18. Jahrhundert verursachten Hasen insbesondere in den Weinbergen beträchtliche Verbissschäden.

155 Die aus dem Stromberger Forst auf den Vorabend des ersten Jagdtags nach Bietigheim einberufenen Fronpflichtigen - ca. 400 meist arme Leute - widersetzten sich aus den bekannten Gründen am Morgen des 25. Januars 1792 dem Auftrag, über die Enz in den Ludwigsburger Forst zu gehen. Der zuständige Oberforstmeister Karl Friedrich von Stedingk ließ sie warten, um Höchste Ordre bei Herzog Karl Eugen einzuholen. Als er zurückkehrte und die Nachricht überbrachte, ihre Mitwirkung am Kesseljagen gereiche dem Regenten $z u$ gnädigstem Woblgefallen, waren die meisten schon nach Hause gegangen. Nach einigen Tagen erging ein Dekret, das einen Verweis für die Gehorsamsverweigerer sowie die Feststellung enthielt, es wäre kein Präjudiz gewesen, wenn sie den Jagddienst aus Ehrfurcht vor dem Landesherrn geleistet hätten. Im Übrigen gab der Herzog den wenigen, die geblieben waren, seine gnädigste Zufriedenheit über ibre bezengte devotion zu erkennen und sicherte ihnen für die nächste Jagd Fronfreiheit zu (HStA Stuttgart A 227 Bü 2712).

156 Ferdinand August Heinrich Weckherlin: Darstellung der Grundsäze, nach welchen Frondienste insbesondere Landesfronen auszuteilen und auszugleichen sind. 1798. S. 155. 
vom wirtembergischen Volk tiefer gefühlt und vielleicht noch unerträglicher gefunden als vormals ${ }^{157}$.

In der Tat war am 24. Oktober 1793 mit dem Tod des Herzogs Karl Eugen in gewisser Weise eine Ära zu Ende gegangen. Schon in seinen letzten Lebensjahren, aber auch in der kurzen Regierungszeit seiner auf ihn folgenden Brüder waren die überhegten Wildbestände spürbar reduziert worden. Diese Entspannung wirkte sich mäßigend auf die Jagddienstanforderungen aus, doch hatte sich die Stimmung der Fronpflichtigen dadurch keineswegs aufgehellt. Widerstand und Widersetzlichkeit standen nach wie vor auf der Tagesordnung ${ }^{158}$. Nachdem Ende 1797 mit Herzog Friedrich II., der als erster württembergischer König in die Geschichte eingehen sollte, wieder ein passionierter Jäger auf den Thron gekommen war, musste er die unliebsame Erfahrung machen, von unerquicklichen Vorfällen dieser Art ebenfalls nicht verschont zu bleiben ${ }^{159}$. Dennoch ging er auf wesentliche Forderungen des Reformlandtags von 1797 ein und hob zur Berubigung der Untertanen alle Forstfronen auf, die nicht in Lagerbüchern verzeichnet oder im alten Herkommen begründet waren. Dabei nannte er ausdrücklich das Bahnschleifen, das Heumachen und die Wildfütterung ${ }^{160}$.

Es dauerte allerdings nicht lange, bis er die Zügel wieder anzog und der Herrschaftsjagd - wenn auch nur für kurze Zeit - zu einer letzten Blüte verhalf: der Wildstand wurde erhöht, die Hofjägerei aufgestockt, neues Jagdzeug angeschafft und die Zahl der Jagdhunde vergrößert ${ }^{161}$. Auch in der Jagdfronpolitik kam es zu einer Kehrtwende, zumal er im Königreich nach der Aufhebung der landstän-

157 HStA Stuttgart L 6 Bü 942.

$158 \mathrm{Zu}$ einem Jagen des Oberforstamts Urach in der Eglinger Hut erschienen 1793 nur 2 von 19 einberufenen Fronpflichtigen. Bei der nächsten Jagd 1794 war es nicht viel besser, denn der Schreiner Jacob Haag hatte viele abspenstig gemacht und verlauten lassen, dass man alle, die dem Aufgebot folgten, henken solle (HStA Stuttgart A 227 Bü 3304).

159 Bei einer Treibjagd am 26. Oktober 1798 in der Umgebung des Schlosses Solitude, an der er selbst teilnahm, erschienen zwar die aufgebotenen 27 Heslacher Bürger, gingen aber aller Ermabnung und Drobung ungeachtet wieder heim, als sie die Grenze zur Gerlinger Hut überschreiten sollten, weil sie nach ihrer Auffassung dort nicht fronpflichtig waren (HStA Stuttgart A 227 Bü 2815). Am 9. Juni 1799 blieb die Jagensmannschaft von Knittlingen (Stromberger Forst) einer Jagd bei dem ca. $12 \mathrm{~km}$ entfernten Ort Enzberg in der irrtümlichen Meinung fern, auf fremden Markungen von Jagddiensten frei zu sein. Der neue Landesherr erteilte Weisung, über die geringste Widersetzlichkeit sogleich informiert zu werden und drohte für den Wiederholungsfall ernstliche Abndung an (HStA Stuttgart A 227 Bü 2742).

160 Generalreskript vom 17. März 1798 (Johann Friedrich Melchior Kapff: Sammlung der im Herzogthum Wirtemberg einzeln ergangener Verordnungen. 1820. S. 476).

161 Durch die Vergrößerung des Landes und die Säkularisation geistlicher Territorien hatte sich in den Jahren 1803 bis 1810 sowohl die Jagdfläche als auch Zahl der Jagdfronpflichtigen erheblich vergrößert. Kurfürst Friedrich beanspruchte z. B. in der ehemaligen Fürstpropstei Ellwangen bei persönlicher Anwesenheit nicht nur die bisher fronpflichtigen Untertanen, sondern auch fronfreie Stadtbürger (StA Ludwigsburg D 1 Bü 686). Die mediatisierten Standesherrschaften behielten ihre alten Jagdrechte und damit auch ihre Fronansprüche. 
dischen Verfassung am 1. Januar 1806 autoritär regieren konnte und keine Rücksichten mehr zu nehmen brauchte. Von Fronverweigerung konnte unter diesen Umständen keine Rede mehr sein, denn dem Volk wurden alle Wege abgeschnitten, um sich über die erlittene Rechtsverweigerung zu beklagen. So ließ er 1807 die vielen Gemeinden zustehenden alten Gerechtsame einer Beschränkung der Fronpflicht auf die eigene Markung nicht mehr gelten, sofern er selbst an der Jagd teilnahm. Zwei Jahre später schaffte er alle Ersatzleistungen für Naturalfronen ab und hob für den Fall seiner persönlichen Anwesenheit alle und jede durch altes Herkommen, Lagerbücher, Verträge oder auf andere Weise erlangte Personalfreiheit auf ${ }^{162}$. Rigoros beseitigte er 1811 die weit verbreitete Praxis, die mit Fuhrfronen belasteten Bauern von den übrigen Jagddienstleistungen freizustellen und verpflichtete sie, sich ibrer mit dem Lagerbuch und dem Herkommen übereinstimmenden Schuldigkeit zu unterzieben ${ }^{163}$. Mit scharfen Anweisungen schritt er gegen Disziplinmängel ein und schreckte selbst vor Gefängnisstrafen nicht zurück $^{164}$.

Wie seine herzoglichen Vorgänger in ihren besten Zeiten hielt der königliche Despot landauf, landab ausgedehnte Treibjagden $\mathrm{ab}^{165}$. Unbestrittener Höhepunkt war das am 9. November zu seinem 58. Geburtstag unweit Bebenhausen veranstaltete Dianenfest, das als letztes Festin-Jagen auf deutschem Boden gilt und eine Million Gulden verschlungen haben soll ${ }^{166}$. In sechswöchiger Vorarbeit hatten ca. 7.000 Fronleute enorme Wildmassen zusammengetrieben, die dazu bestimmt waren, vor einer großen Schaubühne wie Katarakte ibrem unwiderruflich geworfenen Todesloose zuzustürzen ... Das Erstlingsopfer, welches der buldreichen Göttin fiel,

162 Reyscher (wie Anm. 12) Bd. 16,2. S. 112 und 123.

163 HStA Stuttgart A 227 Bü 3060.

164 Weil sich 17 Förster und 25 Obleute 1812 von einem Jagen unerlaubt entfernt hatten, verhängte er gegen sie nicht nur empfindliche Geldbußen, sondern auch drei Tage Turmstrafe zu je 24 Stunden bei Wasser und Brot, während 2.798 Treiber den Ungehorsamsgulden entrichten mussten (HStA Stuttgart E 6 Bü 143). Einen Jägerburschen, der es gewagt hatte, sich bei ihm über den Obristjägermeister wegen übler Beschimpfung und angedrohter Prügel zu beschweren, ließ er 1807 im Arrest 48 Stunden kurz und lang schließen (HStA Stuttgart A 22 Bü 6).

165 Schon zu Beginn seiner Regierungszeit zelebrierte er bis zu einer Woche dauernde Herbstjagden, die täglich mit dem Rendez-vous begannen und nach der kalten Kuche am Mittag mit einem Abendfener abgeschlossen wurden (HStA Stuttgart A 22 Bü 70). Für eine Hofjagd bei Dätzingen (Böblinger Forst) am 25. Juni 1810 mussten 4.000 bis 5.000 Fröner drei Wochen lang das Wild herbeitreiben (In: Aus Schönbuch und Gäu. 1963. S. 33). Für eine Jagdsejour ließ er 1813 Hunderte von Zugpferden für den Vorspann und zahlreiche gesattelte Reitpferde für Postillons und Ordonnanzen requirieren (StA Ludwigsburg D 72 Bü 168). Zu einer „Königsjagd“ bei Bietigheim am 10. November 1815 mussten sich u.a. 400 Mann aus der entfernten Maulbronner Gegend um 5 Uhr früh bei den Förstern im Gasthaus „Krone“ melden (StA Ludwigsburg E 245 I Bü 1132).

166 Die einschlägigen Akten sind nicht erhalten. Einblick in das Geschehen vermittelt die pathetische Beschreibung eines Hofpoeten, die im Druck erschien (Friedrich von Matthison: Das Dianenfest bei Bebenhausen. 1813). 
war ein mächtiges Hauptschwein, durch den Meisterschuß des Königs plötzlich verschweißt (verblutet). Nach zwei Stunden lagen 823 Tiere auf dem Platz. Der von 250 Forst- und Jagdbeamten in Galauniform mit einem Lebehoch begrüßte und von einem hundertstimmigen Jägerchor mit Vivat Friederich-Gesängen gefeierte Herrscher ahnte wohl nicht, dass es mit der feudalen Jagdherrlichkeit schon in wenigen Jahren vorbei sein würde (Abb. 2).

Als er 1815 unter dem Druck der politischen Verhältnisse nicht mehr darum herumkam, in Verhandlungen über eine neue Verfassung einzutreten, stand erneut ein Kurswechsel an, der das gesamte Jagdwesen, in besonderer Weise aber die Fronleistungen betraf. In den „Landesbeschwerden“ der von ihm einberufenen Ständeversammlung spielten sie ebenso wie der Wildfraß auf den Feldern eine gewichtige Rolle ${ }^{167}$. Vor diesem Hintergrund ordnete er obne Rücksicht auf eigenes Vergnügen an, den Rotwildbestand zu dezimieren und das nur noch in Tiergärten geduldete Schwarzwild in der freien Wildbahn auszurotten. Dabei verfolgte der wegen seiner Jagdexzesse berüchtigte König nach seinen eigenen Worten das Ziel, den Übelgesinnten und sein gutes Volk Irreleitenden die Veranlassung zu nehmen, die wohlgemeinten landesväterlichen Absichten zu verkennen ${ }^{168}$. Um es zu erreichen, schränkte er nicht nur den Jagdbetrieb ein, sondern stellte auch den alten Rechtszustand wieder her, wonach Jagdfrondienste nur auf der Grundlage der Lagerbücher und des Herkommens ausgeübt werden durften. An Sonn- und Feiertagen, in Zeiten der Ernte und Weinlese, bei strenger Kälte und einer Entfernung von mehr als sechs Wegstunden sowie im Fall militärischer Einquartierungen waren sie jetzt ganz verboten. Die häusliche Abwesenheit wurde einschließlich der Hin- und Herreise auf drei Tage begrenzt. Auch die Personalbefreiungen traten wieder in $\mathrm{Kraft}^{169}$.

167 Wie aus den Worten der Volksvertreter hervorgeht, hatte sich gegenüber früheren Jahrhunderten nichts geändert, denn sie beklagten, daß mancher Taglöhner mit dem Brode, das er nicht kaufen kann, weil er nur das verzehrte verdienen und bezablen konnte, mit dem Brode, das er betteln mußte, mit dem Kittel, der ibn vor der Witterung schützt, der auf seinem Leibe in Regen und Schnee verwest, in einer Entfernung von 20 Stunden von der Heimath und von den hungernden Kindern, die Hälfte der Woche mit Vernachläßigung der Heu- und Korn-Erndte und der Weinlese sich dem gereitzten Wilde entgegenstellen und die Mißhandlungen übelgelaunter Förster erdulden muß, daß so mancher von diesen Jagden mit erfrornen verstümmelten Gliedern, mit dem Keim der Krankheit und des Todes, daß sogar mancher überhaupt nicht wieder zurückkehrt (Verhandlungen der Ständeversammlung am 22. März 1815. Beilage Nr. 4. S.96).

168 Königliches Reskript die Abstellung des Wildschadens betr. vom 7. April 1815 (Königlich Württembergisches Staats- und Regierungs-Blatt. 1815. S. 149). Das Einfangen der Sauen und ihre Verfrachtung in die ca. 1000 ha großen Schwarzwildparke war enorm aufwändig. Die Füllung der Tiergärten erforderte wochenlange Zeugjagden, wobei die Fronmannschaften alle drei Tage abgelöst wurden (StA Ludwigsburg E 245 I Bü 1132)

169 Königliche Verordnung die Jagdfronen betr. vom 19. April 1815 (Regierungs-Blatt [wie Anm. 168] 1815. S. 159). König Friedrich begründete die Erleichterungen mit der Behauptung, von den Frondienstexzessen nichts gewusst zu haben. Biographen machen für seine 


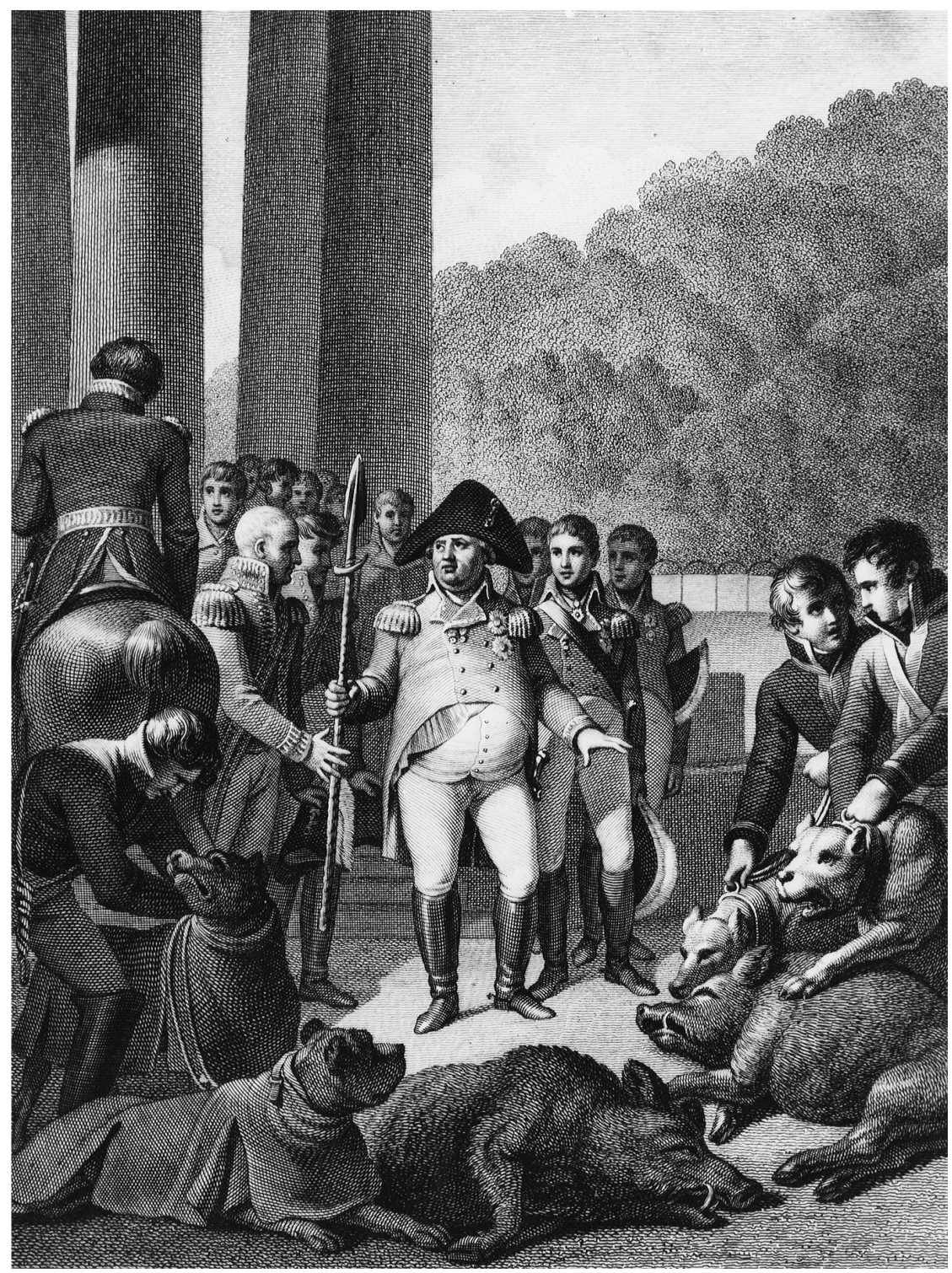

Abb. 2: Der Oberstjägermeister von Lüzow empfängt nach Beendigung des „Dianenfestes“ 1812 den Jagdspieß aus der Hand König Friedrichs (nach Friedrich von Matthison: Das Dianenfest bei Bebenhausen, 1813). 
Die Erwartungen, die der Regent an das Einlenken geknüpft hatte, erfüllten sich indessen nicht. Im Gegenteil: als regelrechter Sprengsatz erwies sich eine neue Kompetenzregelung, die den Forstbehörden die Einberufung der Fronmannschaften entzog und sie ebenso wie die Disziplinargewalt den Verwaltungsbehörden (Oberämtern) übertrug, um den Erpressungen, Eigenmächtigkeiten und Gewalttätigkeiten des Forstpersonals zu begegnen. Wie sich schnell herausstellte, leitete die Entmachtung der Oberforstämter den Zusammenbruch des Jagdfronsystems ein, denn ihre Dispositionen verloren den Bezug zur Realität. Ohne Übersicht über ihre Hilfstruppen waren sie nicht mehr in der Lage, die Jagden effektiv zu organisieren. Vor allem aber büßten sie jede Autorität bei den Dienstpflichtigen ein, nachdem das gesamte Jagdpersonal sozusagen als unmündig erklärt worden war. Die demoralisierende Wirkung dieser Umstellung auf die Fronbereitschaft war so groß, dass sich unübersehbare Auflösungserscheinungen bemerkbar machten.

Zur Nagelpobe kam es bei einer Treibjagd, die König Friedrich am 28. und 29. November 1815 in seinem Ludwigsburger Leibgehege anstellen lie $\beta^{170}$. Das Oberforstamt hatte 1.200 Mann aufgeboten, von denen aber gleich am ersten Tag nur 300 erschienen. Der Boykott löste eine solche Konfusion aus, dass die Veranstaltung abgebrochen werden musste. Der für sein Umfeld ohnehin fast unerträglich gewordene Jagdherr war außer sich. Für den Misserfolg zog er den Ludwigsburger Oberforstmeister Georg Ludwig von Bülow zur Rechenschaft, dem er nicht nur unverantwortliche Nachlässigkeit und organisatorische Mängel zur Last legte, sondern generell vorwarf, seiner Stelle nicht gewachsen zu sein ${ }^{171}$. Offenbar traf ihn dieser Fehlschlag ins Mark, denn aus seinem letzten Lebensjahr sind keine weiteren jagdlichen Aktivitäten bekannt. Von seinem Jägerleben hatte sich König Friedrich bereits verabschiedet, als er am 30. Oktober 1816 unerwartet verstarb.

angebliche Ahnungslosigkeit ebenfalls den Umstand verantwortlich, dass ihm seine „servile Umgebung" die Übelstände geschickt verschleiert habe (Paul Sawer: Der schwäbische Zar. 1986. S. 437). Tatsächlich muss er sich aber ihrer voll bewusst gewesen sein, denn er ließ sich über alles unterrichten, regelte selbst Detailfragen und nahm an zahllosen Jagden teil.

170 StA Ludwigsburg E 245 I Bü 1132. In dem 1709 von Herzog Eberhard Ludwig eingerichteten Leibgehege wurden hauptsächlich Hasen und Rebhühner gejagt, die als heiliges Eigentum des Regenten galten. Aufgrund günstiger Revierverhältnisse, spezieller Schutzmaßnahmen und intensiver Hege konnten in diesem königlichen Kleinod außergewöhnlich hohe Jagdstrecken erzielt werden.

171 Dem zum Sündenbock gestempelten Jagdleiter nützte es nichts, den Kompetenzwirrwarr für das Debakel verantwortlich zu machen. Vergeblich wies er darauf hin, dass ganze Gemeinden ausgeblieben waren und das Forstpersonal davon nichts erfuhr. Seit die Bestrafung durch die Oberämter erfolgt, gibt der Bauer nichts mehr auf die Verlesung der Rottzettel. König Friedrich ließ sich dadurch nicht beeindrucken und belegte ihn mit einer Geldstrafe von 20 Reichstalern. 


\section{Das Ende}

Im frühen 19. Jahrhundert gerieten die Jagdfronen ins Visier der politischen Diskussion. Sie wurden jetzt nicht mehr nur als Missbrauchsphänomen wahrgenommen, sondern auch als gesellschaftliches Problem reflektiert: man forderte ihre Abschaffung $^{172}$. Sie entsprächen nicht mehr dem Zeitgeist, förderten überhöhte Wildstände, schädigten die Land- und Forstwirtschaft und seien schon deshalb untragbar geworden, weil die Fronpflichtigen das Missverhältnis zwischen Zweck und Aufwand und damit die ihnen zugemuteten Anstrengungen nicht mehr akzeptierten. Die Ausbeutung fremder Arbeitskraft für vergnüglichen Zeitvertreib stieß auf blankes Unverständnis. Mit anderen Worten: nicht allein die Jagddienstbarkeit, sondern die Herrschaftsjagd überhaupt wurde in Frage gestellt (Abb. 3) .

Mit König Wilhelm I. übernahm 1816 ein Regent das Ruder, der die Zeichen der Zeit erkannt hatte. Seine tiefgreifende Staatsreform beendete das absolutistische Zwischenspiel und vollzog den Übergang vom Patrimonial- zum Verfassungsstaat, dessen Fundament der freie und mündige Bürger sein sollte. Im Gegensatz zu allen Vorgängern fand er am Jagen nur wenig Gefallen und war damit prädestiniert, die Landeskultur von der jahrhundertelangen Bevormundung durch Jagdinteressen zu befreien. Die Beseitigung der Feudallasten im Allgemeinen und der Jagdprivilegien des Adels im Besonderen stand daher für ihn bereits zu Beginn seiner Regierungszeit auf der Agenda.

Mit dem Organisationsedikt vom 18. November 1817 erklärte er alle ungemessenen Fronen für ungesetzlich, wobei die Jagdfronen ausdrücklich eingeschlossen waren. Sie sollten deshalb vertraglich entweder in gemessene Fronen umgewandelt oder abgelöst werden ${ }^{173}$. In einem zweiten Schritt veranlasste er 1818 die Verpachtung der Staatsjagden und versetzte damit den altwürttembergischen Jagdfronen den Todesstoß ${ }^{174}$. Im Ergebnis kam diese Maßnahme einem Verzicht auf das königliche Jagdregal gleich. Die Feudaljagd lebte somit nur noch in einem vergleichsweise bescheidenen Hofjagdbezirk des Hauses Württemberg und in den neuwürttembergischen Standesherrschaften fort, deren Jagdrechte bei der Mediatisierung als staatlich geschützte Eigentumsrechte anerkannt worden waren ${ }^{175}$.

172 Vortrag des Grafen Adelmann in der Ständeversammlung am 11. Mai 1816. Wo zu viele Mißbräuche bei einer Anstalt vorkommen, kann das Prinzip der Anstalt nicht richtig sein (StA Ludwigsburg E 245 I Bü 1135).

173 Regierungs-Blatt (wie Anm. 168) 1817. Anhang II S. 7.

174 Reskript des Forstrats vom 13. November/15. Dezember 1818 (Gottfried Knapp: Annalen der Königl. Würtembergischen Gesetzgebung. 1822. Bd.2,1. S. 150).

175 Der Hofjagddistrikt wurde aus 17 Huten in fünf zentral gelegenen Forstbezirken (Leonberg, Kirchheim, Tübingen, Engelberg/Schorndorf, Reichenberg) gebildet. Obwohl gelegentlich noch traditionelle Großjagden mit Aufgeboten bis zu 1.500 Treibern stattfanden, wurden die Jagdfronen restriktiv gehandhabt. Ein erheblicher Teil der Fronleistungen bestand aus Wildlieferungen nach Stuttgart. Jährlich fielen durchschnittlich ca. 15.000 Fron- 


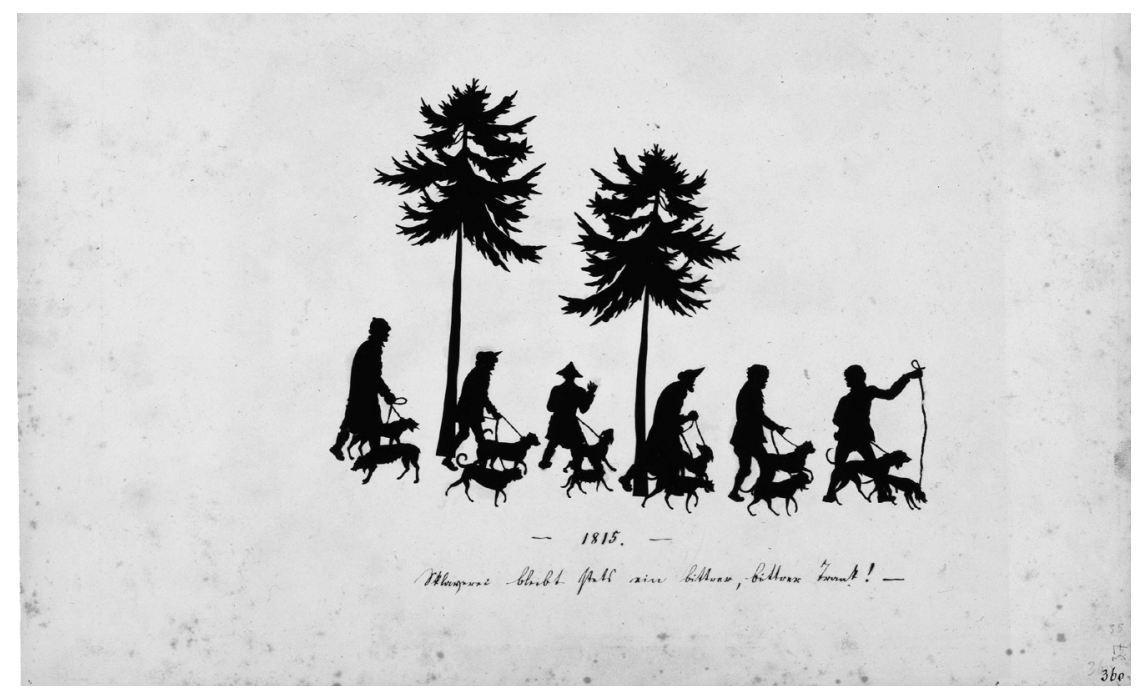

Abb. 3: Jagdfröner als Hundeführer. Scherenschnitt von Luise Duttenhöfer von 1815 mit der Unterschrift: Sklaverei bleibt stets ein bittrer, bittrer Trank! (Vorlage: Deutsches Literaturarchiv Marbach).

Die Staatsjagden wurden an unbescholtene Bürger verpachtet, doch waren gemeine Land-und Handwerks-Leute, deren bäusliche Verbältnisse durch Ausübung der Jagd eine nachtheilige Störung erleiden würden, ausgeschlossen. Als Pächter konnten auch Forstbeamte auftreten, da ein dienstliches Interesse bestand, sie an den Wald zu binden. Für die Forstverwaltung hatte die Etablierung der bürgerlichen Jagd die Wirkung eines Befreiungsschlags, denn sie konnte sich nunmehr mit voller Kraft ihrer eigentlichen Bestimmung - der Waldbewirtschaftung - zuwenden. Die altwürttembergischen Forste wurden nach dem Verlust ihrer Primärfunktion als Rechtsträger durch ein Organisationskonzept ersetzt, das sich an der forstfachlichen Aufgabenstellung orientierte. Eine geradezu revolutionäre Verwaltungsreform unterwarf das Forstpersonal ohne Rücksicht auf Standesprätentionen dem Leistungsprinzip. Erst jetzt war es möglich, den Aufbau der weithin ruinierten Wälder systematisch in Angriff zu nehmen.

Da sich in den Pachtrevieren die Jagdausübung nicht mehr in den Dimensionen der Feudaljagd abspielte, waren überzogene Fronansprüche gegenstandslos geworden, obwohl die Pächter in die Rechtsstellung der ehemaligen Jagdherrschaft ein-

tage an. Der gesetzliche Rahmen wurde nur zu einem Viertel ausgeschöpft (HStA Stuttgart E 14 Bü 246). 
traten. König Wilhelm I. entzog der missbräuchlichen Fronpraxis vollends dadurch den Boden, dass er 1818 die Jagddienste sowohl im Hofjagddistrikt als auch in den verpachteten Landjagden auf höchstens vier Tage jährlich beschränkte. Außerhalb des privaten Großgrundbesitzes verloren sie daher ständig an Bedeutung, zumal die meisten Jagdpächter nicht auf Hilfskräfte angewiesen waren und deshalb auf Fronleistungen verzichteten, um den Pachtschilling zu ermäßigen. Viele Gemeinden waren überdies bereit, ihre Bürger durch jährliche Geldzahlungen an die Staatskasse vom Jagddienst freizustellen oder die Fronverpflichtung dauerhaft abzulösen $^{176}$. Die Standesherren dagegen hielten zäh an ihren Vorrechten fest und verteidigten sie mit Zähnen und Klauen. So kam es 1833 im Landtag zu einer scharfen Attacke gegen das mit dem Malzeichen der Barbarei befleckte Jagdfroninstitut, das zur Schmach für würtembergische konstitutionelle Staatsbürger immer noch bestand $^{177}$. Doch mit dem Fronablösungsgesetz vom 28. Oktober 1836 zeichnete sich definitiv sein Ende $\mathrm{ab}^{178}$. Die Freiheitskultur der modernen Welt war in ihrem Siegeszug nicht mehr aufzuhalten.

176 Es gab aber auch Kommunen, die sich aus finanziellen Gründen dazu nicht in der Lage sahen. So erklärte 1825 die Gemeinde Mähringen (Forstbezirk Tübingen), sie wolle für alle künftigen Zeiten bei der Naturalleistung bleiben, weil dies ihnen bei weitem nicht so schwer falle als bei dem ungeheuren Geldmangel die Bezablung einer kleinen Summe (StA Ludwigsburg E 230 II Bü 5243).

177 Abgeordneter Nefflen in der Kammer der Abgeordneten am 23. Juli 1833. Seine sarkastische Schilderung lässt erkennen, wie obsolet diese Einrichtung geworden war: Dertitulierte Staatsbürger muß dem Vergnügen wirklicher Staatsherren oft bei großer Kälte, in dürftiger Kleidung, mit dem einzigen Trost eines Fläschchens Branntwein und eines gefrornen Stück Brods in der Tasche, unentgeltliche Dienste leisten, muß sich hie und da von irgend einem rohen Jäger auf schneeigtem Felde herumtreiben, muß sich bei feblerhafter Befolgung des Commandos, die mehr aus Überdruß und Entkräftung als aus Ungehorsam und Ungeschicklichkeit herzuleiten ist, anfluchen und beschimpfen lassen, daß er selbst nicht mehr weiß, ob er oder der Hase die verfolgte Bestie ist. Nicht genug! - der Staatsbürger muß alle Jagdbestellungen fronweise von Ort zu Ort tragen, er muß bei Frost und Hitze, bei Sturm und Regen, bei Tag und Nacht das erlegte Wild der Tafel seines Jagdherrn zuhaudern. Er muß es tragen, und wenn es schon einen haut-gout erreicht hat, er muß es thun, selbst wenn er an seinen fünf Fingern abzäblen kann, dass der todte Malefikant nicht die Hälfte der Fracht mebr werth ist ... Auch die Schultheißen dürfen sich am Mitgenuß der Jagdfronen laben. Sie sind in gewissen Bezirken die Jagdfronen-Posthalter, sie haben die Wildbret-Spedition von Ort zu Ort zu besorgen. Bei Tag und Nacht, zu jeder Stunde müssen sie das auf dem Rücken oder Wagen des Fröners angekommene todte Wild in Empfang nehmen, dafür quittiren, und müssen, bis der Amtsdiener herbeigekommen und von diesem der neue Fröner herbeigeschafft ist, bei dem privilegirten Leichname Wache halten (Verhandlung der Kammer der Abgeordneten des Königreichs Württemberg. 1833. Bd. 4. S. 59-61).

178 Regierungs-Blatt (wie Anm. 168) 1836. S.555. Den Dienstpflichtigen wurde ein Rechtsanspruch auf Ablösung eingeräumt. Die Berechnung des Fronwerts erfolgte nach dem Durchschnitt der letzten 15 Jahre. In der königlichen Hofjagd hörten die Jagddienste 1840 auf. Um die Mitte der 1840er Jahre war ganz Württemberg fronfrei. 